Portland State University

PDXScholar

Spring 5-13-2014

\title{
Accountability Models in Policy Design: Understanding the Explanatory Power of the Four Major Accountability Models in Policy Tool Choices
}

David Seiler Jarvis

Portland State University

Follow this and additional works at: https://pdxscholar.library.pdx.edu/open_access_etds

Part of the Public Administration Commons, and the Public Policy Commons Let us know how access to this document benefits you.

Recommended Citation

Jarvis, David Seiler, "Accountability Models in Policy Design: Understanding the Explanatory Power of the Four Major Accountability Models in Policy Tool Choices" (2014). Dissertations and Theses. Paper 1798. https://doi.org/10.15760/etd.1798

This Dissertation is brought to you for free and open access. It has been accepted for inclusion in Dissertations and Theses by an authorized administrator of PDXScholar. Please contact us if we can make this document more accessible: pdxscholar@pdx.edu. 
Accountability Models in Policy Design: Understanding the Explanatory Power of the Four Major Accountability Models in Policy Tool Choices

by

David Seiler Jarvis

A dissertation submitted in partial fulfillment of the requirements for the degree of

\author{
Doctor of Philosophy \\ in \\ Public Affairs and Policy \\ Dissertation Committee: \\ Phillip Cooper, Chair \\ Ronald Tammen \\ Douglas Morgan \\ Craig Shinn \\ Gerard Mildner
}

Portland State University 2014 
(C) 2014 David Seiler Jarvis 


\begin{abstract}
In the study of government accountability, there have long been arguments about which model is superior. These arguments, which are largely made by those in the performance and political accountability camps, state that their particular model is the best, and indeed only legitimate approach to ensuring accountable government. At the same time, there is growing research in policy tools but little in how accountability models and policy tools are linked in policy design.

This study makes use of the context provided by the critical cases of the Troubled Asset Relief Program (TARP) and the American Recovery and Reinvestment Act (ARRA). With such large sums of money in play at a time of serious economic downturn and mounting federal deficits, government clearly has a responsibility to ensure accountability so that the public can be assured not only that its funds are being spent properly but also more generally, that accountability as well as policy tool choice is in the minds of officials as they formulate, adopt and implement public policy.

The intent of this study is to present an argument in two main areas using the critical case studies of TARP and ARRA. First, that no one accountability model fully explains most policy tool choices in TARP or ARRA and that the use of multiple models is superior. Second, that we can link policy tool choices and accountability models in policy design. The standards used to establish what models explain what tool choices are in the models themselves. Each policy is explored individually in a chapter, and the lessons and results of this study are then presented in the final chapter.
\end{abstract}


The data presented in this study indicate that a single-model approach may explain a few, but not most and certainly not all, policy tool choices in TARP and ARRA. Indeed, a multiple model approach proves superior to a single-model approach in all but a few instances. As for the connections between policy tools and accountability models, the data presented in this study show that they were strongly impacted by the policy formulation process itself, specifically the way in which the policy problem was framed and the speed with which it was undertaken. 


\section{DEDICATION}

I dedicate my dissertation in memory of my grandfather Stuart Seiler (19172014). Confucius observed long ago that, "If you think in terms of a year, plant a seed; if in terms of ten years, plant trees; if in terms of 100 years, teach the people." Stuart agreed with this philosophy and believed strongly in the value of education. Stuart was also a key force in helping finance and encourage all of my academic pursuits. Stuart also believed in the value of effective and accountable government and that to live a full life, one must involve oneself in ensuring it is as effective and accountable as possible. It is fitting that I dedicate this last piece of work I will produce as a student in his honor. 


\section{ACKNOWLEDGEMENTS}

I wish to thank my committee members who were more than generous with their expertise and precious time. A special thanks to Dr. Phillip Cooper, my chair, for his countless hours of reflecting, reading, encouraging, prodding and most of all patience throughout the entire process. He has been more than just a dissertation chair to me. Dr. Cooper has become both a lifelong friend and a mentor. Thank you also to Dr. Ronald Tammen, Dr. Douglas Morgan, Dr. Craig Shinn and Dr. Gerard Mildner for serving on my committee.

I would like to thank and acknowledge all the other teachers and administrators at Portland State who have been extremely helpful in bringing this research to completion. I extend a special thank-you to Dr. Lindsay Desrochers and Jim Hough, from whom I learned a great deal while co-teaching the public budgeting class over the past several years.

I also want to thank all the teachers over my lifetime who have taught and encouraged me. Special thanks to Dr. Barbara Trish of Grinnell College, former Grinnell President Russell Osgood, Una Whitcomb and Kit Hawkins of the Arbor School for Arts and Sciences and my kindergarten teacher, the late Mrs. A of Bridlemile Elementary. It has been a long journey but worth every step.

A final and most sincere thanks to my parents Anne and Peter Jarvis, my sister Amy Jarvis and my entire extended family. They have been there for me throughout this entire process, prodding, encouraging and keeping me on track. I am proud to say I am finally finished! 


\section{TABLE OF CONTENTS}

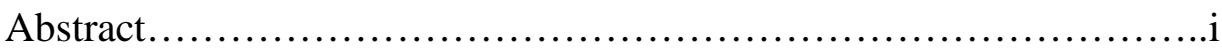

Dedication.....................................................ii

Acknowledgements..............................................

\section{Chapter 1}

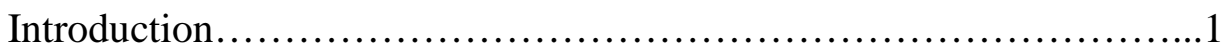

Chapter 2

Framing Policy Tools and Accountability Models....................20

Chapter 3

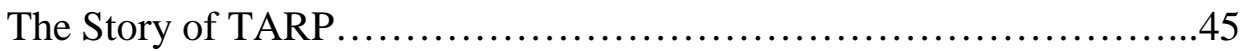

Chapter 4

The Story of ARRA............................................. 87

Chapter 5

Analyzing Trends and Meanings for Future and Current Research......113

References............................................... 152

Appendix A

Coding of Documents..........................................189

Appendix B

Interview List........................................... 190 


\section{Chapter 1: Introduction, the Research Questions and Methodology}

Accountability has been a core concern of American government since the country's founding. As James Madison famously wrote in Federalist 51:

"In a single republic, all the power surrendered by the people is submitted to the administration of a single government; and the usurpations are guarded against by a division of the government into distinct and separate departments. In the compound republic of America, the power surrendered by the people is first divided between two distinct governments, and then the portion allotted to each subdivided among distinct and separate departments. Hence a double security arises to the rights of the people. The different governments will control each other; at the same time that each will be controlled by itself (Hamilton, Jay, \& Madison, 1787-1788)."

Indeed, the separation of powers system suggested in Federalist 51 and present in the US Constitution was designed, in no small part, to help ensure accountable government (Hamilton, Jay, \& Madison, 1787-1788; United States Constitution, 17871788, pp. Arts. I-III). Yet, while accountability has long been a core principle of American and indeed all democratic governance, there is widespread disagreement on what accountability is and how best to ensure it. This study has found that the literature contains no less than eight different and commonly referenced models of accountability, each of which has its own decision rules, assumptions and advocates who claim that their model is the best, and often, only proper model to utilize to ensure accountability.

In the study of government accountability, there have long been arguments about which model is best. These arguments are largely made by those in the performance and 
political accountability camps, who state that their model is the best and indeed only legitimate approach to ensuring accountable government. At the same time, there is growing research in policy tools but little in how accountability models and policy tools are linked.

Concerns about accountability have become particularly acute in the policy responses to the current economic crisis. It is easy to see why that has been the case, as the federal government has authorized expenditures of over $\$ 1.5$ trillion between the Troubled Asset Relief Program (TARP) and the American Recovery and Reinvestment Act (ARRA) alone (ARRA, 2009; Emergency Economic Stabilization Act of 2008, 2008). With such large sums of money in play at a time of serious economic downturn and mounting federal deficits, government clearly has a responsibility to ensure accountability so that the public can be assured both that its funds are being spent properly and, more generally, that accountability is in the minds of officials as they formulate, adopt and implement public policy. However, this study is not really about TARP or ARRA but rather about the accountability models themselves, and the policy tools they utilize, as ways to help us understand how accountability is defined in both theory and practice.

This study seeks to explore ways to understand policy choices aimed at ensuring accountability in a complex context. It seeks to address limitations in the existing use of models of accountability in the existing literature. More specifically, it asks the question of how effectively any of the four most commonly used models of accountability explain the policy tool choices selected to address accountability issues in TARP and ARRA. 
These four models are: (1) political accountability; (2) professional bureaucratic; (3) legal and (4) performance.

This study consists of five chapters. This first chapter will explain how the study uses a case study analysis of TARP and ARRA to assess how well the most widely used models explain the choice of policy tools used in these programs to ensure accountability. This chapter will also explain the research strategy and methodology to be used in that effort.

The second chapter will discuss the state of the literature with respect to the models' theoretical assumptions and their decision rules and will identify the most important gaps in the modern accountability literature. It will also discuss policy tools literature in order to provide proper framing for this study.

The third and fourth chapters will describe in more detail the cases of TARP (in chapter 3) and ARRA (in chapter 4) and the basic findings related to what policy tools were used and which accountability models were used in relation to tho1se policy tools. It will focus on description, with analysis saved for the final chapter.

The fifth and final chapter will then proceed to analyze the data, focusing on what the study argues are three primary gaps in the literature. First, the assumption that a single model of accountability is best and that models of accountability are separable. For example, Robert Behn writes repeatedly that the only correct way to approach government accountability is to utilize "tactics and strategies that seek to enhance the performance of the public sector-to improve the ability of government agencies and their nonprofit and for-profit collaborators to produce results (emphasis in original) (Behn, 2001, p. 26)." 
Second, there is no existing case in which accountability models are tested side by side. Particularly since TARP and ARRA are different approaches to the same overarching set of problems caused by the 2008 economic crisis, this should allow us to see what impact accountability models have on policy tool choice.

The third literature gap is that very little literature matches policy tools and accountability models in policy design. Perhaps if certain policy tools and accountability models match up, something can be learned about both. Since this is a critical case study, it is necessary to focus on cases which are atypical but important. It is precisely in such cases that models are put to the ultimate test, and it might then be possible to make generalizations from these cases, atypical as they are. If those in the field can start thinking of accountability model mixes as the proper way to evaluate accountability rather than single models. This could lead to a deeper examination of previously undiscovered facets of government accountability and their connections to policy tools.

This study focuses on the following research question: How effectively do any of the four most commonly used models of accountability explain the policy tool choices selected to address accountability issues in TARP or ARRA? In order to answer this question, this study focuses on two research hypotheses. First, that no one model explains all the policy tool choices in TARP or ARRA. Second, that using multiple models will better explain most of these policy tool choices. Answering this question should help us advance accountability and policy tools literature.

The thesis of this study is that no single accountability model adequately explains policy tool choices and that a multiple model approach is superior. In addition, the conditions and problem statement on which a policy is based impact policy tool choice. 
The background and basis for this thesis will be explored in more detail throughout this study.

\section{THE CASE: TARP AND ARRA AS PUBLIC POLICY}

In order to understand the appropriateness of TARP and ARRA as a critical case study, it is important to understand in more detail what TARP and ARRA are and how they came about. The following section will therefore briefly discuss the history and design of TARP and ARRA (both are described in far more detail in chapter three for TARP and chapter four for ARRA). This section will then conclude with a discussion of how TARP and ARRA is both an appropriate and feasible critical case study to test how accountability models explain policymaker choices.

In order to solve the problems caused by the collapse of the housing bubble, the US Department of the Treasury asserted that it needed to help banks remove so-called "distressed assets (US Department of the Treasury, 2008b)" from the financial system in order to stabilize banks and other financial institutions. As the US Department of the Treasury stated in proposing the first version of what later became TARP", "When the financial system works as it should, money and capital flow to and from households and businesses to pay for home loans, school loans and investments that create jobs. As illiquid mortgage assets block the system, the clogging of our financial markets has the potential to significantly damage our financial system and our economy, undermining job creation and income growth. (US Department of the Treasury, 2008b)."

\footnotetext{
${ }^{1}$ The bill was formally titled the Emergency Economic Stabilization Act of 2008 (EESA), of which TARP was by far the largest component in both the original and final bill (SIGTARP, 2009, p. 43).
} 
TARP proposed to do so by adopting an approach similar to that used by the federal government in the Savings and Loan crisis of the late 1980s, wherein it provided temporary loans to financial institutions in order to ensure their stability (Seidman W. L., 1996; US Department of the Treasury, 2008b). Once they were able, these financial institutions would then pay back these loans, thus meaning that the cost to the federal government would be far less than the initial $\$ 700$ billion price tag (Seidman W. L., 1996; US Department of the Treasury, 2008b).

While originally intended as a program designed to purchase toxic assets in order to stabilize financial institutions, TARP in fact spent very little money purchasing such assets (\$5 billion as of September 30, 2010) (SIGTARP, 2010b, p. 237). Instead, it spent by far the most funds pursuing three primary tasks: (1) purchasing an estimated $\$ 280$ billion in stock in trouble banks and investment institutions such as Citigroup, JP Morgan and Bank of America; (2) providing \$40 billion in loans to prevent the potentially catastrophic collapse of American International Group (AIG) and (3) providing nearly $\$ 80$ billion in loans to American auto manufacturers in order to prevent their collapse (SIGTARP, 2010b, p. 237). An additional \$45 billion was appropriated to help prevent home foreclosures but as September 30, 2010 only $\$ 600$ million had actually been spent and the administration had yet to come up with a plan to spend the remaining funds in this area (SIGTARP, 2010b, p. 237). As a result, of the total of $\$ 387$ billion actually expended under TARP, greater than $90 \%$ of it went directly to assisting banks, investment houses, AIG or auto manufacturers, far from the original intent of purchasing toxic assets. 
Yet even with its hefty price tag, it was clear that TARP alone was not enough since it only assisted a small part of the American economy. Shortly after taking office in 2009, President Barack Obama proposed an additional stimulus plan entitled the American Recovery and Reinvestment Act (ARRA) (Baker, 2009; Obama, 2009b; US GPO, 2009). ARRA utilized a variety of policy tools such as tax cuts, aid to states and local governments to limit their budget cuts, increased unemployment benefits and direct federal spending largely on infrastructure projects (Baker, 2009; Obama, 2009b; US GPO, 2009). The Obama administration argued that this direct federal spending where, unlike for TARP, the initial cost of the bill was expected to be the final cost as little to no repayment was expected, was the best and arguably only way to stabilize the economy and promote job growth (Baker, 2009; Obama, 2009b; US GPO, 2009). Unlike with TARP, ARRA had no trouble sailing through the legislative process and was signed into law on February 17, 2009, less than a month after President Obama took office (Baker, 2009; Obama, 2009b; US GPO, 2009).

ARRA is composed of three primary components (Recovery.gov, 2010c): (1) a \$288 billion package of tax cuts and tax expenditures for both business and personal taxpayers; (2) \$224 billion in aid to states to help preserve entitlement programs (primarily unemployment benefits), health care and education programs which were otherwise in danger of being cut and (3) \$275 billion in federal contracts, grants and loans to fund a series of projects, from infrastructure to research to environmental preservation and beyond (Recovery.gov, 2010c). It is this last $\$ 275$ billion that has received by far the most scrutiny since it is the portion of ARRA that allows for the greatest spending discretion and thus required the closest scrutiny. 
Although clearly different, TARP and ARRA share two main characteristics which make this study more manageable. First, they are wide-reaching and together rely heavily on spending in both the public and private sector in order to be successful. Second, they are short-term policies, with TARP beginning to wind down in late 2009 and early 2010 and most of the funds in ARRA already spent by mid-year 2010. This short time-frame makes the cases easier to frame and thus manageable for this study. TARP and ARRA: A Useful Context to Challenge Accountability Models

Now that this study has given a brief overview of the history and design of TARP and ARRA, it will briefly discuss why these cases are critical cases. In order to determine if they meet the standards for a critical case study, we must meet the three criteria established by Yin and Flyberg: that the case be atypical, critical to theory development and testing and have enough data to conduct the study (Flyvbjerg, 2006, pp. 219-225; Yin, 2008, pp. 46-59). The following section will address each of these points in turn.

TARP and ARRA are unique policies created to solve the unique problems posed by the economic downturn which began in 2008. The scope of these two policies together touched nearly every aspect of both private and public life and thus required two uniquely different, if related, responses. Their combined appropriations of more than $\$ 1.5$ trillion are substantial and rely on both the private and public sector to implement. An effort of this size and scope is clearly a unique case and one that cannot be assessed using anything but critical case study methodology.

TARP and ARRA are also important to theory testing and development. This is because, again taken together, they comprise the two ends of the modern government 
accountability spectrum, with TARP largely intended to rely on market and performancebased accountability models while ARRA was intended to rely heavily on a legal accountability approach (Congressional Oversight Panel, 2009; Recovery.gov, 2009b). Inherent in both was political accountability, both in terms of what was in the policy when it was designed, passed and then tracked by members of Congress and the public at large, and bureaucratic accountability because, in the end, public administration professionals had and still have a role in how both policies were designed. The combination of these four accountability models in this atypical and important set of circumstances makes clear why a critical case study approach is justified.

Third, this study is feasible both because a significant amount of data exists and because they are short-term policies and can thus be framed properly. This second point is particularly important since one problem inherent in case studies in general is the need to frame them properly in order to limit the number of variables present in a case. The short-term nature of these policies makes that possible. As for data availability, there is arguably more data than needed to conduct this study, rather than too little. In any case, however, TARP and ARRA meet the three criteria established above and therefore an appropriate choice for a critical case study methodology. The following section will briefly discuss the research process as well as the data acquisition strategy for this study.

\section{THE RESEARCH PROCESS AND DATA ACQUISTION}

As noted above, the empirical setting for this research is the two major stimulus bills enacted in response to what has become commonly known as the "great recession (Samuelson, 2010)", which began in 2008 and is arguably still ongoing (Samuelson, 2010). In order to allow for the proper framing of this case study, however, the study will 
consider the time period from September 7, 2008, the day Fannie Mae and Freddie Mac were placed under government control, until February 1, 2010, slightly more than one full year into the Obama administration (New York Times, 2009). This allows for research to explore the background, enactment and much of the implementation of both TARP and ARRA.

The primary sources for this study were the legislation itself as well as the myriad of reports produced by the agencies responsible for ensuring accountability in either TARP or ARRA. Most of these reports were prepared by the five organizations charged with ensuring accountability for TARP and ARRA: (1) the Congressional Oversight Panel (COP); (20 the Recovery Accountability and Transparency Board (RATB); (3) the Special Inspector General for the Troubled Asset Relief Program (SIGTARP); (4) the US Government Accountability Office (GAO) and (5) the US Department of the Treasury (Congressional Oversight Panel, 2009g; Recovery.gov, 2009c; SIGTARP, 2009e; US Department of the Treasury, 2009; Government Accountability Office, 2009; US GPO, 2009). In the specified case period, these five organizations alone produced more than 175 reports on various aspects of TARP or ARRA accountability (Congressional Oversight Panel, 2009g; Recovery.gov, 2009c; SIGTARP, 2009e; US Department of the Treasury, 2009; Government Accountability Office, 2009; US GPO, 2009). When added with the legislation itself as well as other implementing guidance provided by OMB and other federal agencies, there clearly was sufficient data to conduct this research (Office of Management and Budget, 2009c; Office of Management and Budget, 2009d).

In addition to this content analysis, I conducted interviews in February 2012 in Washington, DC with a Senate Finance Committee staffer, the former two top staffers at 
the COP, a Congressional Research Service employee who worked on ARRA and a group of GAO employees led by Chris Mihm who worked on both TARP and ARRA. These interviews were semi-structured, with interviewees being sent a set of 10-15 questions several days in advance. Interviews began with those questions as a base and then flowed from them into the areas deemed appropriate by either the interviewee or myself. These interviews, which took 30-60 minutes each, were not recorded due to the request of the interviewees, but copious notes were taken by myself and each interview was written up the same day it was conducted to minimize data loss. These documents and these interviews combined to comprise the basis of the data from which this study was conducted. The next section will discuss the data collection strategy for this research.

\section{Data Collection: Care is Needed but there are no Significant Barriers}

The data collection strategy for this case is straightforward since this case is a public event and the emphasis is on the formal selection of policy tools. The purpose here is to see how well the models explain behavior in the form of the ultimate decisions taken rather than the motives of any individual participants. The primary sources of evidence are public records such as accountability reports, the legislation itself and other implementing guidance/regulations. These sources were appropriate to use for four main reasons: (1) they are easily available; (2) they allow for the creation of a chronology for the case in order to allow for the case to be properly framed; (3) these sources, taken together, given a fairly complete view of this case and (4) these data come from trustworthy sources and thus provide a reliable record of the case. 
This data collection approach was not without potential challenges, three of which are particularly worth noting (Swanborn, 2010, pp. 76-95; Yin, 2008, pp. 101-123). First, the data available from these documents may not provide all the information one needs to understand the accountability systems in this case (Swanborn, 2010, pp. 76-95; Yin, 2008, pp. 101-123). While it is certainly true that full understanding of the accountability systems in this case may not be possible with this, or any, data source, it is nonetheless believed that more than enough data exists to understand how the four accountability models were applied here. Second, the data are largely framed around the results of the policy and not the accountability systems themselves (Swanborn, 2010, pp. 76-95; Yin, 2008, pp. 101-123). This is where a policy tools approach is useful because, by identifying the policy tools inherent in each element of this case, it can help connect them to the four models and thus solve the framing issue. Third, the data may indicate causality where none exists, particularly in relation to the impacts the policies had on the external environment (Swanborn, 2010, pp. 88-94). However, since this study was not about TARP's or ARRA's effectiveness but rather about their accountability models and the policy tools that were utilized in their design, this is not really a problem here. In any event, these three problems with the data set are not likely to present significant obstacles. While certainly not perfect, the data collection strategy used in this project should provide sufficient data to complete this study.

\section{Data Analysis: Coding and ATLAS}

The data analysis strategy for this study is straightforward. A database was created in ATLAS with all 237 documents collected for this study. The documents were then divided into categories based on source (such as GAO, SIGTARP, Treasury, etc.), 
type of document (such as regulations, legislation, accountability report, etc.) and whether they addressed TARP or ARRA. Codes were then created for each of the policy tools listed in the next chapter and for the four accountability models as well. Each policy tool also had one code created for each of the accountability models addressed in this study (so, for example, the policy tool "Contracting" has codes that read "Contracting-Political", "Contracting-Legal" and so on). Each document was evaluated on the basis of the criteria listed below with passages coded when they met the standards of one or more codes. Passages were often coded with more than one code because it was found in several instances that although only one policy tool was in play, multiple accountability models were. When in doubt, the inclination was to code more passages, and use codes more frequently, in order to avoid missing any possible data points.

The resulting codes were both summarized numerically and then evaluated passage by passage to ensure accuracy. A decision was then made first as to which policy tools were most in use in each policy and second whether and how each of the four accountability models were or were not used. In addition, documents were coded where other accountability models appeared to be present so as to evaluate whether the choice of the four models for this study was proper. These codes were then evaluated to see where trends existed and these trends comprised the majority of data upon which this study was conducted. These data were then supplemented with input from the interviews as appropriate. The interviews also helped to confirm, add to, or deny the findings made in the original data analysis. For example, without the interviews it would not have been known that GAO played such an important role in designing ARRA's implementing regulations. These two types of data, which constitute the raw findings of the study, will 
be discussed in chapter three (TARP) and chapter four (ARRA). Although other researchers using with the same documents and conducting the same interviews might find slightly different results, it is believed that the robustness of the coding (and the evaluation and analysis of the coding), will ensure that such differences are small and not significant.

FRAMING THE MODELS: USING STANDARDS FROM THE MODELS THEMSLEVES

Perhaps the most important part of this study's methodology is in how to determine when models are or are not present. This study uses standards from the models themselves. In other words, we ask whether the standards and approaches match those of each of the models in their literature.

Political Accountability:

For political accountability, we will find that the model is present when at least two of three conditions are met. First, political accountability is utilized in cases where authority or responsibility exists for action within a system (Mayhew, 2004, pp. 110115). For example, in the American system, Congress has the responsibility to oversee the federal bureaucracy (Finer, 1941, pp. 335-338). The act of doing so is by itself an act of political accountability. Second, actors utilizing political accountability must consider whether their actions are in concert with the interests of political actors and stakeholders (Fenno, 1978, pp. 133-138; Mayhew, 2004, pp. 22-25). If conduct is in not in the interests or at the behest of such actors and stakeholders, it is hard to see why the political system would undertake any action. Third, political accountability is called on when a problem is perceived as a political, and not a professional or mechanical, problem 
(Fenno, 1978, pp. 133-138). If there is a public outcry to respond to a particular problem, it almost by definition becomes political (Finer, 1941, pp. 335-338). Absent such an outcry, a problem can often be handled within the existing professional bureaucratic system and thus may not rely on political accountability (Finer, 1941, pp. 335-338). Professional/Bureaucratic Accountability:

For professional or bureaucratic accountability, we shall find it exists when at least two of the following three standards are met: First, when a policy requires determining what the public needs as judged by a professional assessment of problems, contexts and opportunities; second, when the policy calls for professionals determining what is in the public's best long term interests once short term political demands are filtered out and professional judgment is applied; and third, when the policy calls for determining how best to utilize professional and technical expertise to meet these interests (Levitan, 1946, pp. 565-575; Long, 1952, pp. 809-812; Long, 1954, pp. 23-25). What separates this from the political model is this essential focus on professionals determining how to serve the public interests, rather than responding only to the political demands of those in power at any one time. The reasoning is that while political changes may and will occur with some regularity, the day to day administration of the public's business has to able to respond to a range of requirements including representation of the long term public interest as viewed by professionals (Levitan, 1946, pp. 565-575; Long, 1952, pp. 809-812; Long, 1954, pp. 23-25). Professional administrators are needed to ensure that this large body of work, which should not be about politics, can be done and that the lower order politics are adjusted by professional knowledge and values (Friedrich, Beyer, Spero, Miller, \& Graham, 1935, pp. 58-65). 


\section{Legal Model:}

When it comes to the legal model, the standards for determining usage of the model are inherently broad. This study will therefore rely on the following dictum, "the actions of governmental officials must have their basis in public law, not in the pecuniary interests of private entrepreneurs and owners or in the fiduciary concerns of public managers (Moe \& Gilmour, 1995, p. 138)." This broad definition is necessary because legal accountability can differ in appearance based on the official or organization that is taking the action and on the type of situation that is involved (Cooper P. J., 2007; Moe \& Gilmour, 1995; Rohr, 1986). It also depends upon the type of legal question that is raised for resolution. For example, legal accountability can depend on whether an issue is constitutional, statute-based, procedural or factual (Cooper P. J., 2007; Moe \& Gilmour, 1995; Rohr, 1986).

As to the official and organization, the choice of rule is based on whether the action comes from Congress, an administrative agency or concerns an individual official or municipal corporation (Cooper P. J., 2007; Moe \& Gilmour, 1995; Rohr, 1986). These decisions are then also informed by case law in an Anglo-American common law system. The last is the basic point: legal accountability exists when authority for action and the mechanisms for tracking such action lie within the legal system itself.

Performance-Based Management Accountability:

This study shall find that performance-based management accountability (often called performance accountability) exists when we find that measureable standards are used in an attempt to improve government efficiency and effectiveness. This stems from the basic tenet of this approach, which is the assumption that government is inherently 
inefficient and ineffective. In order to fix this problem, government should use its resources in a way that most efficiently produces "performance" via measureable standard, such as those used in the private sector (Behn, 2001, pp. 152-155; DeLeon, 1998; Kassel, 2008; Radin, 2006, pp. 240-244). Performance accountability argues that waste and ineffectiveness can only be determined by utilizing measureable standards. The standards are applied in combination with financial auditing by OMB, the GAO and other agencies so that the government and the public will be able to determine how effective government is and how government can best utilize its resources (ExpectMore.gov, 2009). Tools such as OMB's Program Assessment Rating Tool (PART) provide examples that have been used to measure whether agencies have met these standards (ExpectMore.gov, 2009).

LIMITATIONS OF THE STUDY: GENERALIZABILITY, TIME FRAME, LIMITED MODEL CHOICE AND NO POLICY EVALUATION

Every study has its limitations. In this case, there are four main ones. First, due to the unique nature of both the events that led to the creation of TARP and ARRA as well as TARP and ARRA themselves, it might well be that some of the policy tool choices are not representative of a typical case. Alternatively it might be the case that the nexus between a particular policy tool and the accountability model that explains it might be different than what one might normally see. This study presents the analysis as a critical case study in which the issues are drawn more clearly than normal. However, the strength of critical case studies is that they can isolate key relationships and address important questions as well as general hypotheses. Indeed, it is in such dramatic cases 
that the relationships among the varied models and their explanations of behavior would, or at least should, be particularly clear and significant.

A second potential limitation of this study is related to the limited time frame in which the case is considered (September 2008-end of January 2010). It is likely true that more data and perhaps more findings would result if this time frame were extended. However, in a case study situation, a critical concern is always balancing the value of the additional data with the complexity that expanding the case might bring. While additional data will develop over time as to these policies and some data already exists for the period after the end point of this study, the emphasis here is on policy formulation and not on implementation. The case already contains more than enough data to examine the policy tool choices, their development and implementation.

Third, on a related point, a potential limitation is the choice to focus on only four of the eight accountability models discussed in the literature review. It is possible that including the four additional models would increase the value of this study at some level. Nonetheless, when doing research one must always balance the value of any additional findings with the complexity the additional areas of focus add. It is certainly the case that future research to examine the explanatory power of the other four models along with the findings of this study could be valuable. A further discussion of this point is contained in chapter two.

Fourth, a potential limitation of this study is that it does nothing to evaluate the effectiveness of the policy tools choice or the resulting policy. It might well be interesting, for example, to see whether there might be a difference between the effectiveness of particular policy tools and whether the accountability model that best 
explains the tool choice is a factor in their effectiveness. That is another study for another day, however, and does not fit within the bounds of this study. The question of the choice of any particular policy tool is not a statement about whether it was the best choice or even a good choice.

Conclusion:

This chapter has introduced the study, described the methodology and standards of analysis as well as the data collection method and some limitations of the study. The next chapter will discuss the state of the accountability and policy tools literature and more fully explicate the literature gaps this study intends to address. 


\section{Chapter 2: Framing Policy Tools and Accountability Models}

Introduction:

While the first chapter focused primarily on laying out the basic groundwork for the study as well as the methodology and research strategy, this chapter will focus on the state of the literature. It will do so in three parts. First, it will explain the state of policy tools research in order to frame that essential part of this study. Second, it will explain the state of the accountability literature as well as discuss why this study chooses to focus on four particular accountability models. Third, it will describe in greater detail the literature gaps and how this study intends to address them. This chapter will thus make clear the state of policy tools and accountability research, the existing literature gaps, why these gaps are important and how this study will address them.

FRAMING THE ANALYSIS: ACCOUNTABILITY MODELS, POLICY TOOL CHOICES AND POLICY INSTRUMENTS AND MECHANISMS

As discussed in the introduction, this proposal asks how effectively accountability models explain the policy tool choices chosen to address accountability issues in TARP and ARRA. In order to best explain the policy tool choices in TARP and ARRA, the study will focus on the explanatory power of the four main accountability models most commonly discussed in the accountability literature. These are: (1) political; (2) professional bureaucratic; (3) legal and (4) performance. While the other four models discussed below might well add some value to this study, they are not as important to either the practical or theoretical development of the accountability literature. The following paragraphs will discuss policy tools literature so that one can understand what is meant when policy tool choices are discussed. 
Public administration scholars Anne Schneider and Helen Ingram define policy tools as, "techniques the government uses to achieve policy goals (Schneider \& Ingram, 1990, p. 527)." The study of such tools represents one of the most important fields of new research in modern public administration (Salamon, 2001; Salamon, 2002). As Lester Salamon writes, "A massive proliferation has occurred in the tools of public actions, in the instruments or means used to address public problems. Whereas earlier government action was largely restricted to the direct delivery of goods or services by government bureaucrats, it now embraces a dizzying array of loans, loan guarantees, grants, contacts, social regulations, economic regulations, insurance, tax expenditures, vouchers and more (Salamon, 2002, pp. 1-2) (emphasis in original).”

Salamon argues that there are thirteen different policy tools that government generally uses when designing public policy (Salamon, 2002, p. 21). They are: (1) direct government; (2) social regulation; (3) economic regulation; (4) contracting; (5) grants; (6) direct loans; (7) loan guarantees; (8) insurance; (9) tax expenditures; (10) fees and charges; (11) liability law; (12) government corporations and (13) vouchers (Salamon, 2002, p. 21). Each of these tools has three primary characteristics: (1) a product/activity in which it engages, (2) a vehicle it uses to implement this product/activity and (3) a delivery system to carry out the specific implementation of the product/activity (Salamon, 2002, p. 21). ${ }^{2}$

Yet, not all policy tools are created equal. As Cooper writes, "there are two types of devices involved in the general category that is termed "policy tools" and that should

\footnotetext{
${ }^{2}$ Salamon has a chart of each of his thirteen policy tools and their product/activity vehicle and delivery system on page 21 of his book. (Salamon, 2002, p. 21).
} 
be recognized as distinct (Cooper P. J., 2009, pp. 230-231)." Cooper titles these two groups “policy mechanisms (Cooper P. J., 2009, p. 231)" and "policy instruments (Cooper P. J., 2009, p. 231)." Policy mechanisms are "devices that operate on the basis of some identifiable mobile force that makes them attractive to use in certain circumstances (Cooper P. J., 2009, p. 231).” These policy mechanisms are, in Cooper's view, well encapsulated in Salamon's list of policy tools (Cooper P. J., 2009, p. 231; Salamon, 2002, p. 21).

By contrast, policy instruments are the "authoritative policy documents and processes that put those devices into operation (Cooper P. J., 2009, p. 231)." They are, in short, the actual resulting policies themselves, such as statutes, regulations, treaties and executive orders (Cooper P. J., 2009, pp. 230-231). Cooper argues that is important to recognize this distinction because policy mechanisms and policy instruments operate on “different principles (Cooper P. J., 2009, p. 231)" and thus must be considered to be distinct, if closely related, phenomena.

For the purposes of this research, we focused primarily on what Cooper would call policy mechanisms (Cooper P. J., 2009, p. 231) . This is because while the overarching policy itself is clearly a policy instrument, the main level at which accountability models operate is believed to be at the mechanism level. Although it is certainly true that exploring the intersection of policy instruments and accountability models might well be a future research topic worth pursuing, it was not pursued here.

Since these policy tools lend themselves so well to comparison with our accountability models, and since they are well accepted within the field, this study will frame the study of each of its accountability models in policy tools literature. This will 
allow for the analysis of this case and these four models to be doubly grounded in the established literature of both policy tools and accountability models. The following section will discuss in more detail the research process and data collection strategy this study proposes to utilize.

THE ACCOUNTABILITY LITERATURE: DIFFERENT PERSPECTIVES ON THE PROBLEM AND HOW TO ADRESS IT:

British scholar Peter Barberis wrote that, "the main components of accountability are set out under five headings: who is accountable; for what; to whom (or what); through what mechanism; and with what kind of accountability outcome (Barberis, 1998, p. 466)." Each model of accountability discussed in the literature answers these questions in different ways. Eight primary models of accountability are commonly discussed in the literature: (1) political accountability; (2) professional bureaucratic; (3) legal accountability; (4) performance-based; (5) ethical; (6) market; (7) managerial/organizational and (8) contract. All of these accountability models provide a different answer to the five questions posed by Barberis and thus address different ways of ensuring accountable governance.

Yet for all the accountability literature that exists, there still exist three major gaps in the literature. First, there is the false assumption that there is one universally best model of accountability; second, there is a lack of side by side testing of accountability models, third, there is lack of literature matching policy tools and accountability models in policy design. This study seeks to address these gaps.

This chapter will provide a description of each model, as well as a discussion of policy tools, including its leading figures, theoretical bases and primary approaches 
(sometimes called decision rules). While only the first four models discussed will be examined in full due to the fact that they dominate the accountability literature, it is important to examine the full state of the literature before continuing. The study develops these models more fully when they are applied in the following chapters; the purpose here is primarily to introduce them so as to explain the varied approaches and the problems that remain despite these approaches.

$\underline{\text { Political Model: Accountability through Representation and Oversight }}$

The oldest and most established accountability model in the literature is political accountability. It traces its roots back to Aristotle's politics, through Locke's treatises on government, then through the federalists and beyond to modern political scientists such as Fenno and Mayhew (Aristotle, 350 BCE; Fenno, 1978; Finer, 1941; Hamilton, Jay, \& Madison, 1787-1788; Locke, 1689; Mayhew, 2004). It ranges in scope from broad treatments of political theory, to the relationship between politics and administration, and to contemporary debates about the operation of political systems. Yet while the way authors have described political accountability has differed throughout the model's long history, the guiding theoretical bases and decision rules are all grounded in the political as the core focus of accountability judgments.

There are three basic theoretical bases for political accountability that are commonly employed in this literature: First and foremost, political accountability focuses on pursuing the public good, whether narrowly defined in terms of a single member of Congress or broadly defined as the nation as a whole or in terms of what has been called the "virtuous life (Aristotle, 350 BCE, pp. Book I-2)". While the definition of public good in any case can be problematic, the principle on which is based is doing 
what is in the best interest of the public, or at least the best interest of most of the public (Finer, 1941, pp. 335-338; Storing, 1964, pp. 40-42). Second and perhaps most importantly, political accountability relies on being within a legitimized and accepted system in order to be effective (Mayhew, 2004, pp. 110-115). Thus, political accountability is commonly thought to require a formally accepted political system since it draws its power from the legitimacy of the system itself. Third, political accountability relies on following the political processes of its system in order to ensure accountability (Mayhew, 2004, pp. 110-115). In other words, political accountability is defined as primarily based on process and not necessarily outcomes.

There are three primary approaches that those who utilize political accountability often employ in their decision of how policymakers who operate from the political perspective actually make their decisions. First, political accountability is utilized in cases where authority or responsibility for action exists within a system (Mayhew, 2004, pp. 110-115). In the American system, for example, Congress has the responsibility to oversee the federal bureaucracy (Finer, 1941, pp. 335-338). The act of doing so is by itself an act of political accountability. Second, actors utilizing political accountability must consider whether their actions are in concert with the interests of other political actors and stakeholders (Fenno, 1978, pp. 133-138; Mayhew, 2004, pp. 22-25). This is particularly true in the modern context, with its focus on interest groups and on building coalitions. Third, political accountability is called on when a problem is perceived as a political, and not a professional or mechanical, problem (Fenno, 1978, pp. 133-138). If there is a public outcry to respond to a particular problem, it almost by definition becomes political. Lacking such an outcry, a problem can often be handled within the 
existing professional bureaucratic system and thus may not rely on political accountability (Finer, 1941, pp. 335-338). Scope does not matter to this last point as a political problem can be either large or small in scope. It is the fact that it is or becomes a political problem that counts.

The Professional Bureaucratic Model: Trusting the Professional Expertise of

\section{$\underline{\text { Administrators to Act in the Public Interest }}$}

The history of professional bureaucratic accountability (more commonly called professional or bureaucratic accountability) is largely the history of modern public administration, and it traces its roots back to Woodrow Wilson's well-known 1886 treatise on public administration (Wilson W. , 1886). The professional bureaucratic model evolved during the progressive era reforms that sought to borrow skills in administration of public programs and institutions from the emerging professions, including the scientific management movement. The model thus developed as it was becoming increasingly apparent that "the amount and complexity of specialized skill required in connection with every kind of human enterprise (has) vastly increased (Urwick, 1937, p. 51)" and that technically skilled public administrators were needed order to handle these complexities. Wilson's famous article made clear that one needed to get beyond mere discussions of the political aspects of public work to look at the techniques by which it was carried out. Indeed by the 1930s when Gulick and Urwick edited "The papers on the science of administration," the focus had shifted almost completely to the political aspects (Friedrich, Beyer, Spero, Miller, \& Graham, 1935; Urwick, 1937; Wilson W. , 1886). The more complex aspect to come was a discussion started by Fredrich and Finer and further developed by authors like Long and Levitan 
about the role that professional public administrators would play in accomplishing tasks professionally within a political setting (Levitan, 1946, pp. 565-575; Long, 1952, pp. 809-812; Long, 1954, pp. 23-25). This argument is more commonly known as the professional vs. political balancing act, and it remains one of the more enduring debates in public administration to this day.

The theoretical basis of the professional bureaucratic model is the assumption that the best way for government to remain accountable is by utilizing the technical expertise of professional administrators (Friedrich, Beyer, Spero, Miller, \& Graham, 1935, pp. 5865). Accountable governance should therefore concern itself primarily with doing what is in the long-range interests of the public (Friedrich, Beyer, Spero, Miller, \& Graham, 1935; Jackson, 2009, pp. 66-70; Mulgan, 2000, pp. 555-560). This is intended to help counterbalance the political leadership of many government branches and to help make sure that governance is both responsive to the political needs and wants of the day and mindful of long-term goals and responsibilities (Friedrich, Beyer, Spero, Miller, \& Graham, 1935; Jackson, 2009, pp. 66-70; Mulgan, 2000, pp. 555-560). In short, the role of public administrators is to be a steadying force to help ensure accountable and effective governance and delivery of services, even as the political winds invariably shift over time.

Approaches utilizing this model primarily focus on determining three items: (1) what the public needs as judged by a professional assessment of problems, contexts and opportunities; (2) what is in the public's best long term interests once short term political demands are filtered out and professional judgment is applied; and (3) how best to utilize professional and technical expertise to meet these interests (Levitan, 1946, pp. 565-575; 
Long, 1952, pp. 809-812; Long, 1954, pp. 23-25). What separates this from the political model is this essential focus on professionals determining how to serve the public interests rather than responding only to the short term political demands of those in power at any one time. The reasoning is that while political changes may and will occur with some regularity, the day to day administration of the public's business has to able to respond to a range of requirements including representation of the long term public interest as viewed by professionals (Levitan, 1946, pp. 565-575; Long, 1952, pp. 809812; Long, 1954, pp. 23-25). Professional administrators are needed to ensure the quality of the large body of work that is not political and to assure that longer term matters have their lower order politics adjusted by professional knowledge and values (Friedrich, Beyer, Spero, Miller, \& Graham, 1935, pp. 58-65).

The Legal Model: The Core Role of Law as a Basis for Governance, Judicial Review, Monitoring and Consistent Processes

Legal accountability enjoys a long and storied history, and it is probably the oldest model of accountability other than political accountability. It is based on the principal that, as Robert Christensen writes, "the essence of public administration is the detailed and systematic execution of the public law (Christensen, 2009, p. 602)." More specifically, it operates from the assumption that we operate under the rule of supremacy of law, which makes public administration and questions of accountability very different from the private sector. This topic has been discussed by many authors over the years, including Moe, Gilmour, Cooper and Rohr among others, and it is also often implied, if not also expressly discussed, in many legal decisions (Cooper P. J., 2007; Moe \& Gilmour, 1995; Rohr, 1986). 
The theoretical basis of legal accountability is that, "the actions of governmental officials must have their basis in public law, not in the pecuniary interests of private entrepreneurs and owners or in the fiduciary concerns of public managers (Moe \& Gilmour, 1995, p. 138)." Indeed, what makes government different from the private or even the non-profit sector is that in the end, responsibility is due to the system of laws itself and not to any individual. Those who argue for legal accountability argue that this reliance on legal systems is essential for effective governance (Gilmour \& Jensen, 1998; Moe \& Gilmour, 1995; Rosenbloom \& Piotrowski, 2005). This explains why those who rely strongly on legal accountability are deeply troubled by trends such as government privatization, which can result in a "wholesale loss of government accountability (Gilmour \& Jensen, 1998, p. 247)." Legal accountability additionally serves as the basis for legitimate governance according to these authors since those who govern must have the authority to act and do so within the limits of the law. These authors believe that it is the departure from this approach that has created difficulty in contemporary governance (Moe R. C., 1987, pp. 453-454). As Ronald Moe wrote, "a line must separate that which is public or governmental (while other meanings of public are important, these terms are used here interchangeably), and that which is private. The configuration of the line may vary over time and with circumstances, but it is a vital line nonetheless and the fundamental basis of the line is to be found in public law, not in economic or behavioral theories (Moe R. C., 1987, p. 454).” This connection between government action and public laws is thus viewed as the core of American governance and therefore of accountability. 
Legal accountability has a number of well-established approaches based on the official or organization that is taking action and on the type of situation that is involved (Cooper P. J., 2007; Moe \& Gilmour, 1995; Rohr, 1986). Legal accountability also depends upon the type of legal question that is raised for resolution. Thus, decisions about which rules to apply and how to apply them depend on whether the issue is constitutional, statute-based, procedural or factual (Cooper P. J., 2007; Moe \& Gilmour, 1995; Rohr, 1986). As to the official and organization, the choice of rule is based on whether the action comes from Congress, an administrative agency or concerns an individual official or municipal corporation (Cooper P. J., 2007; Moe \& Gilmour, 1995; Rohr, 1986). These decisions are then also informed by case law in an Anglo-American common law system. What follows are the five main situations in which legal accountability applies and how it is implemented in each case.

First, legal accountability can be used as a check to ensure that government action has legal authority to support it, is exercised within an appropriate jurisdiction and does not violate other provisions of law. In this kind of situation, courts must decide whether the agency's actions exceed this standard or, if not, whether they violate someone's constitutional rights (Chevron U.S.A., Inc. v. Natural Resources Defense Council, Inc., 1984; US Code, 2007, p. 5 USC. 706(2)(A). In the 2007 Supreme Court decision Massachusetts v. Environmental Protection Agency, for example, the US Supreme Court found that the EPA's decision not to regulate carbon dioxide emissions was arbitrary and capricious and thus invalid (Massachusetts v. Environmental Protection Agency, 2007). There are many such legal decisions that have helped define the reach and therefore the limits of government discretion and authority. 
The second type of situation in which the legal accountability model applies is when an agency official is accused of violating criminal or civil law (Cooper P. J., 2007, pp. 247-250). In such a case, the agency itself or a designated individual such as an inspector general or prosecutor investigates the complaint and then determines who may have violated the law and what administrative, criminal or civil sanctions to recommend (Cooper P. J., 2007, pp. 247-250; US Code, 2008, pp. PL 110-409). The focus is on individual guilt or innocence, not necessarily on the problems of the system itself, as in the inspector general system (US Code, 2011). This focus on a single case and not on the system as a whole is in fact a hallmark of legal accountability since, at least in the American context, the focus is on a case by case basis and not on the whole.

The third type situation involving legal accountability concerns contract disputes in which the court's role is both to supervise the dispute and then decide, as a matter of fact or law, how the dispute should be resolved (Cooper P. J., 2003, p. 145). The focus is on a case-specific application of the law without any necessary referral to the public interest. For example, in the case of Hughes Aircraft v. United States, the US Supreme Court decided that a contractor was not subject to punishment for filing a false claim since such filings were not against the law at the time they were made (Hughes Aircraft Company v. United States, 1997). This decision was reached because even though the prevention of false claims is in the public interest, upholding the law itself, and not the public interest, is the core value of the legal model (Cooper P. J., 2003, p. 145).

Fourth, legal accountability is used as a way of ensuring compliance with government obligations and standards. For example, under ARRA, any state agency that has "received a Notification of Award (NOA) of $\$ 25,000$ or greater for American 
Recovery and Reinvestment Act (ARRA) fund (Texas Comptroller of Public Accounts, 2010)" is required to do full reporting of all expenditures of funds on a quarterly basis (Recovery.gov, 2009; Texas Comptroller of Public Accounts, 2010). The standards for whether these reports are considered acceptable are the legal standards laid out in the language of ARRA itself. Thus, legal accountability can be used, on a case by case basis, to ensure that legal standards are met.

Fifth, legal accountability is used to help ensure that the processes, if not outcomes, are consistent (Breyer, 2005, pp. 17-21). Every person might not receive the same outcome, but they should receive the same process (Breyer, 2005, p. 18). This might seem to be more of a bureaucratic problem, since, after all, government bureaucracies are formed with the intent of standardizing procedures but it is indeed a legal one because it has its very roots in that most fundamental of American legal documents, the US Constitution and specifically the $5^{\text {th }}$ and $14^{\text {th }}$ amendments (Breyer, 2005). Cases in this area prove that legal accountability is essential to ensuring that due process, and perhaps more importantly, consistent process, are applied in cases of government action.

$\underline{\text { The Performance-Based Management Model: Measureable Standards for Success }}$

If one reads the literature of performance accountability, one might get the impression that it is a new model. It is not and instead traces its history back to the scientific management movement of the 1920s and 30s. As Harvey Walker wrote in 1937, "the objective of administration is to secure the maximum beneficial result contemplated by the law with the minimum expenditure of the social resources (Walker, 1937, p. 8)." The way to do this, Walker suggested, was via performance measures 
(Walker, 1937, p. 8). Indeed, the famous "Papers on the Science of Administration" spend a great deal of time discussing how to apply scientific management to government work (Gulick \& Urwick, 1937). This model's authors tend to come from a mix of private and public sector backgrounds and include Gore, Ostrom, Radin and Behn among others (Behn, 2001; Gore, 1995; Ostrom, 2008; Radin, 2006).

Performance-based management starts with the assumption that government is inherently inefficient and ineffective. In order to fix this problem, government should use its resources in a way that most efficiently produces "performance" via measureable standards, such as those used in the private sector (Behn, 2001, pp. 152-155; DeLeon, 1998; Kassel, 2008; Radin, 2006, pp. 240-244). This philosophy was well expressed by President Obama in a speech to Congress in 2009 when he said, "My administration has also begun to go line by line through the federal budget in order to eliminate wasteful and ineffective programs (Obama, 2009c)." Such waste and ineffectiveness, performance accountability argues, can only be minimized by utilizing measureable standards.

The approaches used by performance-based management combine application of these performance standards with financial auditing by $\mathrm{OMB}$, the GAO and other agencies, government and the public will be able to determine how effective government is and how government can best utilize its resources (ExpectMore.gov, 2009). Tools such as OMB's Program Assessment Rating Tool (PART) have been employed to measure whether agencies have met these standards (ExpectMore.gov, 2009). Programs that perform well under these standards should in theory be rewarded with increased funds while those that do not should either reform to meet these standards or face cuts, or 
even possibly elimination (Behn, 2001, pp. 152-155; ExpectMore.gov, 2009). Whether this actually happens in practice, however, is open to much debate. Market Accountability: Public Choice and a Private Sector Approach

Market accountability is, for some, the parent of performance accountability and carries echoes of one of the more constant refrains in modern American political discourse: government needs to run more like a private business (Crawford \& Bryce, 2001; DeLeon, 1998, p. 2; Ostrom, 2008, p. xii). Nevertheless, the lines between the models are not as clear as that even though some of the main proponents of this model are also advocate a performance approach.

The theoretical basis of market accountability is that government needs to think of itself less as a regulator and more as a market participant (Ostrom, 2008, p. xii). Proponents of this model assert that the market will monitor itself and thus maintain accountability because it is in the interest of the market to do effective work in much the same way that government does (Ostrom, 2008, p. xii). Market accountability can be defined fairly broadly, much like a continuum. Those on one end of the continuum argue that the basis should be usage of efficiency criteria in the way that private sector actors would use them while the those on other end argue that government should use the type of decentralized decision making employed in the marketplace (Moe T. M., 2002; Ostrom, 2008).

Market accountability's approaches therefore follow a private-sector efficiencybased model for determining success. This is a model in which efficiency is determined in market terms, either in respect to cost, market comparisons or market choice as in public choice models, such as vouchers (DeLeon, 1998, pp. 539-542; Ostrom, 2008, pp. 
47-54). Often, the model boils down to the basic decision rule that whatever produces the most for the least is superior, whether or not it is a private sector or government approach and regardless of the area being discussed. Whether this is true is a matter of debate (Cooper P. J., 2003, pp. 40-46).

Unlike performance accountability, market accountability does not regard any function of government as necessarily needing to be performed by the government itself (Chubb \& Moe, 1988, pp. 1067-1070; Ostrom, 2008, p. 16; Savas, 2000, pp. 237-258). If, for example, public safety services could be provided more efficiently by the private sector, market accountability would suggest that this path be taken even though public safety is viewed by virtually every other accountability model as an inherently governmental function. Also unlike performance accountability, the standards for determining success under market accountability come from the marketplace and, at most, include limited input from the public sector (Ostrom, 2008, pp. 47-54). Whereas in performance accountability, agencies such as the OMB and GAO play a key role in setting and enforcing standards, market accountability does not believe their input should matter much, if at all.

Ethical Model: Subjective Standards Based on Various Ethical Norms

Even though the law may mean different things in different contexts, decisions arising in cases of legal accountability still begin from the rules and laws as they are written. Ethical accountability is not so clearly defined. Instead it is based on value choices which are then framed as accountability rules. A number of theorists have approached ethical accountability from different perspectives, including Terry Cooper, 
John Rohr, Anthony Downs and Joseph Fletcher (Cooper T. L., 2006; Downs, 1965; Fletcher, 1965; Rohr, 1989)

There are three primary considerations with regard to the theoretical basis for ethical accountability. First, ethical accountability is based in the fundamental belief system of a group, culture or person (Fletcher, 1965; Rohr, 1989). In short, they are the morals or values of different individuals or groups. Second, ethical accountability is unchecked by any formal system (Fletcher, 1965; Rohr, 1989). While formal systems may certainly rely on ethical accountability, the essential check with regard to ethical systems is through informal systems in which group norms may result in pressure for conformity but not in the same manner as formal rules. Third, ethical accountability changes relatively slowly because it is typically based on closely held values which are not themselves easily changed (Rohr, 1989, pp. 65-75). This is unlike legal accountability, where change in the legal system can happen much more quickly since it does not rely on changing closely held values.

Although many types of ethical accountability that exist within modern government, three are particularly important. First, the regime ethics approach relies on a society's values for determining what the correct path to follow is. As John Rohr writes, "Regime values refer to the values of that political entity that was brought into being by the ratification of the Constitution that created the present American republic. (Rohr, 1989, p. 68)" Government should therefore be accountable on the basis of the regime's values expressed formally through its law and informally through society at large (Rohr, 1989, pp. 68-75). 
The second approach to ethical accountability is known as the personal ethics model and asserts that professionals are best able to determine whether their actions are ethical (Cooper P. J., 2007, p. Ch. 13). This is similar to the professional bureaucratic model in that professionals make the key decisions. The key distinction is that there is no necessary check on the exercise of individual ethical decision-making, arguably leading to a hodgepodge of disparate ethical choices (Cooper P. J., 2007, p. Ch. 13; Downs, 1967).

The third approach to ethical accountability is situational ethics and involves the substitution of personal or organizational principles or criteria in place of what would otherwise be regarded as recognized or accepted legal and moral criteria (Fletcher, 1965; Price, 2006). As Joseph Fletcher writes in his classic "Situation Ethics", this kind of ethics, "calls upon us to keep law in a subservient place, so that only love and reason really count when the chips are down (Fletcher, 1965, p. 31). (Emphasis in original)" Situational ethics are oftentimes referred to in other literature as "groupthink (Janis, 1972, p. 9)" since they often result from justifications of otherwise unethical actions taken by groups. This is particularly important for public administrators since they must often balance not only legal but ethical concerns as well (Cooper T. L., 2006, pp. 66-84). As Terry Cooper's well-known decision making model shows, the appropriate decision for a public administrator requires balancing moral rules, considering alternatives that fit within an organization's norms, consulting ethical principles and then finally seeing if the resulting decision fits within a person's moral framework (Cooper T. L., 2006, p. 20). This application of situational ethics is not easy to do but is nonetheless essential to effective and accountable public administration. 
Managerial/Organizational Accountability: Looking at Accountability from a Leadership

\section{$\underline{\text { Point of View }}$}

Closely related to the professional/bureaucratic model is the so-called managerial model. What differentiates the two is that this model focuses on managerial decisions rather than on day to day decisions by professional public administrators. This model relies on the work of organizational theorists such as Mintzberg, Perrow and Romzek and Ingraham.

The theory behind this model is that accountability is ensured primarily by balancing formal and informal systems in an organizational setting from a management perspective (Mintzberg, 1983, pp. 23-28; Perrow, 1986; Romzek \& Ingraham, 2000, pp. 242-243). This model is most concerned with what drives management decisions, with the model positing several considerations that managers balance based on the situation (Romzek \& Dubnick, 1987, pp. 227-230).

As for its decision rules, Romzek and Ingraham provide one approach by positing that there are four main types of accountability--two formal and two informal (Romzek \& Ingraham, 2000, pp. 242-243). They are: (1) traditional hierarchical accountability, which relies on maintaining accountability via formal top-down organizational methods; (2) legal accountability, which relies on formal compliance with external legal constraints and laws; (3) professional accountability, which relies on informally allowing professional discretion to play a role in key day to day decisions; and (4) political accountability, which relies on informal responsiveness to external stakeholders, whether they are politicians, interest groups or simply the public at large (Romzek \& Ingraham, 2000, pp. 242-243). Under this model, those at the top begin the formal decision-making 
process by setting basic goals about what an organization can and should do (Mintzberg, 1983, pp. 23-28; Perrow, 1986; Romzek \& Ingraham, 2000, pp. 242-243). Internal, often hidden, processes then influence how these decisions are actually implemented.

\section{Contract Accountability: Negotiated Relationships in the Public Eye}

While legal accountability focuses primarily on vertical relationships within the legal system, contract accountability focuses on the horizontal relationships that exist throughout the entire contracting process. Since modern government contracts out so much of its work, contracting accountability has become a primary concern for modern governance. It relies heavily on the work of theorists such as Cooper and Keyes (Cooper P. J., 2003; Keyes, 2000)

From a theoretical perspective, contracting accountability focuses on how best to manage contractual relationships in order to get a good deal for the public (Cooper P. J., 2003, pp. 1-13). This relationship is essentially negotiated and yet must operate in a public setting (Cooper P. J., 2003, pp. 1-13). This requires that accountability operate at the intersection of both the private relationship between multiple parties and the public nature of government work (Cooper P. J., 2003, pp. 1-13). At its root, contracts are individual sets of relationships, each with its own rules of operation and requirements for accountability.

The decision rules of contracting accountability rely on a complex balance of six main factors: (1) economy or cost; (2) efficiency; (3) effectiveness; (4) responsiveness to the public; (5) responsibility or accountability to the government and (6) equity (Cooper P. J., 2003, pp. 1-7) . Contracting choices inevitably involve trade-offs between these criteria (Cooper P. J., 2003, pp. 1-7). For example, a focus on economy, which typically 
means a lower-priced contract, will often require a higher level of continuing governmental oversight and thus may cost more to make accountable than a low-cost contract (Cooper P. J., 2003, pp. 143-155; Strayhorn, 2006, pp. 28-38).

As noted above, a focus on contract accountability throughout the process is essential because, among other things, a contract is a negotiated agreement that can be changed at any time. Particularly with longer-term contracts, one must assume that conditions will change and that there will be a need for what are known as change orders (Cooper P. J., 2003, pp. 106-108; Keyes, 2000, pp. 14-22). Although some contractors may have a history of abusing change orders, most change orders are necessary parts of the contracting process due to changing market conditions, such as an increase in fuel or steel prices (Cooper P. J., 2003, pp. 106-108; Keyes, 2000, pp. 474-476).

WHY THESE FOUR MODELS? IMPORTANCE TO THE LITERATURE, APPLICABILTY TO THE CASE AND DELINEATION OF DIFFERENCES

The question has been asked why this study chose to focus only on political, performance, professional and legal accountability. While there is certainly a case to be made that other models have value, the choice of these four models is proper for three primary reasons. First, the four selected models are all important to contemporary accountability literature. Political accountability is foundational to understanding both how politicians act to serve their own constituents as well as their role in overseeing the government. Professional accountability is important to understanding how and why professional administrators act as they do. Legal accountability is important to understanding how the legal system and the rule of law impact government action. Finally, performance accountability is important to understanding the value of numerical- 
based data in ensuring government efficiency and effectiveness. Indeed, one could make an argument that the other four models highlighted in this chapter flow from these four basic models and there is strong evidence in the literature to suggest that. The bottom line is that the literature review shows that these four models are more prominent and important than the other alternatives.

Second, the four models chosen are clearly present in the cases chosen. One does not have to look far to find examples of each of these models in both TARP and ARRA. In relation to TARP, for example, Congress authorized creation of both a special inspector general, which focused primarily on legal accountability, as well as a congressional oversight panel, which focused primarily on professional, performance and political accountability. In relation to ARRA, the Recovery.gov website alone contains data such as "jobs created or saved (a classic exercise of political accountability as well as performance accountability) and the implementing regulations from OMB rely heavily on legal accountability and professional accountability in order to ensure their effectiveness (Recovery.gov, 2010). Since these models are present in the case, they are clearly appropriate models for this case.

Third, choosing these four models allows for fairly clear lines to be drawn between the models. This is particularly important for legal and performance accountability. If ethical accountability were added, the lines between what is a matter of legal accountability and what is a matter of ethical accountability could get blurred and make clear findings difficult. In relation to performance accountability, were market accountability added, it could be difficult to distinguish between what is a market accountability-type standard and what is more traditional performance accountability 
standard. Therefore, to avoid this needless confusion, only these four models have been chosen.

In the end, it is likely that including all eight of these models, instead of only four, could increase the value of this study in some respects. However, the purpose here is to test individual models that are more widely used in the field and more importantly perhaps, are clearly at use in this case. It is certainly the case that future research to examine the explanatory power of the other four models along with the findings of this study could be valuable.

LITERATURE GAPS; SEPARABLE MODELS, LACK OF TESTING OF MODELS SIDE BY SIDE, LACK OF CONNECTION BTWEEN POLICY TOOLS AND ACCOUNTABILTY MODELS IN POLICY DESIGN

While the eight accountability models described above cover much of what government needs to consider in terms of accountability, there are three areas where the current literature falls short. The first is that the literature posits that these models of accountability are separable and that there is generally one right way to ensure accountability. The second is a lack of side by side testing of accountability models. The third is a lack of connection between policy tools and accountability models in policy design. These gaps will be briefly discussed in the section below.

As stated above, the first literature gap this study will address is that the literature posits that these models of accountability are separable and that there is generally one right way to ensure accountability. For example, Ostrom argues that the best way to view accountability is a private-sector market-based approach while Mayhew argues that the best way is via a political approach (Mayhew, 2004, pp. 22-25; Ostrom, 2008, p. xii). 
The fact of the matter is that there is no one right way to ensure accountability and that no accountability model exists in a vacuum by itself. Instead, these accountability models are best applied in concert with one another. For example, while it is clear that TARP is primarily concerned with performance-based accountability as one can see through its limited rules on the expenditure of funds by TARP recipients, TARP also utilizes at least three other models: (1) political accountability (through the creation of the Congressional Oversight Panel (COP)), (2) legal accountability (through the monitoring of the Special Inspector General for TARP (SIGTARP) and (3) to a certain extent, professional accountability (as a result of the fair amount of discretion given to the US Treasury in dispersing TARP funds) (Congressional Oversight Panel, 2009; SIGTARP, 2009). It is this study's assertion that any one model alone only explains, at best, part of the policy tool choices in either of these two cases.

Second, the literature consists largely of authors who advocate their particular model and thus do not present side by side applications with other models. For example, Robert Behn writes repeatedly that the only correct way to approach government accountability is to utilize "tactics and strategies that seek to enhance the performance of the public sector-to improve the ability of government agencies and their nonprofit and for-profit collaborators to produce results (emphasis in original) (Behn, 2001, p. 26).” Behn is but one example of the accountability literature's refusal to utilize a comparative side by side approach. It is this study's belief that utilizing a multi-model approach will explain significantly more than a single-model approach.

Third, there exists a lack of literature connecting accountability models and policy tools are applied together in policy design. This is somewhat understandable as policy 
tools are a relatively new field and the literature as a whole is still relatively small. This study believes addressing this gap is important because if we are to be able to design accountable policies, knowing which accountability models match up best with which policy tools will help us do. While this study will not by itself fill this gap, it may go a fair distance to start to fill it.

These are not the only literature gaps present in the accountability literature. However, they represent three of the most important issues in accountability literature today. Filling these gaps will significantly help improve the state of the literature.

Conclusion:

Now that this study has outlined the study as a whole, its methodology and research strategy and the status of the literature, it will now proceed to discuss the two specific cases at hand. In the next two chapters, first TARP and then ARRA will be described as a case and findings will be presented as to what the top policy tools were and the accountability models they appeared to rely upon. This will set the stage for the final chapter where we will discuss what it all means for both the cases specifically and the literature as a whole. 


\section{Chapter 3: The Story of TARP}

The following two chapters will discuss the background, policy tools and accountability models present in each of the two cases, beginning with TARP in this chapter. This chapter will first describe the background of TARP and the history that led to the need for TARP. Next, this chapter will describe how the policy was designed relative to policy tools and accountability models. This chapter will then move on to discuss the top four policy tools used in TARP and which accountability models were applied in relation to each policy tool. It will also discuss additional models that were expected to be used or asserted as being used but were not, in fact, utilized, such as economic regulation.

This chapter will reveal that there were four main policy tools used in relation to TARP and that three of the four policy tools (the exception being grants) can be at least partially explained by more than one accountability model. This reveals that for the most part, the contention that multiple accountability models better explain policy tool choice is correct.

This chapter will begin however, with a discussion of how TARP became necessary in the first place since this crisis was a long time coming. As one Congressional Research Service report put it, "The roots of the crisis go back much further (Jickling, 2010, p. 2)" than just 2007-2008. This chapter will then discuss how credit default swaps and derivatives work so as to explicate may understand the main factors that led to this crisis. 


\section{A PROBLEM LONG COMING: HOW DEREGULATION AND IGNORING WARNING SIGNS LED TO A FINANCIAL MELTDOWN}

The financial crisis of 2008 did not come out of nowhere. Something like it had been predicted for years but little was done to stop it. Instead, the mantra of the beneficial effects of deregulation had been going since at least the Carter administration (Cooper P. J., 2009, pp. 15-21). This section is divided into four components: first, the savings and loan crisis of the late 1980s, second, the deregulation of Fannie Mae and Freddie Mac, third, the repeal of the Glass-Steagall Act in 1999 and fourth, the corporate governance scandals of 2001-02. Each of these events was a watershed moment in deregulation that helped lay the groundwork for the 2008 financial crisis.

\section{The Savings and Loan Crisis:}

Savings and loans, also known by their original name of "thrifts", trace their roots back to 1831, as a community-based, not-for-profit way to loan and save funds (Mason, 2010, p. 1). Before the creation of Fannie Mae and Freddie Mac after World War II, savings and loans were perhaps the primary way by which middle and lower income people were able to buy homes (Mason, 2010, pp. 1-2). Savings and loans dealt primarily with what is known as an "amortizing mortgage", in which a person paid back both the principal and the associated interest at the same time over an extended period (originally eight to ten years) (Mason, 2010, pp. 1-2). This type of mortgage is the model for most home mortgages in the modern marketplace. Indeed, a broad expansion in home ownership was exactly what the savings and loans wanted; they "believed they were part of a broader social reform effort and not a financial industry (Mason, 2010, pp. 4-5)." 
Savings and loans also had a specific advantage in that they could afford to provide higher interest rates to depositors since their loans were generally considered safer and it was much harder to withdraw funds because only limited amounts could be withdrawn at any time. That, combined with longer term loans, led to rapid growth in the industry. In 1945, savings and loans held about $\$ 8.7$ billion in assets; by 1965 that sum had exploded to more than $\$ 129$ billion. By 1965 savings and loans controlled 26 percent of consumer savings and provided 46 percent of loans for single-family homes (United States Savings and Loan League, 1966, p. 92). This threatened the established commercial banking sector, which engaged in rate wars in which banks and savings and loans would periodically increase interest rates for depositors (Mason, 2010, pp. 8-10). These rate wars became so severe that they ultimately prompted Congressional action. In 1966, Congress passed laws setting specific rates for both banks and savings and loans, with savings and loans only being allowed to provide marginally higher rates than commercial banks (Mason, 2010). This put dramatic limits on the industry's growth and ended up leading to the consolidation of smaller savings and loans into larger ones. Although the assets held by savings and loans increased to $\$ 579$ billion by 1979 , the number of savings and loans plummeted from 6,071 in 1996 to 4,709 in 1979 (United States Savings and Loan League, 1980, pp. 48-51). Even with increasing size, many in the savings and loan industry still argued that regulation was holding them back. With demand rising to deregulate the industry and a favorable attitude towards deregulation set by President Carter, Congress passed laws removing rate controls in 1979 (Mason, 2010, pp. 7-8). This proved not to be enough to help savings and loans as the doubling of oil prices led to both higher interest and inflation, threatening the savings and loan industry 
as a whole (Mason, 2010, pp. 7-8). In response, Congress passed two laws, the Depository Institutions Deregulation and Monetary Control Act of 1980 and the Garn-St. Germain Act of 1982, which together allowed savings and loans to act like banks and not just home lenders, but without the oversight that was a part of normal commercial banks (Mason, 2010, pp. 9-10).

For a while, this appeared to work. Even though some savings and loans failed, the industry grew as a whole. Nonetheless, problems quickly emerged. Lender fraud and corruption became epidemic, with the failure of Empire Savings in Texas costing taxpayers nearly \$300 million in 1984 (Mason, 2010, pp. 9-10). In addition, and although most deposits were insured by the Federal Savings and Loan Insurance Corporation (FSLIC), many were insured by far less financially stable state systems (Mason, 2010, pp. 9-10). These systems began to crack as deregulation led to unwise lending, runaway growth and investments in industries other than traditional home loans. In a tale that seems all too familiar today, this led the savings and loan industry to the brink of insolvency. In 1987, GAO declared the FSLIC insolvent, although Congress delayed resolution of the problem for a few years by replenishing FSLIC's funds. In 1989, Congress passed the Financial Institutions Reform Recovery and Enforcement Act, which regulated and bailed out the industry (Cooper P. J., 2009; Mason, 2010; Barth, 1991). By the time the smoke had cleared, the savings and loans crisis had resulted in the loss of more than $\$ 600$ billion in assets previously held by savings and loans--a warning that deregulation was perhaps not the panacea it was often said to be. 


\section{Privatizing Fannie Mae and Freddie Mac:}

The Federal National Mortgage Association, better known as Fannie Mae, was created in 1938 to provide federal funds to banks in order to allow for greater home ownership (Pickert, 2008, p. 1). Fannie Mae effectively created what is known today as the secondary mortgage market, which allows banks to make more loans by buying Federal Housing Agency (FHA) insured mortgages (Alford, 2003). This policy worked especially following World War II as more and more people bought homes (Alford, 2003).

For nearly thirty years, Fannie Mae was effectively the only player in the secondary mortgage market. In 1968, however, Fannie Mae was split into two entities, a publicly financed organization on the one hand and a private corporation on the other (Koppell, 2001, pp. 469-470). The publicly financed organization, colloquially known as Ginnie Mae, continued to guarantee the value of mortgages to veterans and government employees while the original Fannie Mae no longer guaranteed the value of mortgages to most of the market (Reiss, 2008, pp. 1027-1033). In 1970, and in order to increase the size of the home loan market, Congress passed the Emergency Home Finance Act of 1970, which created the Federal Home Loan Mortgage Corporation, better known as Freddie Mac (Alford, 2003). Freddie Mac took the secondary mortgage market to a new level by creating "mortgage backed securities", under which mortgages would be pooled and sold as a group. This increased the amount of funds available for home loans and once again increased home ownership. As with the post-1968 Fannie Mae, there was no actual guarantee that the government would back failed loans, but there was an assumed guarantee of sorts (Reiss, 2008, pp. 1042-1045). Specifically, it was assumed that the 
government would bail out Fannie Mae or Freddie Mac if it was ever needed so that the risk was far lower than might otherwise be thought. In fact, $\mathrm{CBO}$ director Daniel Crippen told Congress in 2001 that "debt and mortgage-backed securities of GSEs are more valuable to investors than similar private securities because of the perception of a government guarantee. (Crippen, 2001).” This implicit but not actual guarantee contributed much to the 2008 financial crisis. The assumption was why worry if Fannie Mae and Freddie Mac were going to be bailed out if there was ever a problem. This assumption would also be sorely tested in the 2008 financial crisis.

Repealing the Glass-Steagall Act:

When the economy crumbled during the great depression, one of the greatest governmental concerns was ensuring the stability of the remaining banks. A major concern at the time was that banks were engaging in both deposits/loans and investments, thereby putting depositor funds at risk in the case of market downturns (Freidman \& Schwartz, 1993, pp. 71-77). Many in Congress argued that this had to change and that banks should be split into two categories. The first would be commercial banks, with deposits insured by the Federal Deposit Insurance Corporation (FDIC), which would be able to engage in short-term loans and accept deposits (Burns, 1974, pp. 77-90; Kennedy, 1973, pp. 140-145). The second were investment banks, which would be allowed to take funds and invest them in the broader marketplace (Burns, 1974, pp. 77-90; Kennedy, 1973, pp. 140-145). These changes were codified into the Banking Act of 1933, better known as the Glass-Steagall Act after its chief sponsors, Senator Carter Glass (D-VA) and Representative Henry Steagall (D-AL). The law overwhelmingly passed Congress 
and was signed into law by President Franklin D. Roosevelt on June 16, 1933 (Burns, 1974, pp. 77-90; Kennedy, 1973, pp. 140-145).

The most important, and for some problematic, aspect of the act was the creation of so-called firewalls which separated the commercial and investment halves of banks (Hendrickson, 2001, pp. 849-852). This meant that they could not coordinate with each other and would in effect have to operate as separate entities. By ensuring that there were two distinct parts to banks that had to operate as separate entities, this would, it was thought, decrease the risk of bank failure by providing for a separation of different activities with different sets of incentives. Although it restricted bank growth in the short term, the long term effect on stability of the system was considered more important by those behind Glass-Steagall (Burns, 1974, pp. 77-90; Kennedy, 1973, pp. 140-145).

Although constant attempts were made to repeal it, the law largely stood untouched for more than sixty years. In the early 1990s, however, pressure built to change the law as commercial banks complained that their growth was hurt by limits on their investment opportunities (Hendrickson, 2001, pp. 849-852). Reform was broadly supported by many in Congress as well as the administration. President Clinton himself argued that the Glass-Steagall Act needed to change and pushed strongly for its repeal (Glater, 1995, p. C1). President Clinton argued that the act was no longer appropriate to the current environment (Clinton, 1999b). As he said when a repeal was eventually signed "It is true that the Glass-Steagall law is no longer appropriate to the economy as it was presently formed. It worked pretty well for the industrial economy, which was highly organized, much more centralized and much more nationalized than the one in which we operate today. But the world is very different (Clinton, 1999b)." 
In 1995, an attempt to repeal the act, led by Representative Jim Leach (R-IA)

failed. After the 1998 elections, Leach chose to try again. In 1999, the Senate passed a law repealing the separation of commercial and investment activities on a party line vote (Hendrickson, 2001, pp. 849-852; US Senate, 1999). The House took a far more generous view and passed the repeal by a vote of 343-86 (Clerk of the US House, 1999). Shortly thereafter, President Clinton willingly signed the repeal (Clinton, Statement on Signing the Graham-Leach-Bliley Act, 1999). The firewalls were gone and the banking sector was now allowed to openly engage in both commercial and banking activities as a single unit. This action has been widely credited with being perhaps the single largest regulatory change that allowed the financial crisis of 2008 to occur (Cooper P. J., 2009, pp. 67-68, 73-74; Markham, 2010; White, 2010)

The Corporate Governance Scandals of 2001-02, the Case of Enron:

In 1979, the Northern Natural Gas Company was reorganized as the largest subsidiary of a holding company known as InterNorth, a company which specialized in investments in energy industries and plastics (BBC, 2002). In 1985, InterNorth purchased the Houston Natural Gas Company, a leader in the growing natural gas industry (BBC 2002). InterNorth was reorganized and renamed Enron later that year (BBC 2002).

For approximately the first eight years of its new existence, Enron was a growing company specializing in delivering power and natural gas (and later water as well), growing comfortably but not spectacularly (Gilliam \& Martin, 2007, p. 930). In 1993, however, Enron began to engage in "limited liability special purpose entities (Gilliam \& Martin, 2007, p. 931)" (SPE), which allowed it to tout its profits but hide its liabilities 
from public view. This allowed Enron to grow rapidly and it quickly became the darling of the corporate world--even being named “America's Most Innovative Company” for six straight years by Fortune Magazine (Gilliam \& Martin, 2007, pp. 930-932).

Unfortunately, Enron's profits were not real and the company was increasingly teetering on the brink of collapse for three reasons (Gilliam \& Martin, 2007, pp. 930933). First, Enron was using these SPEs to hide losses and was, in addition, lying about its profits. As one analysis wrote "Contrary to the perception that leverage disciplines management (Jensen 1986), it appears Enron used leverage to manipulate reported earning (Gilliam \& Martin, 2007, p. 931).” Second, Enron's auditor, the well-respected firm Arthur Andersen, failed to detect and report potential problems (Gilliam \& Martin, 2007, pp. 930-933). Third, Enron incentivized short-term gains, which were often illusory, over long-term sustainability (Gilliam \& Martin, 2007, pp. 930-933). This set Enron up for a collapse, and collapse it did-- declaring bankruptcy in November 2001. In response to the corporate governance and regulatory failures of Enron and similar cases such as WorldCom, Congress passed the Sarbanes-Oxley Act in 2002 (Kimmel, Kieso, \& Weygandt, 2009, p. 337). Among other things, the act created the Public Company Accounting Oversight Board, required additional auditor independence, made corporate executives more responsible for accurate reporting, increased required financial disclosures and tried to limit conflicts of interest between stock analysts and the industries they analyzed (Kimmel, Kieso, \& Weygandt, 2009, p. 337). However, the law was attacked as too restrictive almost immediately upon its passage, and many in Congress sought to limit the funds provided for its enforcement (Kimmel, Kieso, \& 
Weygandt, 2009, p. 337). The result was that the increase in regulations was largely illusory.

Derivatives: A Largely Unregulated and Large Marketplace

One of the main financial instruments that led to the 2008 crisis was derivatives. The Office of the Comptroller of the Currency defines derivatives as follows "A derivative is a financial contract whose value is derived from the performance of underlying market factors, such as interest rates, currency exchange rates, and commodity, credit, and equity prices. Derivative transactions include an assortment of financial contracts, including structured debt obligations and deposits, swaps, futures, options, caps, floors, collars, forwards, and various combinations thereof (Office of the Comptroller of the Currency, 2013)." Derivatives are largely not traded on public exchanges. As the Economist notes, the total derivative market in 2012 was estimated at $\$ 700$ trillion, with only $\$ 83$ trillion traded on public exchanges (The Economist, 2012, p. 83). The result was that the market was, and remains, largely unregulated, and is an extremely high risk environment in which to operate.

In 2008, these derivatives were a huge part of the financial crisis. As Professor Michael Greenberger said before a hearing of the Financial Crisis Inquiry Commission "What you have is a $\$ 600$ trillion notional value market that is completely unregulated and dark; therefore regulators don't know what's happening out there, market observers don't know what's happening out there, and that led to a belief that we needed to rescue the entire market in the fall of 2008 (Greenberger, 2010)." This unregulated market of derivatives presented a huge potential pitfall for the economy and was problematic to 
rescue as well. After all, how can something be rescued if the value of the item being rescued isn't specifically established?

\section{Credit Default Swaps: Private Loan Insurance}

There is an old saying on Wall Street that if allowed to do so, the financial markets will find a way to make money on anything. Such is the case with credit-default swaps (CDS), which were created by Blythe Masters of JP Morgan Chase in 1994 (Simkovic \& Kaminetzky, 2011, pp. 118-124). A CDS is essentially another form of loan insurance. Specifically, someone issuing a loan will sell a CDS to a buyer who purchases a loan with the assurance that if the loan defaults, the buyer will receive the value of the loan (Simkovic \& Kaminetzky, 2011, pp. 118-124). The cost of the swap is typically determined by the risk of the loan. It works even if the loan defaults as long as the asset on which the loan is based does not substantially decline in value (Simkovic \& Kaminetzky, 2011, pp. 118-124)

Credit default swaps were largely unregulated. Even though some investment entities, most notably AIG, sold insurance for credit default swaps, they were not required to hedge such insurance in case the value of the assets behind these credit default swaps decreased. When it did decrease during the 2008 financial crisis, AIG was in trouble and something like TARP was needed (Economist 2009). TARP, and the events leading up to it, are explained more fully in the next section.

\section{Conclusion:}

These actions set the stage for what would become the financial crisis of 2008 . Decades of deregulation and the ethos that the private sector worked best when it was least watched by the government left the door wide open to abuse. Abused it was, with 
the greatest financial crisis since the great depression as a result. This chapter will now discuss the specific legislative history and design of TARP.

THE CASE OF TARP, ATTTEMPTING TO STEM A FINAN CIAL SECTOR CRISIS:

The specific policy that became TARP developed as a result of four sets of events, all of which took place between September 7 and October 3, 2008. These were: (1) the initial collapse and the resulting events it triggered, (2) the immediate policy reactions, (3) the initial failure of the first version of TARP in the US House and (4) the final design and passage of the bill. These stages represent both the crisis itself and the initial attempts to respond, first by executive action and then via Congress. The Initial Collapse:

There had been mounting signs for years that the US housing market was at a breaking point. Lack of regulation, overbuilding in growing markets and risky loans had made the housing industry very vulnerable. Economist Robert Shiller foresaw the housing market collapse in 2005, arguing that "The home-price bubble feels like the stock-market mania in the fall of 1999 , just before the stock bubble burst in early 2000 , with all the hype, herd investing and absolute confidence in the inevitability of continuing price appreciation (Laing, 2005, p. 1)." Yet unlike the economic collapse of 2000, the housing market and the industries that relied on it, such as construction and the financial services industry, were far more integral to the overall economy than the tech companies had been. Indeed, the Bureau of Economic statistics estimates that the housing market directly, in and of itself, accounts for about $18 \%$ of GDP, with the financial services industry adding another $8 \%$ of GDP (Bureau of Labor Statistics, 2009).

Things came to a head on September 7, 2008, when the US Treasury seized 56 
control of Fannie Mae and Freddie Mac, which had become unable to continue providing the financing needed to properly collateralize the loans (Paulson, 2008). This action wiped out the investors who had bought stock in Fannie Mae and Freddie Mac in order to attempt to save the company. This response was, in the words of Federal Housing Financing Agency director James Lockhart "one of the most sweeping government interventions in private financial markets in decades (Lockhart, 2008). " Yet given the alternative--that loans would be unable to be issued for many individual home purchasers--the action was seen as necessary (Goldfarb, Cho, \& Appelbaum, 2007). As several members of the House Financial Services committee noted in a September 2008 hearing, Fannie Mae and Freddie Mac posed such “systemic risk (US House Financial Services Committee, 2008, p. 58)" to the financial system as a whole that action had to be taken to keep them from collapsing (US House Financial Services Committee, 2008, pp. 58-60).

For all the doom and gloom that the collapse of the housing market foretold, it was dwarfed eight days later by the dual collapse of both Merrill Lynch (which was purchased by Bank of America) and Lehman Brothers on September 15, 2008 (Goldfarb, Cho, \& Appelbaum, 2007; US House Financial Services Committee, 2008). This caused widespread panic in the financial markets for one major reason. If the crisis could take down two of the most respected investment firms in the country, nothing appeared to be safe (US House Financial Services Committee, 2008). As Secretary Paulson said in the House Financial Services Committee hearing noted above, "We must do so in order to avoid a continuing serial of financial institution failures and frozen credit markets that threaten American families' financial wellbeing, the viability of businesses both small 
and large, and the very health of our economy (US House Financial Services Committee, 2008, p. 26)." Sadly this was nowhere near the worst for the economy. Indeed, things would get worse for the government and the country rather quickly, as events forced the US Treasury into further action the next day.

The Immediate Federal Response:

On September 16, 2008, only 24 hours after the dual collapse of Merrill Lynch and Lehman Brothers, the financial market was rocked by another dual set of blows. The first related to American International Group (AIG) and the second was the money markets "breaking the buck."

AIG had long been a leader in the insurance industry, amassing some $\$ 81$ billion in assets by early 2005, making it one of the largest financial services companies in the world (Zuill, 2009). AIG typically specialized in providing insurance to larger companies, and was very successful. However, after years of having grown comfortably but within established rules, AIG began to take some serious risks in the early 2000s, moving into areas such as derivatives and credit default swaps (Insurance Journal, 2004). These largely unregulated areas provided problematic for AIG as it was hit with a series of penalties from 2002-2005, which totaled nearly $\$ 2$ billion for violating regulatory protocols and as a result of "steering" business to insurers from whom AIG received illegal kickbacks (Woehr, 2010; Insurance Journal, 2004; Zuill, 2009). Unfortunately, these penalties (which amounted to a fraction of AIG's next worth), did not do much to change their behavior as they sunk a lot of money into credit default swaps, which would prove to be AIG's downfall (Woehr, 2010; Insurance Journal, 2004; Zuill, 2009).

Early on September 16, 2008, AIG's credit rating was downgraded (Morgenson, 58 
2008). The downgrade led to the requirement that AIG post additional collateral when looking to make credit default swaps. The company did not have the cash on hand to fulfill this requirement (Morgenson, 2008). This led to a 95\% drop in AIG's stock price in little more than a week, and it raised the fear that the company was about to collapse (Morgenson, 2008). This was a serious problem since "AIG was so interconnected with many large commercial banks, investment banks, and other financial institutions through counterparty credit relationships on credit default swaps and other activities such as securities lending that its potential failure created systemic risk (Financial Crisis Inquiry Commission, 2011, p. 352).” This had been allowed to happen because AIG took advantage of the loose regulatory infrastructure to increase its business in largely unregulated markets, including credit default swaps (Financial Crisis Inquiry Commission, 2011, pp. 350-354).

Moving quickly, the Federal Reserve acted late on September 16, 2008 and authorized $\$ 85$ billion to purchase nearly $80 \%$ of AIG in an attempt to stave off this collapse (Board of Governors of the Federal Reserve System, 2008). This was necessary because, in the Board's own words "The Board determined that, in current circumstances, a disorderly failure of AIG could add to already significant levels of financial market fragility and lead to substantially higher borrowing costs, reduced household wealth, and materially weaker economic performance (Board of Governors of the Federal Reserve System, 2008)." In other words, if AIG collapsed it was feared it might take the whole financial system with it. Indeed, "Without the bailout, AIG's default and collapse could have brought down its counterparties, causing cascading losses and collapses throughout the financial system (Financial Crisis Inquiry Commission, 2011, p. 352)." 
The second shock to hit the markets on September 16 was the money markets "breaking the buck", meaning that investors lost money on essential transactions needed to finance short term debt and operations (Condon, 2008). This historic failure was principally caused by the Lehman Brothers collapse. The oldest money market in the US, the Reserve Primary Fund, broke the buck and dropped to 97 cents after writing off Lehman's debt (Condon, 2008). This was only the fourth time (and the first since 1994) in the 37 year history of the money market system that a fund had broken the buck (Condon, 2008). After this drop in value, there was nearly a run on the money market system as a whole, with net outflows outpacing net inflows by nearly 20 to 1 , threatening to collapse this key source of funding for normal business operations (Investment Company Institute, 2008). Moving quickly, the Federal Reserve announced on September 19 the creation of an optional program to extend financing to help lenders purchase commercial paper and to eliminate fears of the money market's collapse (Gullapalli \& Annand, 2008). This approach, which required a fee paid by participating funds, would essentially insure that the federal government would back the fund's value. It worked and the immediate panic was averted (Gullapalli \& Annand, 2008).

In order to prevent additional failures, the SEC also took a key additional step by banning so-called "naked short selling" on September 17, 2008. As the SEC wrote in its press release that day "In an ordinary short sale, the short seller borrows a stock and sells it, with the understanding that the loan must be repaid by buying the stock in the market (hopefully at a lower price). But in an abusive naked short transaction, the seller doesn't actually borrow the stock, and fails to deliver it to the buyer. For this reason, naked shorting can allow manipulators to force prices down far lower than would be possible in 60 
legitimate short-selling conditions. (US Securities and Exchange Commission, 2008)"

The fear was that if naked short selling was allowed to continue unabated, stock markets would collapse. The SEC's actions both banned naked short selling and provided stiff penalties for violators (US Securities and Exchange Commission, 2008).

Yet for all the federal government was able to do by executive action, it wasn't nearly enough. The crisis grew and it was readily apparent to all involved that there would have to be far more significant actions. The focus turned to Congress. The Initial Stages of TARP's Development and its Failure in the US House:

On September 20, 2008, the federal government circulated the first draft of the Emergency Economic Stabilization Act of 2008 (EESA), of which TARP was the biggest part. In order to resolve the problems caused by the collapse of the housing bubble, the US Department of the Treasury asserted that it needed to help banks remove so-called "distressed assets (US Department of the Treasury, 2008b)" from the financial system in order to stabilize banks and other financial institutions. As the US Department of the Treasury stated in proposing the first version of what later became TARP, "When the financial system works as it should, money and capital flow to and from households and businesses to pay for home loans, school loans and investments that create jobs. As illiquid mortgage assets block the system, the clogging of our financial markets has the potential to significantly damage our financial system and our economy, undermining job creation and income growth. (US Department of the Treasury, 2008b)." TARP proposed to do so by adopting an approach similar to that used by the federal government in the savings and loan crisis of the late 1980s, when the government had provided temporary loans to financial institutions in order to ensure their stability (Seidman L. W., 2000). 
Once they were able to do so, these financial institutions would then pay back these loans, thus meaning that the cost to the federal government would be far less than the initial $\$ 700$ billion price tag (Seidman L. W., 2000; US Department of the Treasury, 2008b)

The proposal developed and expanded over time, growing from an only three page bill designed to give the Treasury Secretary nearly unlimited authority to do what he wished with TARP funds. The initial proposal, which was kept short in order to allow for and force quick Congressional action, was strongly panned by many in Congress and public. The proposal then expanded from one that focused almost entirely on purchasing failing mortgage-backed securities in order to stabilize the market. Yet, even that wasn't enough since it only addressed US-based banks. On September 21, foreign financial institutions with a presence in the United States were included (Paulson, 2008). On September 23, the Senate Banking Committee rejected this plan (Ahrens, 2008). Echoing the comments of many, Senator Dodd said, "After reading this proposal, I can only conclude that it is not only our economy that is at risk, Mr. Secretary, but our Constitution, as well (Mullins, 2008)." Criticism of the plan came from both the left and the right and in both the House and the Senate.

The tumult against the plan continued to grow both outside and inside the beltway in the coming days. On September 24, 2008, a letter from over 100 leading economists was released critiquing the plan for three primary reasons (Wolfers, 2008). First, the letter asked whether it was fair to in effect bail out those institutions for their own bad choices. Second, the letter challenged the plan's ambiguity, as its writers were concerned that it granted too much authority to Secretary Paulson. Third, the letter was concerned 
whether the infusion of cash would have unintended consequences and weaken the financial markets far beyond the current crisis due to moral hazard (Wolfers, 2008). Indeed, one of the biggest concerns that many had in relation to TARP was the problem of "moral hazard." Paul Krugman defined the problem of moral hazard as "any situation in which one person makes the decision about how much risk to take, while someone else bears the cost if things go badly (Krugman P. R., 2012, p. 37).” More simply put, moral hazard exists when businesses are willing to take risk that might otherwise be deemed unwise because they will be assisted and saved by others if they fail. This was certainly the case in the great depression, as those institutions which were insured failed at a rate significantly higher than those that were uninsured (Grossman, 1992, pp. 817-819). Further buttressing the claim that moral hazard is real is the fact that the World Bank reports that all 100 of the largest banking crises prior to the year 2000 were resolved in substantial part by government bailouts (Boyd, Gomis, Kwak, \& Smith, 2000, pp. 1-3). This shows that there is a wide-spread perception that government will save financial institutions if they fail (Boyd, Gomis, Kwak, \& Smith, 2000, pp. 1-3).

Moral hazard has been a big concern in American financial bailouts, perhaps most notably in the response to the savings and loan crisis of the 1980s (Shoven, Smart, \& Waldfogel, 1991, p. 3). Due to the fact that savings and loans knew they would likely be bailed out if they failed, they were willing to take more risks, increasing the need for government intervention and leading to more reckless behavior (Hellman, Murdock, \& Stiglitz, 2000, p. 147). Not only was this a problem in this specific case, as noted above, but it was seen as setting a dangerous precedent for future crises (Cole, McKenzie, \& White, 1995, pp. 30-32). This would be proven true, as is discussed below. 
The concern over moral hazard was one of the primary criticisms of the design of TARP. As Harvard economist Jeffrey Mirron wrote, "Government purchase of bank stock, therefore, is a transfer from taxpayers to people who took huge risks and lost. . . [This] will generate even greater problems down the line (Mirron, 2008). "Indeed, many who supported TARP agreed with this point, arguing that economic regulation was necessary. As Secretary Paulson said in November 2008, "it is already clear that we must address a number of significant issues, such as improving risk management practices, compensation practices, oversight of mortgage origination and the securitization process, credit rating agencies, OTC derivative market infrastructure and regulatory policies, practices and regimes in our respective countries (Simons, 2010, pp. 43-44).” Yet the argument was that such work could wait. As Federal Reserve Chairman Ben Bernanke said in late 2008, "You want to put the fire out first and then worry about the fire code. (Simons, 2010, p. 46)" So the decision was made to focus on bailing out the banks and other financial institutions that were in danger of failure, without focusing on economic regulation, since the risk of inaction was too great. The result is that, as John Cochrane wrote, "As long as some firms are considered too big to fail, those firms will take outsized risks. (Cochrane, 2010, p. 34)"

In spite of these and other misgivings, there was a realization by many in Congress that they could not simply do nothing. As Congressman Bauchus (R-AL) said, the proposal was "a gun to our head" (Wilson K. , 2008) but many in Congress believed they had to act. There was widespread concern, largely from the President's own party, that the plan gave too much power to Secretary Paulson on how to disperse the funds appropriated under this measure (Vekshin \& Rowley, 2008). The original proposal had 
even exempted the secretary's actions from judicial review, something which was reversed in the final proposal (Washington Post, 2008)

This accountability concern was no small thing as, in fact, one of the biggest problems with TARP was that programs were announced for political reasons without full consideration of how to implement them (Baum, 2013). The federal government would often announce a program such as with housing or foreclosure relief and would then set up measures on the fly (Baum, 2013). The result was little to no accountability measures and no penalties in programs to make them accountable or mandatory (Baum, 2013).

In the wee hours of September 28, 2008, Congressional leaders and the White House reached a deal on a final proposal. President Bush expressed confidence the plan would pass Congress and a vote was scheduled for the next day, September 29 even though media reports suggested that many in the President's own party were opposed (Washington Post, 2008). Underestimating the opposition, the plan failed 205-228, with 133 Republicans and 95 Democrats voting against it (Clerk of the US House, 2008). The immediate response to this was panic, as the stock markets dropped $8 \%$ the following day, the largest drop since Black Monday in 1987 (Isidore, 2008). Congressional leaders scrambled to find something that could pass and thus the stage was set for the final passage of TARP.

\section{The Final Passage of TARP:}

Recognizing that the bill must pass in order to ensure the stability of the US financial system, media reports suggested that the US Senate chose to combine the bill with one that proposed tax breaks for renewable energy usage (in order to garner 
Republican votes), mental health parity (in order to garner some reticent Democratic votes) and a series of earmarks (in order to garner the support of several other members of Congress) (Hulse, 2008). This earmark-laden measure easily passed both houses of Congress and was signed into law by President Bush on October 3, 2008 (US Senate, 2008; Clerk of the US House, 2008b; Emergency Economic Stabilization Act of 2008, 2008)

While originally intended as a program designed to purchase toxic assets in order to stabilize financial institutions, TARP in fact spent very little money purchasing such assets ( $\$ 5$ billion as of September 30, 2010) (SIGTARP, 2010, p. 237). Instead, TARP spent by far the most funds pursuing three primary tasks: (1) purchasing an estimated \$280 billion in stock in trouble banks and investment institutions such as Citigroup, JP Morgan and Bank of America; (2) providing $\$ 40$ billion in loans to prevent the potentially catastrophic collapse of American International Group (AIG) and (3) providing nearly $\$ 80$ billion in loans to American auto manufacturers in order to prevent their collapse (SIGTARP, 2010, p. 237). An additional $\$ 45$ billion was appropriated to help prevent home foreclosures but as September 30, 2010, only \$600 million had actually been spent and the administration had yet to come up with a plan to spend the remaining funds in this area (SIGTARP 2010, 237). Of the total of $\$ 387$ billion actually expended under TARP, greater than $90 \%$ of it went directly to assisting banks, investment houses, AIG or auto manufacturers, far from the original intent of purchasing toxic assets (Mihm \& al, 2013). 
ACCOUNTABILITY IN TARP: CONGRESS, GAO, TREASURY, SIGTARP AND

COP:

Despite what many might assert, TARP was very concerned with accountability. In fact, TARP used a five-pronged accountability approach, with Congress leading the process and relying on four other organizations to ensure overall accountability. Two of these organizations previously existed (the GAO and the US Department of the Treasury) and two were created specifically by the law, the Special Inspector General for TARP (SIGTARP) and the Congressional Oversight Panel (COP). This section briefly introduces the role and approaches that each of these five organizations were given. Congress's Role: Political Accountability, Systemic Stability and Avoiding Abuse

Congress took the lead role in ensuring accountability for TARP (and later on ARRA), holding constant hearings and keeping the pressure on both the Bush and Obama administrations in order to ensure that the program remained effective and accountable. Congress focused on three primary things. First, accountability for the money, where it was going and to whom, to which specific banks and businesses. Second, avoiding, or at least limiting, potential waste, fraud and abuse. Third, and perhaps most importantly, stopping the crisis and ensuring overall system stability (Green, 2013).

In this vein, many in Congress were concerned about lack of staffing in the US Treasury's Office of Financial Stability (OFS). This was due to the transition between Bush and Obama and what many in Congress saw as a lack of concern for accountability (Green, 2013). Treasury's relationship with Congress was strained because it wasn't staffed up to deal with the program. Programs weren't well designed in the view of many in Congress and were often left up to agencies to design them, or perhaps most 
worryingly, to the banks that were receiving the funds themselves (Green, 2013). This was a point echoed by other organizations. Many in Congress also had large concerns about how the law was structured to favor larger firms. The government was unwilling to use the full authority the law gave provided for fear that it would be seen as running private organizations. The government did not want to be seen as doing that because it smacked of over-reach of government in private sector (Green, 2013). As a result, a lot of light touch was used, with the hope being that incentive would encourage private parties to do the right thing.

Congress had strong relationships with COP, SIGTARP and GAO. They frequently used the work of these organizations to amplify their own findings (Green, 2013). Congress would also use their investigations to set the issues on which Congress would hammer away. Congress also used these organization's reports to stir political outrage, largely as to who was benefiting from the law. This strong formal and informal interplay played a key role in ensuring TARP accountability (Green, 2013).

\section{GAO: A Broader Quicker Mission Than Before}

The GAO has a long and distinguished history as the nation's premier government accountability organization, dating back nearly 90 years to the Progressive Era (Mihm \& al, 2013). Typically, GAO has been a slower-moving organization, very deliberately considering every report it produces and taking about 3-6 months to produce each report. However, in the case of TARP (and later ARRA), GAO was asked to produce reports both quickly and in larger number, with the first reports due less than 2 months after TARP was enacted into law (Mihm \& al, 2013). All indications are GAO was up to and met this task with its customary professionalism and quality. 
The GAO undertook this task with a focus on institutions, choosing to focus more on the banking and financial sectors rather than on any one organization. GAO focused primarily on the internal controls and oversight of the process as a whole (Mihm \& al, 2013). In order to complete this work, GAO primarily reassigned people internally, hiring only two new people whom were experts in the market and valuation.

GAO started off by focusing the Office of Financial Stability (OFS), especially since OFS was heavily staffed by contractors at the start of the process. GAO had to report every 60 days. This was a challenge at first but once GAO got in the rhythm of writing these reports, it was able to get the job done (Mihm \& al, 2013).

GAO had strong coordination with SIGTARP, COP and Congress. SIGTARP, COP and GAO were given identical mandates but had different approaches. GAO was more or less objective, while SIGTARP and COP were more aggressive, albeit in different ways. This allowed the three organizations to approach the same issues with different lenses and thus more fully ensure accountability from many different angles (Mihm \& al, 2013).

During the study period, GAO produced 40 different reports related to TARP and also testified before Congressional committees numerous times (Mihm \& al, 2013). These reports were both descriptive and analytical, focusing in one specific aspect of TARP or another. They would both describe the situation as it existed and then provide recommendations to improve both the tracking of money and programmatic effectiveness overall. GAO took a broader and deeper view than any of the other organizations to ensure accountability. 
The US Department of the Treasury: Tracking Money and Reporting Results

In the beginning, the US Department of the Treasury (DT) asked had basically asked for a blank check, which it did not get, although what it got was not far removed (Paulson, 2008). In order to track the funds as they were going out, the DT established an Office of Financial Stability, within the existing Office of Domestic Finance, that would be headed by an Assistant Secretary for Financial Stability. In theory, this person was appointed by the President and confirmed by the Senate, although no such appointee was confirmed until June 2011, meaning that the Office was headed by an interim director during this study period (US Office of Financial Stability, 2012). This office was responsible both for expending and then tracking and recovering TARP funds.

The DT produced and still produces daily and monthly reports on the status of all investments made as a result of TARP. These reports consist of lists of transactions as well as any holdings or loans the government has made under TARP. Beyond these numerical reports, the DT produced 14 monthly reports related to overall TARP spending/loans and 13 "tranche" reports related to the expenditure of funds as well. These reports help us understand how the agency primarily responsible for expending TARP funds actually spent, tracked and recovered them.

The Special Inspector General for the Troubled Asset Relief Program (SIGTARP): An Inspector General to Ensure Compliance

In order to ensure that funds were expended, tracked and recovered in concert with existing laws, Congress authorized creation of SIGTARP as part of the overall TARP law (SIGTARP, 2013c). The special inspector general who would head SIGTARP would be appointed by the President and confirmed by the Senate. The person initially 
chosen (and who remained in charge during the entire study period) was Neil Barofsky. Barofsky had a long distinguished career as a prosecutor of financial crimes in the Southern District of New York, which includes all of Manhattan and thus Wall Street (Associated Press, 2008).

SIGTARP produced 22 full length reports during the study period as well as sending out numerous letters to agencies and businesses handling TARP funds, asking them to report information on how they spent, tracked and recovered these funds (SIGTARP, 2013). These reports concerned themselves primarily with two things. The first was general auditing of funds and ensuring that all senior individuals who handled these funds, whether in a public or private organization, were acting in concert with the law. The second was management structure and effectiveness, specifically from a legal perspective. In other words, that they tracked whether these structures met legal standards and whether individuals were operating in concert with the law (SIGTARP 2013). This legal individual perspective stands in stark contrast to the work done by other organizations and was a key part of ensuring accountability for TARP. The Congressional Oversight Panel (COP): The Overall View of the Legislation and Its $\underline{\text { Programs }}$

The second oversight body created specifically to ensure accountability for TARP was the Congressional Oversight Panel or COP. COP consisted of five members, one each appointed by the Speaker and the Minority Leader of the US House, one each appointed by the Majority and Minority Leaders of the US Senate and one appointed jointly by the Speaker of the House and the Majority Leader of the Senate (Wilkerson, 2013). Now-Senator Elizabeth Warren was selected by the five members as COP's chair, 
with associate AFL-CIO general counsel Damon Silvers selected as vice-chair. COP was given a broad mandate to track both TARP overall as well as individual programs, and it was asked to produce reports on at least a monthly basis (Baum, 2013).

COP saw its primary role as overseeing Treasury's use of its authority. COP focused on ensuring money was being tracked and assessing its use. This was especially important when TARP programs crossed over different federal departments and preexisting programs (Baum, 2013). COP's decision on what to report was determined primarily by two factors. Most importantly, what the panel wanted to focus on, with the input of the professional staff being paramount. The panel would listen to what Congress wanted but wouldn't necessarily respond to every request. This was necessary in order to establish COP's independent credibility, by showing that COP was not just reacting to what Congress wanted. The other factor that determined what COP focused on was what the law required it to focus on, specifically the later legislative requirement that COP focus on farm loans (Baum, 2013).

COP enjoyed a close relationship with Congress, SIGTARP and GAO. They would often consult formally and informally on what each other was working on. This was so they would complement and not duplicate each other's work. Sometimes COP would lead the way with an initial report. They would then let SIGTARP and GAO follow up with other more detailed work (Baum, 2013). COP would also hold joint Congressional hearings with GAO/SIGTARP and would communicate informally with Congress on a regular basis (Baum, 2013). COP was able to be more flexible than other two organizations because it was not beholden professional audit standards while SIGTARP and GAO had to deal with established standards. By contrast, COP was an 
audit body with a political purpose, rather than a more typical auditing or accountability one.

COP produced 21 reports on TARP during the study period (Wilkerson, 2013). They began first as analyses of TARP as a whole and then moved down to individual programs, such as the aid to AIG and to the auto companies. These reports were largely descriptive but also included recommendations on how to improve both the tracking of funds and programmatic effectiveness. On more than one occasion, the members of COP disagreed on some points and so minority recommendations (nearly always those by the GOP-appointed members) were appended to those of the majority. COP also testified before Congress numerous times on its findings. COP's findings proved invaluable in giving Congress yet another way to ensure TARP was effective and accountable.

Now that this chapter has described the organizations responsible for ensuring accountability in TARP, the next section will tell more of the story of how it came about and what it consisted of. This chapter will then describe the policy tools used for TARP and the accountability models used to evaluate its usage.

POLICY TOOLS IN TARP: DIRECT GOVERNMENT, LOAN GUARANTEE, DIRECT LOAN AND GRANTS

The remainder of this chapter will discuss the policy tools utilized in TARP in the following manner. First, this section will identify the top policy tools used in TARP, recognizing that while there were certainly other policy tools being used, four were paramount: (1) direct government, (2) loan guarantees, (3) direct loans and (4) grants. Each of these tools will be discussed first in terms of how the tool is defined in the literature as discussed in chapter two. Second, each tool will be discussed in the context 
of where each is utilized in the legislation. Third, this section will discuss the extent to which the four accountability models appear to be used in relation to these policy tools. In some cases all four were present, while in others only one or two were. Fourth, this section will briefly discuss three policy tools that were expected to be present, or arguably should have been, but were not in fact present. They are (1) economic regulation; (2) government as a corporation and (3) public information. Identifying these tools will help us begin to answer the question how policy tools and accountability models may line up. These tools will then be further analyzed in chapter five as this study will attempt to uncover the significance of what has been learned to the literature and to the practice of either accountability models or policy tool usage.

\section{Direct Government:}

Direct government is defined as "the delivery or withholding of a good or service by government employees (Lenan, 2002, p. 49)." Direct government is utilized when the government directly provides a service or undertakes an activity (Lenan, 2002, pp. 4143). This is as opposed to indirect government, where government provides such a service via a third party, as is the case in contracting (Lenan, 2002, pp. 41-43). Direct government services are highly visible and the spending for them is easily apparent in the government's budget (Lenan, 2002, pp. 41-43).

In the case of a major economic collapse such as this, one of the first things that often comes up in legislation is the need for direct government action. Such was the case with TARP. Direct government action was utilized by TARP in one major way. As already noted the US Department of the Treasury created the "Office of Financial Stability (OFS)" to ensure the long-term financial market sustainability and to manage 
TARP ( (Emergency Economic Stabilization Act of 2008, 2008; US Office of Financial Stability, 2012). As also noted, this office was to be headed by an Assistant Secretary for Financial Stability, appointed by the President and confirmed by the Senate. However, such a person was not confirmed until 2011, so for the purposes of this study period this office was run by an interim director. Nonetheless, the creation of this office was a usage of the "Direct Government" policy tool.

All four types of accountability were utilized in regards to this policy tool. Political accountability was utilized in two ways. First, Congress had a role in approving the director of the new Office of Financial stability (Emergency Economic Stabilization Act of 2008, 2008; US Office of Financial Stability, 2012). In fact, the decision not to approve this director immediately is a form of political accountability because it represents a potential form of disapproval for this choice. Second, Congress had a key role in holding oversight hearings related to the money market policy. It did so on several occasions (Green, 2013; Congressional Oversight Panel, 2009e, pp. 52-62; Doardo G. , 2009, pp. 4-10); the act of holding these hearings is a form of political accountability.

Legal accountability existed in the oversight of SIGTARP in ensuring that the Treasury correctly implemented its duties under this law. SIGTARP played a key role in double-checking the results of the OFS's actions and also ensuring that individual persons followed the law as directed (SIGTARP, 2009d, pp. 3-8). This legal accountability was essential in ensuring that the actions of individuals were in concert with the law as it existed. Especially given the concerns in TARP's design over having too much authority placed in the hands of a few individuals, this was essential. 
Professional accountability was present in two ways. First, OFS's work was evaluated based on established professional standards related to tracking of funds (Mihm $\&$ al, 2013). Second, OFS had a key role in ensuring that the money market actions were undertaken in concert with professional standards (Mihm \& al, 2013). These actions represent a key usage of professional accountability. This is important in terms of counterbalancing the political accountability of the policy itself, especially as it was a concern that TARP was going to be overly controlled by political appointees (Mihm \& al, 2013).

Performance accountability was present in relation to the money market actions. Specifically, such actions were designed to avoid "breaking the buck" and performance metrics, however informal, were utilized to ensure that this standard was met (Baum, 2013). This was not necessarily the most important usage of performance accountability but it certainly was one such usage.

\section{Loan Guarantees:}

Loan guarantees exist when "the government enters into a contractual agreement to make full or partial payment to the lender in case the borrower defaults on the agreed loan. The private lender originates the loan, secures the government guarantee and services the loan according to government regulations or minimum standards (Stanton, 2002b, p. 381)." In effect, loan guarantees allow the government to provide stability to the marketplace without expending as much in funds as would be needed if the government made direct loans (Stanton, 2002b, pp. 381-383).

In order to ensure skittish markets that it was safe to invest, the federal government had to both give loans directly and guarantee loans as well. Loan guarantees 
were a key part of TARP, particularly in relation to the housing market (Emergency Economic Stabilization Act of 2008, 2008; Congressional Oversight Panel, 2009b, pp. 38). Fannie Mae and Freddie Mac were given loan guarantees in order to ensure the overall market that it was safe to invest and that the federal government would ensure that the housing market wouldn't collapse (Emergency Economic Stabilization Act of 2008, 2008). Loan guarantees were also attempted in relation to individual foreclosures, but concerns about how this was going to be implemented kept them from being fully utilized.

All four accountability models were present in relation to this policy tool. Political accountability was present in two ways. First, loan guarantees were given to secure the future of politically important (as well as financially important) institutions such as Fannie Mae and Freddie Mac (Congressional Oversight Panel, 2009d, pp. 3-8; SIGTARP, 2009b, pp. 5-12). This represents a usage of political accountability because these institutions were seen as important to political stakeholders. Second, political accountability existed in the oversight of such guarantees through Congress, both directly and through the creation of both the COP and SIGTARP (Congressional Oversight Panel, 2009d, pp. 3-8; SIGTARP, 2009b, pp. 5-12). These congressional organizations were classic examples of political oversight accountability.

Legal accountability was not particularly present in relation to this tool except in one important respect. SIGTARP ensured that these loan guarantees were properly administered in concert with the law (SIGTARP, 2009b). Beyond that, legal accountability was limited. 
Professional accountability existed in two main ways. First, the US Treasury played a key role in deciding where and when to issue loan guarantees (United States Department of the Treasury, 2008). This discretion, in concert with established professional standards, is a classic usage of professional accountability. Second, SIGTARP audited the decisions on where and how loan guarantees were given (SIGTARP, 2010, pp. 8-11). GAO additionally utilized professional standards from the federal government's "green book" and "yellow book" to determine how and whether these loan guarantees were properly administered (Mihm \& al, 2013). This focus on best practices and on meeting the standards established in the federal auditing guidelines was crucial to successful tracking of these policies.

Performance accountability was utilized because the success of this particular policy tool was, at least partially if not substantially, evaluated on the basis of market outcomes and performance. For example, in the case of the money market loan guarantees, the performance standards were whether the market no longer "broke the buck" and was therefore stabilized (Financial Crisis Inquiry Commission, 2011, pp. 353365; Board of Governors of the Federal Reserve System, 2008). In many cases, the guarantees of possible loans, rather than the loans themselves, were enough to move the needle to show adequate performance improvements as a result of TARP. While this is more of a market accountability standard than a performance one, performance accountability is certainly a model which borrows from market accountability, and what it borrows clearly applies here. 


\section{Direct Loans:}

Direct loans are utilized when "the government makes a direct loan...(and) after making the loan, the government then services the loan (Stanton, 2002b, p. 381)." Direct loans, simply put, are loans which are given out directly by the government for which the government earns interest and expects repayment (Stanton, 2002b). They have been commonly used for decades to help provide needed financing when private funding is not forthcoming.

Direct loans were utilized in four primary areas. First, as part of an attempt to stop individual foreclosures, the program was set up and funds appropriated (although it was not fully implemented) (Federal Housing Authority, 2009; Baum, 2013). Second, direct loans were given to AIG in order to prevent its collapse (SIGTARP, 2009f, pp. 39). Third, direct loans were given to the so-called big three auto manufacturers in order to avert their collapse (SIGTARP, 2009h, pp. 11-15; Government Accountability Office, 2009e, pp. 5-10). Fourth and finally, many banks and other financial institutions were given loans, in addition to having other assets purchased, to help stabilize the financial system (SIGTARP, 2009h, pp. 11-15; Government Accountability Office, 2009b, pp. 510).

The accountability models that applied in relation to direct loans were mainly political, professional and performance, with only a tiny usage of legal accountability. Political accountability was present in three major ways. First, political accountability exists in the decision to focus on loaning funds to politically important institutions, most notably Fannie Mae and Freddie Mac (Baum, 2013; Green, 2013; Wilkerson, 2013). Given the important role Fannie Mae and Freddie Mac play in the home loan business, 
this was no small thing. Second, political accountability existed in the decision to provide loans to politically important businesses, most notably the automobile industry (Green, 2013; SIGTARP, 2009f, pp. 3-9). While once again, there clearly are plenty of policy reasons to avoid this industry's collapse, the political cost of losing such a key industry could have been immense. Indeed, the fact that TARP saved this industry arguably was one of the key factors in Obama's 2012 reelection. Third, political accountability existed in the oversight of such loans through Congress both directly and through the creation of both the COP and SIGTARP (Mihm \& al, 2013; SIGTARP, 2009h, pp. 11-13). These congressional organizations were classic examples of political oversight accountability.

Legal accountability was not particularly present in relation to this tool except in one important respect. SIGTARP had the responsibility to track these loans and ensure that none of the parties violated the law. Beyond that, legal accountability was limited.

Professional accountability existed in two main ways and was very similar to that in relation to loan guarantees. First, the US Treasury was responsible for deciding where and when to issue loans (Financial Crisis Inquiry Commission, 2011, p. Ch. 22; Board of Governors of the Federal Reserve System, 2008). Although they were guided by the policy itself, the decision of how to issue loans, and at times where to issue them, was one left to professional discretion and thus professional accountability. Second, SIGTARP audited these loans based on professional standards (SIGTARP, 2009h, pp. 511). As with loan guarantees, GAO utilized professional standards from the federal government's "green book" and "yellow book"; to determine whether these loans were properly given and administered (Mihm \& al, 2013). This focus on best practices and 
meeting standards established in the federal auditing guidelines was crucial to successful tracking of these policies (Congressional Oversight Panel, 2009c, pp. 2-6)

As with loan guarantees, performance accountability was utilized because the success of this particular policy tool was, at least partially if not substantially, evaluated on the basis of market outcomes and performance. For example, in the case of loans to AIG, the basis for evaluation was whether AIG survived as a result of getting these loans from the federal government (Board of Governors of the Federal Reserve System, 2008). Direct loans were necessary when combined with the loan guarantees in order to prevent this collapse. They were, in effect, a tandem approach. While, as with loan guarantees, this is more of a market accountability standard than a performance one, performance accountability is certainly a model which borrows plenty from market accountability, and what it borrows clearly applies here.

\section{Grants:}

A grant is defined as a "gift that has the aim of either 'stimulating' or 'supporting' some sort of service or activity by the recipient (Bean \& Conlan, 2002, p. 341)." Grants do not disabuse the government of responsibility for a service but they transition responsibility for actually undertaking it to a third party, whether private, nonprofit or government (Bean \& Conlan, 2002). They are commonly used to help achieve either political or policy goals.

While by no means a major part of TARP, grants were included in TARP in order to get the bill through Congress after it failed the first time. The federal government issued grants in areas ranging from county and forest payments, to transportation subsidies and to research in order to ensure that individual members of Congress would 
vote to approve TARP (Green, 2013). This sort of action is, of course, extremely common in relation to bills with a significant dollar value, and it is therefore not surprising that this was the case here.

The accountability model utilized in this case was almost entirely political--so much so that it does not make sense to discuss the use of other models. While one can argue that professional accountability was used to track these grants, the real motivation was political (Green, 2013; Mihm \& al, 2013). These grants were given to specific persons or groups that were politically important or well-connected. The grants were a necessary political evil to get an essential bill passed. Policy Tools Expected or Asserted but Not Utilized:

For a variety of reasons, TARP might have been expected to contain some elements that were in fact absent. The policy tools described below were either supposedly part of TARP according to its proponents or are surprising exclusions from TARP. For example, while economic deregulation led to the crisis, no real effort was made to include economic regulation in the actual TARP law. On another track, there were constant assertions that public information about those getting funds would be provided in order to impact the behavior of actors in the marketplace. Finally, there was a mistaken assumption that government was acting as a corporation. This section describes these tools, why they were assumed or thought to be present and how they were not.

\section{Economic Regulation:}

Economic regulation is defined as something that "imposes formal limitations on activities considered undesirable (Salamon, 2000, p. 1652)." Economic regulations 
"intervene directly in market decisions such as pricing, competition, market entry, or exit. (OECD, 1997, p. 11)." The point of economic regulation is to restrict undesirable activity, to prevent marketplaces from being monopolized or to provide a fair and free playing field to consumers. While many argue that economic regulation restricts economic growth, others argue that proper economic regulation ensures growth is balanced across the system.

Given the history of deregulation as described in the early part of this chapter, one could well assume that TARP would reverse this trend. As Federal Reserve Chairman Ben Bernanke said in a September 2008 hearing before the Senate Committee on Banking, Housing and Urban Affairs, "the shortcomings and weaknesses of our financial markets and regulatory system must be addressed if we are to avoid a repetition of what has transpired in our financial markets over the past year (Bernanke, 2008, p. 4)." Others at the same hearing agreed, including SEC Chairman Christopher Cox, who said "the last six months...have made abundantly clear that voluntary regulation doesn't work. This is a fundamental flaw in the statutory scheme that must be addressed, as I have reported to the Congress on prior occasions (Cox, 2008, pp. 5-6)." There was clearly broad understanding that financial regulation needed to increase to help resolve the problems that necessitated TARP's creation.

However, no further regulation actually happened at the time. There are two principal reasons why. First, and as expressed by Bernanke, "the development of a comprehensive proposal for reform would require careful and extensive analysis that would be difficult to compress into a short legislative timeframe now available (Bernanke, 2008, p. 5)." Stated another way, it was felt that although additional 
regulation was going to be necessary, increasing regulations would be too time consuming and money instead needed to flow immediately to recipients who were in trouble at the time. Second, some in the Bush administration argued that, while some further regulation was warranted, it was not, in fact, the root cause of the problem. As Secretary Paulson told a Senate Committee "that root cause (of the crisis) is the housing correction (Paulson, Testimony by Henry Pauslon Before the Senate Banking Committee, 2008b, pp. 1-2)." While Paulson and others later admitted that further regulation was necessary, they believed that regulation was not the root cause of the market's failure. Thus, economic regulation was not a part of TARP, even though many assumed it would or should be.

Public Information:

"Information is a tool for eliciting desired policy outcomes (Weiss, 2002, p. 218)." The public information policy tool can be said to exist when the government attempts to use public information in an attempt to change behavior by one or more targeted groups. Perhaps the simplest example is food labels, which are intended the buying choices of the general public.

Part of the case for TARP was that the amount of money being allocated and put into the marketplace made it was necessary to disseminate information on these policies as widely as possible. If the public was going to trust that the government was responsibly going to responsibly send out funds at this magnitude, constant and complete information to the public was required (Baum, 2013; Wilkerson, 2013). To that end, OFS created a database, updated daily, which contained information on any transactions using TARP funds and the present value of any assets held by the government that were 
purchased with such funds (Wilkerson, 2013). This database was used both by the public and by those evaluating the policy's accountability and effectiveness. In addition, any company that had a loan or had stock purchased a result of TARP funds was required to reveal significant information publicly (Green, 2013). This information was intended to force the companies to be accountable and more responsive to the public, which, it was thought, would surely use this information to decide which companies to support. However, this did not occur (Mihm \& al, 2013; Baum, 2013; Wilkerson, 2013). Instead, and as SIGTARP commonly stated, this public information did not appear to change the behavior of market actors and was not provided as such (SIGTARP, 2010, pp. 2-5).

\section{Government as a Corporation:}

Government corporations exist when "a government agency, owned and controlled by the government (is) set up as a separate corporate entity legally distinct from the rest of government (Stanton \& Moe, 2002, p. 81)." Government as a corporation does not exist simply when government is a market participant, although many assume it does. Instead, there must be a more business-like, yet government owned, activity, such as Fannie Mae.

It might appear that government as a corporation was perhaps the biggest tool in TARP in that governments have the funds to make purchases and infuse cash into a cashstarved marketplace (Congressional Oversight Panel, 2009d; Government Accountability Office, 2009c). The OFS purchased and held billions of dollars in stocks, preferred assets and other private assets of companies ranging from AIG to banks to auto manufacturers (US Office of Finanical Stability, 2010; Congressional Oversight Panel, 2009f). The government has, and still is, attempting to sell of all of these assets as it took 
the dominant position in some companies. However, despite the intentions to act as a corporation, there was no separate government corporation created as a part of this law, just government purchasing private assets as a market participant. Consequently, the government as a corporation model was not actually utilized

Conclusion:

This chapter has shown that in three of four cases multiple accountability models explain the policy tool choices. This tends to prove that the research hypotheses are correct and a multiple-model approach has greater explanatory power than a single-model approach in almost all cases.

Nevertheless, it is also clear that TARP was notably complex but also significantly different than what was either originally intended, as stated by the proponents of the law, and that TARP contained different tools than we might expect. Much of this doubtless stemmed from the decision to focus on the outcomes of the crisis rather than fixing the system as a whole. As stated above, this was an understandable choice. Whether or not it was the "right choice" is not for this study to say. This study will now turn to the design of ARRA and the accountability models and policy tools it utilized. 


\section{Chapter 4: The Story of ARRA}

This chapter will first tell the story of how ARRA was designed and how its review was intended to be undertaken. It will then discuss the main policy tools used in ARRA and which accountability models were applied in relation to each policy tool. This chapter will reveal that all but one of the policy tools (the exception being tax expenditures) are at least partially explained by more than one accountability model. This reveals that for the most part, the contention that multiple accountability models better explain policy tool choice is correct.

Before we go any further, however, this chapter will set the stage for ARRA by discussing additional aspects of the roots of the crisis. As with TARP, the events that led to the need for ARRA did not begin in 2008 or 2009. Instead, they began at least as far back as 1995 with the beginning of the cycles of jobless recoveries as well as deregulation. The following section will describe that trend in greater detail.

\section{THE ROOTS OF THE CRISIS:}

As with TARP, the roots of the crisis that led to ARRA have existed since at least 1995. In 1995 , the mean income of the American family was about $\$ 80,000$, which was up about $\$ 20,000$ from the early 1980s (Krugman P. R., 2012, p. 74). Since 1995, however, the mean income has actually dropped slightly, even without adjusting for inflation (Krugman P. R., 2012, p. 74). In that same time period, from the early 1980s to 2012, the income of the top $1 \%$ of American earners has more than doubled (Krugman P. R., 2012, p. 74). Why did this happen? The root cause lies in the cycle of jobless recoveries and deregulation. The following section will describe the two recessions that 
occurred in the early 90s, as well as the tech bubble burst of 2000-2001, both of which were precursors to the so-called "Great Recession" of 2008.

The Recession of the Late 1980s/Early 1990s:

On October 19, 1987, known in the financial community as "Black Monday (Carlson, 2007, p. 7)" the stock market dropped $22 \%$ in one of the biggest single day declines in US history (Carlson, 2007, pp. 5-9). There were many causes, not least of which was the savings and loan crisis discussed in chapter 3, but one of the major causes was deregulation, and perhaps most importantly, rampant borrowing and margin calls that allowed traders to buy stocks with money they did not have (Carlson, 2007, pp. 1214). When these margin calls could not be met, as rules of the time required, the bottom fell out of the market (Carlson, 2007, pp. 12-14).

This market crash immediately sent the worldwide economy into recession, with the United States and the rest of the developed world particularly affected (McKnees, 1992, pp. 1-3). However, it quickly looked like the economy was going to recover quite well, as government spending ahead of key elections in the United States and other developed nations provided a brief moment of respite, with both consumer spending and consumer confidence rising quickly. Unfortunately, this rise was short-lived as by 1989 inflation had spiked to $5.9 \%$ and economic growth had slowed to a crawl, a factor further exacerbated by the Federal Reserve's decision to raise interest rates in order to avoid runaway inflation (McKnees, 1992, pp. 3-6). The problem was then further exacerbated by the 1990 Gulf War and the resulting spike in the price of oil from $\$ 17$ a barrel to $\$ 36$ a barrel in just a few months (Taylor, Discretion Versus Policy Rules in Practice, 1993, pp. 197-202). This sent the US economy into recession, with unemployment rising from 
5.5\% in 1991 to $8 \%$ two years later (Bureau of Labor Statistics, 2013). The effects were widespread, economic, cultural and political. For example, this recession was most likely directly responsible for the defeat of President George HW Bush and the election of President Bill Clinton in 1992.

This recession was followed by the greatest economic expansion since World War II. Although this growth was based on part on technological changes, it was at least somewhat illusory. As Joseph Stiglitz wrote, "The Internet was rightly judged to be a transformative innovation. But the irrational exuberance on the part of investors went well beyond anything that could be justified (Sitglitz, 2012, p. 84).” Leaders and investors pumped money into companies they knew, or should have known, were probably losers and the legions of tech companies that received funding and had high stock prices even though they never made a dime in profits created a bubble that although it helped dig the US out of one recession, set the stage for the next one ten years later (Sitglitz, 2012, pp. 83-86).

\section{The Tech Bubble Bursts:}

In the run-up to the 2000 election, the US economy was widely perceived as booming. The average standard of living had risen substantially, the government was actually running a surplus and the world was relatively peaceful. However, trouble lurked just below the surface as the massive bubble that had fueled much of the tech bubble threatened to burst (Lowenstein, 2003, pp. 114-115).

Some in the US government had seen this day coming. For example, the Federal Reserve raised interest rates six times between 1998 and 2000, raising the prime interest rate from $4.5 \%$ to $6.5 \%$ in an attempt to control run-away growth and ease the US 
economy into a soft landing (Federal Reserve Board, 2013; Lowenstein, 2003, pp. 114115). Unfortunately, this did not work as banks continued to lend to companies that had never made a profit, with the mantra of growth over profit ruling the day.

The first tremors of the upcoming bursting of the bubble began to occur in March 2000 as NASDAQ dropped from a high of around 5000 to just 1700 a year later (Willoughby, 2000, pp. 1-2). Companies began crashing left and right as profits finally became more important than growth. The list of major tech firms that crashed in that period is full of names that many Americans would recognize, such as Pets.com, Broadcast.com and Geocities (Economist, 2000). These failures, referred to by some as “.Dot Bombs (Economist, 2000)" represented the collapse of the tech sector. Yet, matters were about to get far worse.

The September 11, 2001 attacks provided an economic shock that exacerbated the already existing problems. These effects were primarily felt in three industries: insurance, tourism and the airline industry. Insurance was impacted both directly by the crisis and indirectly by how it changed future practices. As a Congressional Research Service report noted, "The loss of life and property gave rise to the largest property/casualty claim in history, estimated at $\$ 40$ billion (Makinen, 2002, p. 4).” In addition, this report noted that future insurance for terrorist attacks was more expensive, limited and harder to come by (Makinen, 2002, pp. 3-4). The airline industry was obviously directly affected by the crisis but it also helped push over the edge an industry that had been teetering (Makinen, 2002, pp. 3-6). Not only was overall airline use down but a drop in tourism due to fears related to travel was a dual blow to both industries (Makinen, 2002, pp. 3-6). 
Nonetheless, the impact of the economic crisis began to abate in 2002, with GDP rising as the economy dug itself out of its tailspin (Bureau of Ecnomic Analysis, 2013). Even as the growth of GDP continued and the jobless rate dropped, however, much more of the growth was in GDP than in jobs, making this largely a "jobless recovery (Krugman P. R., 2012, pp. 228-229).” More to the point, the jobs that were created were at lower income levels, even as productivity continued to climb (Bureau of Labor Statistics, 2013b).

What does all this have to with the 2008 financial crisis? The growth of income inequality and the jobless recovery were part of the overall economy and thus became a key factor in the 2008 economic crisis. In fact, income inequality in 2007 was about as bad as it was in the years leading up to the great depression of the 1930s (Krugman P. R., 2012, pp. 79-84).

Yet, others argue that while income inequality might be a part of the problem the main cause of the downturn was the government's own failures. Taylor, Rogoff and others instead argue that, for example, government's policy decisions to encourage home ownership among those that could not reasonably be expected to afford a home played a role in the crisis and that the government's interference in the marketplace generally does more harm than good (Reinhart \& Rogoff, 2009; Taylor, 2008; Rose \& Spiegel, 2009). As a result of this, they argue that government should not act to try and fix these problems but instead largely leave it to the private sector to sort them out.

THE CASE OF ARRA: ATTEMPTING TO KICK START A STALLED ECONOMY

Let us now fast forward to late 2008. The following section will provide the background behind ARRA and describe the need for, development of, passage and 
components of this critical piece of legislation. First, this chapter will describe the initial need for a further stimulus package. Second, this chapter will describe the development of the proposal between the Obama White House and Congress. Third, this chapter will describe the final passage and design of ARRA. The case history is far less complex and more straightforward than with TARP but it is no less important.

\section{The Initial Need for a Further Stimulus Package:}

Keynesian economics is based on the fundamental assertion that when economic times are slow, the best way to move forward is for government to spend more in order to fill the gap in demand not being filled by the private sector (Keynes 1936). As Keynes himself wrote to FDR in 1933, "The United States is ready to roll towards prosperity if a good hard shove is given in the next sixth months. (Keynes, 1933)." During the great depression, FDR listened to such advice and created programs such as the Works Progress Administration to provide jobs to citizens in order to decrease, at least slightly, the huge unemployment problems of the times. Similar problems, although not nearly as widespread, beset the United States during the 2008 economic crisis.

Even with TARP's hefty price tag, it was clear to the incoming Obama administration that TARP alone would not avoid further economic deterioration since, among other things; it only assisted a small part of the American economy. Specifically, TARP attacked the problems in the financial markets but did nothing to stop the jobs crisis that had put millions of Americans out of work. Moreover, TARP was never intended to attack the jobs problem (Baum, 2013).

The need for an additional stimulus bill was perhaps best highlighted in a national radio address aired by then President-elect Obama on January 8, 2009, in which he spoke 
of the need for a sweeping stimulus bill (Obama, Obama's Speech on the Econmy, 2009). Obama set out six goals that any stimulus legislation should accomplish: (1) creating three million new jobs- $80 \%$ in the private sector, (2) doubling renewable energy production and renovating old buildings, (3) rebuilding infrastructure, (4) updating and computerizing the health care system, (5) building " $21^{\text {st }}$ century classrooms" and (6) providing tax relief to $95 \%$ of Americans (Obama, Obama's Speech on the Econmy, 2009). As Obama said in the same speech, "I don't believe that it's too late to change course, but it will be if we don't take dramatic action as soon as possible. If nothing is done, this recession could linger for years. The unemployment rate could reach doubledigits. (Obama, 2009). "To help prevent such a jump in unemployment, Obama proposed a broad counter-cyclical stimulus designed to create jobs, both directly and indirectly as much to prevent further job losses in areas such as education and healthcare (Obama, 2009). Obama's team then predicted that its proposed stimulus plan would keep unemployment under $8 \%$ and that unemployment could otherwise be expected to reach or exceed 10\% (Romer \& Bernstein, 2009, p. 4).

Yet, there was not broad agreement among all economists that spending and tax expenditures would actually help. As Kenneth Rogoff wrote in 2008, “A large expansion in debt will impose enormous fiscal costs on the US, ultimately hitting growth through a combination of higher taxes and lower spending (Rogoff, 2008)." Despite this and other concerns, Obama pushed ahead with his plan and began development of it in earnest shortly thereafter as described in the next section.

Proposal Development Between the Obama White House and Congress:

Even before he took office, President-elect Obama met constantly with leaders 93 
from both houses of Congress so that a stimulus bill could be designed and voted on as quickly as possible. Obama set a goal of getting the law to his desk for signature by February 16, less than a month after he took office (Obama, 2009). The basis for the bill's design was the framework Obama set out in his January 2009 speech (Obama, 2009).

Many economists agreed that a stimulus bill was necessary and that the only question was how big and how to design and approach it. Yet this feeling was far from universal. In a January 2009 ad published in the Wall Street Journal by the Cato Institute, several leading conservative economists argued that, "it is a triumph of hope over experience to believe that more government spending will help the U.S. today. To improve the economy, policymakers should focus on reforms that remove impediments to work, saving, investment and production. Lower tax rates and a reduction in the burden of government are the best ways of using fiscal policy to boost growth. (Cato Institute, 2009)." These economists argued that Obama had it all wrong and that the proposed plan would therefore do far more harm than good.

On the other side, some, such as Paul Krugman, thought the proposed stimulus bill was too small to achieve the hoped for outcomes (Krugman P. , 2009). As Krugman wrote, "Whatever the explanation, the Obama plan just doesn't look adequate to the economy's need. To be sure, a third of a loaf is better than none. But right now we seem to be facing two major economic gaps: the gap between the economy's potential and its likely performance, and the gap between Mr. Obama's stern economic rhetoric and his somewhat disappointing economic plan (Krugman P., 2009).” While some agreed with Krugman that the bill was too small, many others thought either that the bill was well 
designed and of the right size (Center for American Progress Action Fund, 2009) or that the bill should focus more heavily on tax relief and cutting the size of government as noted above (Cato Institute, 2009).

The initial version of ARRA was introduced as HR 1 on January 26, 2009, sponsored by Appropriations Committee Chair Rep. David Obey (D-WI) (HR 1, 2009). The House bill focused on three broad categories of spending (HR 1, 2009). The first, was tax expenditures, primarily focused on helping those who were unemployed or middle or low income (HR 1, 2009). Second, the act proposed a "state stabilization fund" in order to backfill lost revenue in state and local budgets (HR 1, 2009). Third, the act proposed broad direct federal spending in areas such as infrastructure and health care in order to provide jobs and to fill gaps not currently being filled by the struggling private sector (HR 1, 2009). The House version of ARRA was priced at approximately $\$ 827$ billion (Congressional Research Service, 2009c, pp. 1-4). 206 amendments were scheduled for floor votes but were combined into only 11 so as to ensure quick passage (Congressional Research Service, 2009c, pp. 1-4). On January 28, the House passed HR 1 by a vote of 244-188, with 11 Democrats and the entire House GOP caucus voting against the bill (Clerk of the US House, 2009).

The Senate had already introduced its own version of ARRA on January 1, 2009, S. 1, with the lead sponsor being Senator Majority Leader Harry Reid (D-NV) (S 1, 2009). There were three major differences between the House and Senate bills. First, Senate Democrats proposed a one year extension of revisions to the Alternative Minimum Tax (AMT), which added $\$ 70$ billion to the bill's cost (Congressional Budget Office, 2009, pp. 4-5). Second, Senate Democrats proposed cutting aid to states and 
providing additional aid to the elderly (Congressional Budget Office, 2009, pp. 2-5).

Third, Senate Democrats favored spending on health care and renewable energy while the House favored spending on education, infrastructure and aid to the unemployed (Congressional Research Service, 2009b, pp. 1-4; Congressional Budget Office, 2009, pp. $2-5)$. The final Senate version was priced at approximately $\$ 820$ billion $(S 1,2009)$. In spite of these differences, the Senate still realized it had to move quickly. The results of failing to act were seen as potentially catastrophic by many in Congress, especially by those on the President's side of the aisle (Associated Press, 2009). As Congressman David Obey (D-WI) said on the US House floor on January 28, 2009, "This bill is hugely expensive. But it is not nearly as costly as continuing business as usual. It has a big price tag because we are dealing with a big problem (Congressional Record, 2009, p. H620)." The Senate took up the bill on February 6 and debate moved quickly. The Senate invoked cloture on February 7 by a vote of 61-36 (US Senate, 2009). The Senate then passed its version of the bill on February 10 by a vote of 61-37 with Senators Snowe and Collins of Maine and Specter of Pennsylvania being the only Republicans to vote in favor while all Senate democrats voted in favor of the amended HR 1 (US Senate, 2009b).

A conference committee was created immediately upon the Senate's passage of HR 1. A conference report was quickly agreed on and largely stuck to the Senate version of the bill when it came to bridging the gap. (Conference Commtitee on HR 1 (2009), 2009) Specifically, the conference report kept the Senate's AMT changes, although it slightly raised the level at which relief was provided (Conference Commtitee on HR 1 (2009), 2009, p. Part 2). The conference report also increased the so-called "Making 
Work Pay" tax credit (Conference Commtitee on HR 1 (2009), 2009, pp. Part 1-Sec 1001). It also provided COBRA subsidies for workers who had been laid off in order to make it easier for them to afford health care, as well as other provisions (Conference Commtitee on HR 1 (2009), 2009, pp. Part VI, Sec. 1889F). The cost of the conference report bill was lower than either the Senate or House bills, primarily because the conference committee chose to provide less direct aid to individuals than had been proposed by either chamber (Congressional Research Service, 2009). The final bill proposed a $\$ 250$ onetime payment to low income workers/retirees instead of the $\$ 300$ proposed by the Senate and the $\$ 450$ proposed by the House (Congressional Research Service, 2009).

The conference report was completed on February 11. The House voted on the revised bill on February 13, approving the conference report by a vote of 246-183, again without a single Republican "yes" vote (Clerk of the US House, 2009b). The Senate approved the conference report later that same day by a 60-38 vote, with the same three republicans in favor and every Democrat voting in the affirmative (US Senate, 2009c). President Obama signed the bill into law on February 17, 2009 (ARRA, 2009). The Design of ARRA:

ARRA is composed of three primary components (Recovery.gov, 2010c): (1) a $\$ 288$ billion package of tax cuts and tax expenditures for both business and personal taxpayers; (2) \$224 billion in aid to states to help preserve entitlement programs (primarily unemployment benefits), health care and education programs which were otherwise in danger of being cut; and (3) \$275 billion in federal contracts, grants and 
loans $s^{3}$ to fund a series of projects, from infrastructure to research to environmental preservation and beyond (Recovery.gov, 2010c; Congressional Budget Office, 2009). It is this last $\$ 275$ billion that has received by far the most scrutiny since it is the portion of ARRA that allows for the greatest spending discretion and thus required the closest scrutiny. Projects often had to be shovel-ready. As a result, money wasn't necessarily going to be used where it might arguably have been most needed. This concerned many members of Congress since it meant that only governments already prepared to spend funds actually got them.

This was no WPA-style approach like that seen back in the Great Depression (Krugman P. R., 2012, pp. 118-123). Although direct spending to create jobs occurred in addition to amounts used to backfill state budgets, this was a very small part of the overall picture (Krugman P. R., 2012, p. 121). Much of this spending on infrastructure projects was also designed from the start to utilize contractors rather than direct spending, further adding to the costs of the programs since the contractors had to make a profit (Krugman P. R., 2012, pp. 121-124; Sitglitz, 2012, p. 271). Even if all the money that had been designed to be spent on direct job creation was in fact spent, this would have amounted to two percent of total economic activity during the three year period over which many, including Krugman, expected the crisis to last (Krugman P. R., 2012, p. 122). As a result, there could be no fundamental fix here.

Adding to the problem was the fact that during this time, there was no approved head of the office of federal procurement policy (OFPP) (Office of Management and

\footnotetext{
${ }^{3}$ According to Recovery.gov, as of late 2010, 174,195 grants were issued under this section of ARRA, along with 34,191 contracts and 1,600 loans (Recovery.gov, 2010c).
} 
Budget, 2011). In fact, a head of OFFP was not appointed and confirmed until October 2009, several months after ARRA's passage (Office of Management and Budget, 2011). This meant that there was no one in charge of policy changes needed to implement this large amount of government spending. This likely had an impact on ARRA's implementation, but may also have affected its design since there was no person at OFPP to help design or implement these regulations.

OMB took a very unusual approach for ARRA by being very open to comments and by getting the initial regulations out and then constantly adapting them (Mihm \& al, 2013). OMB is usually far more insular, more willing to dictate what will happen than being willing to listen to how it should happen. This was due to the accountability community insisting on involvement from the start (Mihm \& al, 2013). Attempts were made to involve state and local auditors, but they left out many cities and smaller governments (Mihm \& al, 2013). Most notably, the accountability systems set up in ARRA responded to the concerns of entities with the capacity to respond to these requirements but did not allow for smaller cities to be able to take advantage of ARRA funds as they could not afford the staff time to account properly for their expenditures as the law required (Mihm \& al, 2013).

\section{SETTING THE STAGE FOR ACCOUNTABILITY: GAO AND RATB}

In order to ensure accountability for ARRA, the law relied primarily on two organizations, one of which previously existed (the GAO) and one which was created by the legislation (the Recovery Accountability and Transparency Board or RATB). This section briefly introduces the role and approaches that each of these two organizations took in carrying out their responsibilities in this case. 


\section{GAO: A Broader and Quicker Mission}

Since the GAO was already introduced in chapter 3, this chapter will move immediately to describe its role in this case. During the study period, the GAO produced 49 different reports related to ARRA and also testified before congressional committees numerous times. These reports were of three primary types. First, reports which summarized ARRA more generally and considered its overall effectiveness. Second, reports which analyzed specific aspects of ARRA and made suggestions, primarily concerning how to better manage aspects of its implementation (Mihm \& al, 2013). Third, reports tracking state level spending of ARRA funds in select states. Simply put, GAO created a select group of representative states and tracked the spending of ARRA funds in them (Mihm \& al, 2013). Regardless, GAO took a broader and deeper view than any of the other organizations established to ensure accountability under ARRA.

GAO's primary focus was on the 11 mandates it had under the law (ARRA). GAO particularly focused on two main ones, state and local government spending and job numbers (Mihm \& al, 2013). GAO encouraged Congress to focus on how many jobs were funded rather than created or saved since this was seen as a more reliable metric. GAO also sought to help Congress's own internal controls and reporting. GAO reported constantly but their main reports came out on a bimonthly basis (Mihm \& al, 2013).

In order to track state and local funds, GAO placed teams in 16 different states. GAO picked states to focus on based on money and population. GAO started with big states and then looked to fill the gap in what was not represented, such as the South and Midwest. GAO ended up with teams in states representing about two thirds of the money and people. GAO was given $\$ 25$ million to help track ARRA and hired over 100 new 
employees, many of whom were former auditors or GAO employees,, most of whom were sent to one of the new field offices (Mihm \& al, 2013). The field teams would observe and send data back to GAO's DC headquarters where topic experts would confirm it, as is normal GAO procedure. When the money ran out to fund GAO's ARRA operations in late 2010 , all of the temporary offices were closed. GAO then continued reporting on those states, albeit from afar instead of on the ground (Mihm \& al, 2013).

GAO focused on four primary measures. First, was the money sent out? Second, was the money tagged properly? Third, where did the money actually go? Fourth, how many jobs were created or saved? This led to a focus on real time reporting and maps (Mihm \& al, 2013). This was not something GAO was used to. Accountability is usually reactive and this was more proactive. Nonetheless, it was a useful approach and one the GAO asserts will help improve work processes in the future. As one GAO employee said "Tracking money in real time will help us learn better what we should be alert for during the normal report-writing process, even as it remains mostly after the fact and not realtime (Mihm \& al, 2013).”

GAO viewed ARRA as a pure political calculus. This was because a lot of focus was on being able to brag about projects locally. In the GAO' s view, ARRA ended up becoming almost a grant program, providing temporary aid to distressed governments in order to help replace revenue lost by the recession (Mihm \& al, 2013).

The RATB: Inspector Generals Tracking ARRA's Implementation

In order to ensure that the funds expended in ARRA were spent in an efficient, effective and legal manner, ARRA created an 11-member board, known as the RATB, which oversaw ARRA's implementation. This board consisted primarily of inspectors 
general from federal agencies which received funds under ARRA. They were responsible for tracking funds, receiving reports from those that spent ARRA funds (specifically from any organization that spent more than $\$ 25,000$ in ARRA funds) and for running the Recovery.gov website, which was the primary public portal for information on ARRA (Office of Management and Budget, 2009, p. 14).

Unlike the other organizations that were part of ensuring accountability for TARP or ARRA, RATB did not write many reports. In fact, RATB only wrote six fairly general reports on ARRA implementation and accountability during the study period. Instead, RATB's role was to track expenditures of funds, ensure proper utilization of metrics such as "jobs created or saved" and ensure compliance of individual actors with the law (Recovery.gov, 2010). Given the inspector general style under which the RATB operated, this was not surprising. Reports by inspector generals are rarely public.

Now that this chapter has described the organizations responsible for ensuring accountability in ARRA, the next section will describe the policy tools used for ARRA and the accountability models designed to evaluate their usage.

POLICY TOOLS IN ARRA: TAX EXPENDITURES, CONTRACTING, GRANTS AND PUBLIC INFORMATION:

While TARP was focused on making sure key institutions did not collapse with most funds expected to be returned to the taxpayers, ARRA was a more typical countercyclical stimulus bill. There was nothing new or different about how ARRA undertook its work; the tools were used in ways they had commonly been used before. They were just used on a larger and broader scale. 
This section focuses on the main policy tools used in ARRA. Each policy tool will be described as to its definition in the literature, usage in ARRA and the accountability models relied upon. The main tools were (1) tax expenditures, (2) contracting, (3) grants and (4) public information. These are by no means an exhaustive list of the policy tools used in ARRA but they are the main ones and are in agreement with those listed in OMB's initial ARRA guidance, which listed the rules for each program by policy tool (Office of Management and Budget, 2009; Office of Management and Budget, 2009b).

\section{Tax Expenditures:}

A tax expenditure is defined as "a provision in tax law that usually encourages certain behavior by individuals or corporations by deferring, reducing or eliminating their tax obligation (Howard, 2002, p. 411)." Tax expenditures, in effect, “expend" funds through the tax code indirectly rather than through direct spending. The cost may be the same, but the tool and approach are different. Tax expenditures are broadly used by government to encourage behavior in a number of areas (Howard, 2002, pp. 410-415). Some classic examples include those designed to encourage home buying by allowing taxpayers to deduct mortgage costs, as well as targeted tax credits/deductions to encourage purchase of energy-efficient vehicles or home items.

Of the three main parts of ARRA, tax expenditures were arguably the least controversial. Although there was debate over which tax expenditures made the most sense, there was widespread agreement that significant tax expenditures were necessary for any stimulus bill. Tax expenditures in ARRA totaled $\$ 288$ billion, more than any other single part of the bill (Government Accountability Office, 2010, pp. 2-6). They 
were split into several parts, with $\$ 237$ billion earmarked for individuals, mainly in Alternative Minimum Tax and Payroll Tax changes and \$51 billion for corporations (ARRA, 2009, p. Title I). These tax expenditures, most of which were temporary, constituted 37\% of ARRA's total cost (ARRA, 2009, p. Title I; Recovery.gov, 2010b).

In spite of the high cost of these tax expenditures, there was almost no accountability for how the funds were spent and how effective they were. Only the political model of accountability was really put into effect here. While there are certainly many legitimate policy reasons why tax expenditures were the right choice to make, there was no tracking by GAO, RATB or anyone else in determining the impact these tax expenditures had on the economy or on jobs created or saved (Government Accountability Office, 2010, pp. 2-6). They were, as GAO's Chris Mihm stated "purely political (Mihm \& al, 2013)." For example, and given the administration's stated goal of assisting those most directly affected by the economic downturn, reducing FICA taxes in particular was both a political and policy win for the Obama team. Members of Congress had to be able to bring something tangible home to their districts in order to sell ARRA to a public already skeptical about bailing out the financial sector a few months earlier.

As Senator McCain (R-AZ) said in the Senate's final debate on ARRA, "We are on a spending spree of unprecedented and historic proportions. We are committing what some of us have called generational theft because we are laying this debt on our children and our grandchildren (Congressional Record, 2009b, p. S2311).” However, this does not mean that there was a lot of accountability; beyond political accountability there was not (Government Accountability Office, 2010, pp. 4-5; Mihm \& al, 2013). 


\section{Contracting:}

Contracting is defined as a "business arrangement between a government and a private entity in which the private entity promises, in exchange for money, to deliver certain products or services to the government agency or to others on the government's behalf (Kelman, 2002, p. 282)." Contracting is one of the most pervasive tools utilized in government today, with many services formerly directly provided by government being contracted out (Cooper P. J., 2003, pp. 1-20). It is important to note, however, that, even when services are contracted out, government is still responsible for ensuring the quality of contracted goods and services, and should take due care to ensure they are efficiently and effectively provided (Cooper P. J., 2003, pp. 1-20).

While many ARRA funds went directly to state and local governments to help fill their budget holes, most new projects were contracted out. These funds, mainly in the areas of infrastructure and energy efficiency, were designed to give business directly to the private sector. Most of these funds were dispersed via "pass through" methods which involved giving state and local governments the balance of the funds to distribute with a smaller amount distributed by the federal government itself (Government Accountability Office, 2010b, pp. 1-5). GAO identified more than 28,000 contracts that had been issued by late November 2009, only nine months after ARRA's passage (Government Accountability Office, 2010b, pp. 1-5).

The accountability models in place for contracts were primarily legal and professional, with some political and performance accountability thrown in. The political accountability is fairly straightforward. The signs that were everywhere after ARRA's passage were intended to allow both the federal government and local representatives to 
make clear where the money was being spent in each community (Mihm \& al, 2013). Without those signs, political accountability for these contracts would likely have been more difficult to achieve.

Legal accountability existed because of the personal and institutional responsibility of those signing such contracts to avoid waste, fraud and abuse. The rules set out by the RATB and OMB made clear that those receiving funds as a result of a contract would be held personally responsible for the proper expenditure and service delivery required under those contracts (Office of Management and Budget, 2009, p. Sec. 2; Office of Management and Budget, 2009b, p. Sec 2 and 3). As the updated guidelines on implementing contracts under ARRA stated, "The critical importance of the Recovery Act, and the funds it will make available to stimulate the American economy, require heightened management attention on acquisition planning. (Office of Management and Budget, 2009b, p. 52)” Agencies were required to provide heightened scrutiny to all contracts and to ensure that they were undertaken with full transparency and dollar for dollar accountability (Office of Management and Budget, 2009b, p. Sec. 6). As Acting Comptroller General Gene Doardo noted in testimony before the Senate Committee on Oversight and Government Reform, RATB also had a key role here, as it was required to "review grants and contracts, to ensure they meet applicable standards, follow competition requirements and are overseen by sufficient numbers of trained acquisition and grants personnel (Doardo G. L., 2009b, p. 3).” The RATB was thus responsible for ensuring that contracts followed all standard protocols and were in concurrence with existing contracting laws, rules and regulations, a clear usage of legal accountability. 
Professional accountability existed in the evaluation of with whom to contract, where to contract and evaluation of contract success. Where to contract out was a decision based on exiting federal standards (Mihm \& al, 2013; Office of Management and Budget, 2009, p. Sec. 6) and the best professional judgment of those in the state or agency administering these contracts. With pressure to act in order to encourage private sector job growth, there was doubtless pressure to contract out as much as possible, but the decisions made were still fundamentally based on professional standards. In fact, even though there was pressure to get funds out quickly, ARRA did not authorize usage of expedited emergency contracting procedures (Office of Management and Budget, 2009b, p. Sec. 6.2.1). Instead, agencies were required to follow normal procedures, which are based on professional standards, in order to ensure the best outcome for each contract. GAO reports that nearly all of the contracts issued under ARRA were issued competitively, meaning that a professional determination was made as to who was the best to contract with (Government Accountability Office, 2010b, pp. 1-10). Evaluation of contract success would then be based on established professional standards, even if the ultimate responsibility for any shortcomings was more of a legal accountability approach. Regardless, these three areas represent a clear usage of professional accountability as it relates to contracts under ARRA.

Performance accountability was present as well. According to OMB's ARRA regulations, agencies were required to produce performance plans both for ARRA generally and for specific contracts and to ensure that these were met (Office of Management and Budget, 2009b, p. Sec. 6). Specifically, "Agencies must provide for appropriate oversight of contracts to ensure outcomes that are consistent with and 
measurable against agency plans and goals under the Act (Office of Management and Budget, 2009b, p. 59)." Put briefly, agencies had to show, every step of the way, that they were making progress towards measurable outcomes. This requirement that performance and measurable outcomes be a direct part of any contracting decision was a clear usage of performance accountability.

Grants:

As explained in the last chapter, a grant is a "gift that has the aim of either 'stimulating' or 'supporting' some sort of service or activity by the recipient (Bean \& Conlan, 2002, p. 341)." Grants do not excuse the government from responsibility for a service but they transition responsibility for actually undertaking it to a third party, whether private, nonprofit or government (Bean \& Conlan, 2002, pp. 340-343). They are commonly used to help achieve either political or policy goals.

In addition to contracts, ARRA included many grants in areas ranging from education to technology development to community health. The idea behind these grants was twofold. First, to use the available funding under ARRA to jumpstart research in areas that either hadn't been funded to the new administration's satisfaction or had seen the economy sap available grant funds (Office of the Inspector General for the USDA, 2009, pp. 2-7). Second, to help backfill state or local funding that had dried up as a result of the recession (Green, 2013; Government Accountability Office, 2009k, pp. 3-8). While contracts and grants are often confused with one another, including, at times, on Recovery.gov, this study makes a clear distinction between contracted services, where something tangible like a road or a direct service is to be delivered, and grants for research or technological development that are meant to be temporary and do not 
necessarily result in a tangible outcome (Green, 2013; Government Accountability Office, 2009k, pp. 3-8).

There was a problem, however, with issuing grants since during this period grants.gov, the federal government's primary grant application system, was undergoing serious problems. For example, it was extremely difficult to submit applications to grants.gov due to technical problems, including problems uploading needed attachments and logging in to the system at all (Government Accountability Office, 20091, pp. 18-22). While this issue deals with primarily implementation and not design, the fact that grants.gov was not fixed when it was known to be a problem before ARRA is nonetheless worth noting.

As with contracts, the accountability models in relation to grants are primarily legal and professional but with some performance and political accountability as well. Unlike contracts, and since grants are not often as visible, there is not as much political accountability except inasmuch as politicians may brag about a specific grant for their specific districts. Legal accountability existed, as with contracts, in the tight control and responsibility that grant recipients had for funds (Government Accountability Office, 2009k, pp. 3-8). For example, USDA Inspector General Phyllis Fong stated that the inspectors general, both independently and as a result of ARRA, would be focusing on monitoring all "grant planning activities (Fong, 2009, p. 7)" and would focus their efforts on those grants deemed high-risk given their experience with the agency, recipient and the grant in question (Fong, 2009, p. 7). Every penny had to be recorded and reported and constant reports were required in order to discourage and hopefully avoid waste, 
fraud and abuse. As with contracts, this approach, placing a personal or organizational onus for reporting and accountability, is a clear usage of legal accountability.

Also as with contracts, professional accountability was utilized in the grant process. Where to issue grants was certainly directed by the legislation but broad leeway was given within program areas. For example, although much grant funding was designated for new renewable energy technologies, there was plenty of leeway for professional standards to determine which technologies deserved grant funds (Office of Management and Budget, 2009b, p. Sec. 5). The same was true when it came to deciding who should get the grants. As was the case with contracts, expedited award procedures were generally not authorized under ARRA (Office of Management and Budget, 2009b, p. Sec 5.2). Instead, standard federal grant rules were used, based on professional standards, to choose among grant applicants (Office of Management and Budget, 2009b, p. Sec. 5.2). In fact, the actual standards were even higher, since, as OMB wrote in the implementing regulations, "Agencies must take steps, beyond standard practice, to initiate additional oversight mechanisms in order to mitigate the unique implementation risks of the Recovery Act. (Office of Management and Budget, 2009b, p. 49)” As for evaluation of grants issued, professional standards as laid out by GAO and OMB were once again the focus for evaluation (Government Accountability Office, 2010b; Office of Management and Budget, 2009b, p. Sec. 5). These represent a clear usage of professional accountability as it relates to the grants policy tool.

The implementing regulations for grants under ARRA require that "Agencies must adapt current performance evaluation and review processes to include the ability to report periodically on completion status of the program or activity, and program and 110 
economic outcomes, consistent with Recovery Act requirements. (Office of Management and Budget, 2009b, p. 49)" Agencies were required to show that each grant not only met specific performance goals but also that the overall grants structure in the agency met the general performance goals of the required ARRA performance plan (Office of Management and Budget, 2009b, p. Sec. 5.4.1) Agencies were also required to validate their performance measures with the relevant Inspector General's Office, to ensure that they were sufficient to ensure measureable outcomes (Office of Management and Budget, 2009b, p. Sec 5.4.1).

\section{Public Information:}

As defined in the last chapter, the public information policy tool can be said to exist when government uses public information as a way to encourage a change in behavior, largely by private actors but possibly by public ones as well. Public information was utilized in relation to ARRA in the broad publication of all data on those sending and receiving funds on recovery.gov, most notably by placing all recipients on a map with these details of the funds they were awarded clearly displayed (Recovery.gov, 2010b). These steps represent public information policy because they are intended to influence the behavior of decision-makers on where to send funds, contracts and grants. Knowing that their decisions will be immediately subject to public scrutiny was intended to change the behavior of these actors since they might tend to make different decisions knowing that their work was clearly public.

Political and performance accountability were present in relation to this tool. Political accountability was present in two ways. First, the map-based reporting system allowed members of Congress to demonstrate where funds were being spent locally 
(Green, 2013). This was then used to help encourage support, by some at least, for ARRA. Second, congressional oversight was based on this localized approach and Congress chose to evaluate ARRA's public information based on this standard (Green, 2013).

Performance accountability was present due to the usage of the jobs created/saved versus funds expended as based on the map-based localized approach. The focus here was on ensuring that each community got equal, or close to equal, help from their share of ARRA funds in various forms. This type of local approach to ensuring that each community recovered its "fair share" of funds and that the funds were to be spent properly is an example of performance accountability.

\section{Conclusion:}

Unlike TARP, ARRA was fairly close to what was originally intended: a broadbased stimulus bill focused primarily on direct government spending (albeit via indirect means such as grants and contracts) and tax expenditures. Whether or not this is the right policy mix is not for this study to say. This study will now proceed to analyze what this all means relative to the initial research questions posed and analyze the extent to which each accountability model does, or does not, explain policy tool choice. 


\section{Chapter 5: Analyzing Trends and Meanings for Current and Future Research}

In chapters 3 and 4 , this study described the cases of TARP and ARRA. This chapter will analyze these cases and describe what they mean for both theory and practice. This chapter will explain the answers to the questions posed by the literature gaps in chapter one. It will do so by focusing first on the two primary research hypotheses, that a single model approach is insufficient to explain policy tool choice and that a multiple model approach is superior. This chapter will then proceed to describe what this means in relation to theory and practice, to explain what this study has added to the literature and to provide some guidance for future research.

\section{ANSWERING THE RESEARCH QUESTION: SINGLE MODELS INSUFFICIENT,}

\section{MULTIPLE MODELS SUPERIOR, TOOL MATCH NOT AS CLEAR}

The research question for this study was how effectively any one of the four most commonly used models of accountability explains the policy tool choices made to address the accountability issues in TARP and ARRA. To answer this question, the study posed two hypotheses. First, that no one model explains the policy tool choices in either TARP, ARRA or both. Second, that using multiple models will better explain these policy tool choices. This section will analyze both of these hypotheses before moving on to answer the main research question.

\section{Single Models Insufficient to Explain Policy Tool Choice:}

The first hypothesis was based on the assumption that tool choices are complex and therefore that none of the four accountability models would, by themselves, fully explains most policy tool choices. In all but two cases, the tax expenditure tool for ARRA and grants for TARP, the data supported this hypothesis. In order to demonstrate 
that the data back up this assertion, this section will go through each of the pertinent policy tools in turn, beginning with the policy tools used in TARP and then moving on to the policy tools used in ARRA, attempting to explain them using only one policy tool.

\section{Direct Government in TARP:}

Direct government was used in TARP in the creation of OFS. Political accountability explains this choice in the requirement that the Senate approve the director of OFS and that OFS had a key role in managing treasury's investments in relation to TARP (Office of Financial Stability, 2014). It might even explain the creation of SIGTARP as a body to monitor and provide oversight, but it does not explain the standards SIGTARP used, which focused on standard inspector general auditing standards and procedures (SIGTARP, 2009f, pp. 1-10). SIGTARP evaluated OFS's decisions of where to invest its funds and how it monitored them based on the principle of individual legal responsibility, a typical legal accountability approach (SIGTARP, 2009f, pp. 1-10). The legal accountability used in SIGTARP along with political and professional accountability mean that the data shows that a single model does not explain the tool choice.

\section{Loan Guarantees in TARP:}

Loan guarantees existed in TARP's provisions guaranteeing that the government would ensure that Fannie Mae and Freddie Mac would be solvent so as to avoid their (and arguably the housing market's) collapse. Professional accountability explains part of this choice as the US Treasury was given a role in determining where and when to issue loan guarantees in concert with established professional standards, which after all is the basis for professional accountability (Baum, 2013). However, professional 
accountability does not explain the performance metric by which these loan guarantees were based on, that the areas in which they were being given remain stable and that, for example, the money market not break the buck (Condon, 2008). Once again, therefore, a single model approach does not fully explain tool choice.

\section{Direct Loans in TARP:}

Direct loans were utilized in TARP in the form of loans given to the big three auto manufacturers as well as to AIG. Political accountability explains part of this tool choice in that the institutions chosen to get loans were not only economically important but also politically important (Wilkerson, 2013). As the two former top staffers in the COP said in interviews, the reason why the auto manufacturers in particular had to be rescued was as much politics as it was policy (Baum, 2013; Wilkerson, 2013). Underscoring this point, President Bush said in relation to the auto bailout "The American people want the auto companies to succeed, and so do I (Neuman, 2008)." However, while they were politically important, professional accountability also demanded that these loans be made in a way that would serve the public interest. Similarly, and in relation to AIG, the Federal Reserve board said "a disorderly failure of AIG could add to already significant levels of financial market fragility and lead to substantially higher borrowing costs, reduced household wealth, and materially weaker economic performance (Board of Governors of the Federal Reserve System, 2008b)." The loans given were therefore evaluated by GAO and the COP on the basis of whether they were in the public interest in concert with professional standards in place at the agencies giving the loans (Baum, 2013; Mihm \& al, 2013). While a case could be made for these loans being politically important and thus representative of political accountability, the reason behind the choice 
of direct loans can be better explained by professional accountability and thus a single model approach once again fails.

\section{Contracting in ARRA:}

This chapter will now address the policy tools used in ARRA, beginning with contracting. Under ARRA, thousands of contracts were issued by all levels of government. In fact, GAO noted that 28,000 contracts had been issued under ARRA as of November 2009, only nine months after ARRA's passage (Government Accountability Office, 2010b, pp. 1-5). Legal accountability explains part of this choice in that the contracts were evaluated on the basis of contract law and other related legal standards, most notably by GAO (Government Accountability Office, 2009f). An individualistic legal standard was used, as was described in chapter four. However, professional accountability explains this tool choice more fully as the decisions on when, with whom and how to contract were designed to be made on the basis of professional judgment and were evaluated as such (Mihm \& al, 2013). More specifically, while the evaluation of the contract was based on legal standards and legal accountability, the choice of with whom to contract was based on professional accountability. Therefore, once again, a single model approach is insufficient to explain this policy tool choice

\section{Grants in ARRA:}

As already noted, grants and contracts are not the same. They have a different control mechanism, with the issuing agency holding more control over the funds and their dispersal, than contracts, which are typically more of a partnership (Cooper P. J., 2003). In addition, grants and contracts utilize different bodies of law and must therefore be considered separately (Cooper P. J., 2003). Grants were also broadly utilized in ARRA 
in relation to a number of areas, such as research and development of new energy technologies (Mihm \& al, 2013). The decision on where and how to issue grants can be partially explained by professional accountability as ARRA granted broad discretion for agencies to expend funds earmarked for grants as they saw fit to meet policy goals, such as energy efficiency (Mihm \& al, 2013). However, OMB's requirement that all grants be evaluated on the basis of performance accountability makes it apparent that performance accountability is also necessary to explain this policy tool choice (Office of Management and Budget, 2009b, p. Sec. 6). Therefore, no single accountability model can fully explain this tool choice.

\section{Public Information in ARRA:}

Public information was utilized in relation to ARRA in the broad publication of all data on those sending and receiving funds. These steps represent public information policy because they are intended to influence the behavior of decision-makers on where to send funds, contracts and grants. Knowing that their decisions will be immediately subject to public scrutiny was intended to affect the behavior of these actors since they might tend to make different decisions knowing that their work was clearly public.

This was partly representative of political accountability as members of Congress, and the public, could then use this data to ensure that funds were being spent evenly across districts as well as properly within them (Mihm \& al, 2013). However, performance accountability explains some additional reasoning behind this tool choice as the jobs created/saved metric, as well as where those jobs were created/saved, was a key part of the pitch for ARRA (Mihm \& al, 2013). Once again, a single model approach is insufficient to explain this tool choice. 


\section{The Two Exceptions: Tax Expenditures in ARRA and Grants in TARP}

This chapter will now discuss the two cases where a single model approach is sufficient to explain policy tool choice. The first is tax expenditures in ARRA. As noted in chapter four, tax expenditures totaled $\$ 288$ billion, more than any other single part of the bill (ARRA, 2009, p. Title I; Recovery.gov, 2010b). They were wide-ranging, although mostly directed towards those at the lower end of the income scale (ARRA, 2009, p. Title I; Recovery.gov, 2010b). There are sound policy and, of course, political reasons for these tax expenditures but no metrics or other evaluations were put in place to determine the effectiveness of these tax expenditures (Mihm \& al, 2013). No part of ARRA assigned any responsibility for tracking these tax expenditures to any of the bodies tracking the broader law (Mihm \& al, 2013). The accountability, therefore, was purely political (Mihm \& al, 2013). This was intentional. As one Senate staffer said, members of Congress wanted something tangible to bring home to their districts and tax expenditures were an easy way to do so (Green, 2013). Therefore, and as stated in chapter four, this is an instance in which only one model explains the tool choice.

In relation to grants in TARP, most of the grants were given to those whom were politically powerful in order to secure important votes (Pope, 2011). For example, money for timber payments was included in order to get the votes of some members of Congress in the Pacific Northwest (Pope, 2011). This decision could be explained on other grounds but it is mostly explained by politics as a classic example of "vote-buying" (Fenno, 1978) since it resulted in members of Congress who had voted against the bill the first time voting in favor the second when these grants were included (Pope, 2011). 
These vote-switches were necessary to pass TARP. Thus, grants in TARP represent a second case in which a single model approach is sufficient to explain tool choice.

Nevertheless, while there are two instances in which a single model approach explains tool choice, the data from the rest of the policy tools indicate that a single model approach is insufficient. In all other case, utilizing at least two models explains the other policy tool choices more fully than one model alone. As a result, the data support the hypothesis that a single-model approach is generally insufficient to explain policy tool choice. This chapter will now proceed to examine the data around the second hypothesis and evaluate whether a multiple model approach is superior for explaining policy tool choice.

\section{Multiple Models Have Greater Explanatory Power:}

The second hypothesis was that using multiple accountability models would have greater explanatory power in explaining policy tool choices. The reasoning behind this was, as noted above, policy tools are complex instruments and there are often many reasons why they are chosen, whether political, professional, legal or performance-based. As a result of this complexity, it is typically the case that tool choices need to be viewed from the perspectives of multiple accountability models in order to explain tool choice. With the exception of two instances noted in the last section, the policy tools used in TARP and ARRA required multiple models to fully explain.

This section will now evaluate the remaining tools where multiple model approaches provide greater explanatory power. The tools used will be loan guarantees, direct government and direct loans for TARP and contracting, grants and public information for ARRA. 


\section{Loan Guarantees in TARP:}

One of the major ways in which TARP was designed to prevent a collapse of the financial system was by providing loan guarantees to those in the marketplace so as to calm skittish investors (Baum, 2013). Loan guarantees were primarily given to Fannie Mae and Freddie Mac in order to shore up the housing market and make clear that federally backed loans were secure (Baum, 2013). As discussed in chapter 3, this study found that all four accountability models played a role in this policy tool choice.

Political accountability was present both in the choice to use loan guarantees to save politically important institutions such as Fannie Mae and Freddie Mac and in the choice to give oversight for loan guarantees to the COP, which was a political body chartered by Congress to evaluate TARP (Wilkerson, 2013). This choice to give oversight authority to a political body is representative of political accountability.

Legal accountability was present in the role a special inspector general (SIGTARP) had in ensuring that these loan guarantees were administered in accordance with the law (Congressional Oversight Panel, 2009d, pp. 3-8; SIGTARP, 2009b, pp. 512). These legal standards, which included, for example, whether banks had misrepresented their financial status to the federal government before receiving TARP funds, were based on both civil and criminal law (SIGTARP, 2012). They resulted in SIGTARP pursuing multiple criminal and civil cases against parties that violated the law, as one would expect in an approach based on legal accountability (SIGTARP, 2013b). As a result they were representative of legal accountability.

Professional accountability was present in this tool choice in the discretion given to the US Treasury in how and when to issue such guarantees as well as the established 
federal standards by which they were evaluated by GAO and SIGTARP (Mihm \& al, 2013). For example, GAO evaluated whether the US Treasury was properly issuing and monitoring these loan guarantees (Government Accountability Office, 2013, pp. 2-5). GAO created a list of recommendations, based on professional standards, to determine if Treasury was properly monitoring and issuing loan guarantees and then evaluated Treasury against those recommendations (Government Accountability Office, 2013, pp. 12-17). Since these recommendations were based on professional standards, this represents a usage of professional accountability as defined in chapter 2 .

Finally, performance accountability was present in the extent to which the performance of the market was clearly intended to be a barometer of this tool's success (Baum, 2013). Specifically, if an institution which was given a loan guarantee did better, it was regarded as a success, while if it failed, it was regarded as a failure (Baum, 2013). This market performance metric is a key way in which performance accountability can be invoked. It certainly was the case here.

To look at just any one of these models in relation to this tool choice would be to miss an important part of the picture. As shown above and in chapter three, more than one model is needed to explain this tool choice. Therefore, with regards to this tool, the second hypothesis is true.

\section{Direct Government in TARP}

Direct government was a key part of TARP. As discussed in chapter three, direct government was a part of TARP in the money market rescue program and the creation of OFS within the US Treasury 
All four models applied to the usage of the direct government tool in the case of TARP. Political accountability was present in relation to TARP in the role Congress had in confirming OFS's director and in the oversight hearings held in relation to the money market policy (Emergency Economic Stabilization Act of 2008, 2008; US Office of Financial Stability, 2012). Political accountability was also present in relation to TARP in the congressional oversight hearings related to TARP (Government Accountability Office, 2009f).

Legal accountability was present in relation to TARP in the oversight of SIGTARP in ensuring that the Treasury correctly implemented their duties under this law (SIGTARP, 2013b). Specifically, SIGTARP was responsible for ensuring that government action was within the law and that all participants were acting legally and responsibly as determined by federal legal standards (SIGTARP, 2009h).

Professional accountability was present in relation to TARP in two ways. First, OFS's work was evaluated based on established professional standards related to tracking of funds (Baum, 2013). Second, OFS had a key role in ensuring that the money market actions were undertaken in concert with professional standards (Baum, 2013). OFS was held to account by the professional standards of those in the COP and were evaluated against those standards constantly, marking a usage of professional accountability in relation to this tool (Wilkerson, 2013).

Performance accountability was present in relation to TARP in the money market actions in that performance metrics, however informal, were utilized to ensure that the money market was not "breaking the buck" (Baum, 2013; Condon, 2008). COP and others evaluated the success of TARP based on whether or not they were able to keep the 
money market from "breaking the buck". This focus on measureable standards represents a usage of performance accountability.

It would be missing part of the picture to look at only one accountability model in relation to this policy tool choice. As shown above and in chapter three, more than one model is necessary to explain this tool choice. Therefore, with regards to this tool, the second hypothesis is true.

\section{Direct Loans in TARP:}

Direct loans were another critical part of TARP. As discussed in chapter 3, loans were given to institutions including auto manufacturers, banks and AIG. These loans were at the heart of TARP, as it fed money back into a financial system that lacked capital flows.

All four accountability models explain this policy tool choice to some extent. Political accountability explains the focus on saving politically important governmentfunded institutions such as Fannie Mae and Freddie Mac and auto manufacturers. Although these choices could be justified on policy grounds, saving them was also important because the political damage caused by their failure could have been significant (Baum, 2013; Green, 2013; Wilkerson, 2013).

Legal accountability explains this tool choice with the role SIGTARP was given in tracking these loans and ensuring that none of the parties violated the law. For example, SIGTARP ensured that banks properly accounted for the loans they received through TARP (SIGTARP, 2013d). In one case, SIGTARP's charges resulted in FifthThird Bank paying a $\$ 6.5$ million fine as a result of the bank's failure to properly account 
for TARP loans (SIGTARP, 2013d). This represents a usage of legal accountability in relation to direct loans.

Professional accountability explains this tool choice in the role that the US Treasury was given in deciding where and to whom to issue loans. It was also present in the standards to be used by SIGTARP and GAO in evaluating such loans. Specifically, these loans used professional standards from the federal government's "green book" and "yellow book" to determine how and whether these loan guarantees were properly administered (Mihm \& al, 2013).

Performance accountability explains this policy tool choice because the success of this particular policy tool was, at least partially, evaluated on the basis of market outcomes and performance (Congressional Oversight Panel, 2009). Specifically, the concern was whether companies benefited as a result of these loans. If they did, that was considered a success under TARP's performance standards (Congressional Oversight Panel, 2009). This is representative of performance accountability in relation to this policy tool.

Once again to look at any one of these models in isolation only gets to part of the picture. All four models can help explain this policy tool choice. Once again, a multiple model approach is superior and this hypothesis is validated.

\section{Contracting in ARRA:}

Contracting was a critical part of how ARRA dispersed funds. In order to undertake the actual projects authorized under ARRA, federal, state and local governments largely contracted out the performance of this task. As already noted, 
28,000 contracts were issued under ARRA as of November 2009, only seven months after ARRA's passage (Government Accountability Office, 2010b, pp. 1-5).

As noted in chapter four, this study found that although accountability in relation to this tool was primarily legal and professional, there was some performance and political accountability as well. Political accountability existed in the specific selection to award contracts to those that were politically powerful (Green, 2013; Mihm \& al, 2013). Some evidence appeared to suggest that big political contributors might have gotten bigger contracts under ARRA (Hoover, 2010). However, an academic study argues this point, stating that there is limited evidence to suggest that contracts were awarded based on political factors (Boone, Dube, \& Kaplan, 2014). Nonetheless, it appears that politics probably played at least some role in awarding contracts.

Legal accountability existed because of the personal responsibility of the organization and persons in the organization responsible for signing such contracts to avoid waste, fraud and abuse (Mihm \& al, 2013). Specifically, GAO evaluated whether those receiving contracts were administering them in concert with state law (Government Accountability Office, 2009d). This type of focus on the legal procedures and rules is representative of legal accountability.

Professional accountability existed in the evaluation of whom to contract, where to contract and evaluation of contract success. Where to contract out was a decision based on exiting federal standards (Mihm \& al, 2013; Office of Management and Budget, 2009 , p. Sec. 6) and the best professional judgment of those in the state or agency administering these contracts. GAO evaluated whether both states and the RATB 
followed these standards in relation to contracts (Government Accountability Office, 2009d, pp. 5-7).

Performance accountability was present in that, according to OMB's ARRA regulations, agencies were required to produce performance plans both for ARRA generally and for specific contracts and to ensure that these were met (Office of Management and Budget, 2009b, p. Sec. 6). This is a usage of performance accountability in relation to this tool.

In short, the choice to utilize the contracting policy tool was based on all four models. This makes sense because contracts really do draw on all aspects of accountability. As a result, multiple accountability models are present in relation to the contracting policy tool in ARRA.

\section{Grants in ARRA:}

ARRA included a variety of grants in areas ranging from education to technology development to community health. As already noted, this study makes a clear distinction between contracted services, where something tangible like a road or a direct service is to be delivered, and grants for research or technological development that are meant to be temporary and do not necessarily result in a tangible outcome (Green, 2013; Government Accountability Office, 2009k, pp. 3-8).

All four accountability models explain part of this policy tool choice. Political accountability existed inasmuch as grants were given to individual districts, where local members of Congress were able to brag about them to their constituents. For example, Oregon Senator Jeff Merkley (D-OR) openly asserts that securing ARRA grant funds for the state is proof that he can deliver for his constituents (Oregon's Senator Jeff Merkley, 
2014). This sort of behavior is what that would be expected for a policy predicated in part on political accountability.

Legal accountability existed, as with contracts, in the tight control and responsibility that grant recipients had for funds (Government Accountability Office, 2009k, pp. 3-8). For example, USDA Inspector General Phyllis Fong stated that inspectors general, both independently and as a result of ARRA, would be focusing on monitoring all "grant planning activities (Fong, 2009, p. 7)" and would focus their efforts on those grants deemed high-risk given both their experience with the agency, recipient and the grant in question (Fong, 2009, p. 7).

Professional accountability explains this tool choice in the role that agencies were given in determining where, with whom and how to evaluate grants. The guidelines under ARRA gave broad latitude to agencies to issue grants to specific recipients as they felt best served the public interest (Office of Management and Budget, 2009c, p. Sec. 3). For example, although much grant funding was designated for new renewable energy technologies, there was plenty of leeway for professional standards to determine which technologies deserved grant funds (Office of Management and Budget, 2009b, p. Sec. 5). As for evaluation of grants issued, professional standards as laid out by GAO and OMB were once again the focus for evaluation (Government Accountability Office, 2010b; Office of Management and Budget, 2009b, p. Sec. 5). .

Performance accountability was present in this tool choice since the implementing regulations for grants under ARRA required that, "Agencies must adapt current performance evaluation and review processes to include the ability to report periodically on completion status of the program or activity, and program and economic outcomes, 
consistent with Recovery Act requirements. (Office of Management and Budget, 2009b, p. 49)." These plans are representative of exactly the sort of metrics used in a performance-accountability case.

If one were to consider only one accountability model, one would miss a key part of the picture. Approaching this tool choice from a multi-model perspective increases what can be explained. Once again, the hypothesis that a multiple model approach is superior is confirmed.

\section{Public Information in ARRA:}

As noted in the prior section, public information was utilized in relation to ARRA in the broad publication of all data on those sending and receiving funds. These steps represented public information policy because they are intended to influence the behavior of decision-makers on where to send funds, contracts and grants. Political accountability explains this tool choice in that the map-based reporting system allowed members of Congress to demonstrate that funds were being spent locally (Green, 2013). In addition, congressional oversight was based on this localized approach and Congress chose to evaluate ARRA's public information based on this standard (Green, 2013).

Performance accountability explains this tool choice due to the usage of the jobs created/saved versus funds expended as based on the map-based localized approach. The focus here was on ensuring that each community got equal, or as close to equal, help from their share of ARRA funds in their various forms (Boone, Dube, \& Kaplan, 2014, pp. 1-3).

Although the public information tool did not utilize all four models, looking at only one model is missing part of the picture. It is not enough, for example, to say that 
the map-based approach was utilized only because of political reasons when the reasoning behind it was performance-based as well. Once again, the hypothesis that a multiple model approach is superior is supported by the evidence.

\section{Summing Up the Results: Multiple Model Approach Superior}

As shown here, as well as in chapters three and four, a single model approach leaves out important factors that policy makers considered in determining which tools to use and therefore only gets to part of the picture. Utilizing a multi-model approach has greater explanatory power in relation to tool choices in every instance except tax expenditures for ARRA and grants for TARP. As a result, it is clear that the hypothesis that a multi model approach explains more about the tool choice than a single model approach is true.

\section{POLICY TOOL CHOICE AND ACCOUNTABILITY MODELS: EXPLANATORY}

\section{POWER STRONG IF UNEVEN AND STILL POSSIBLE TO LEARN MUCH}

This chapter will now consider the question "How effectively does any one of the four most commonly used models of accountability explain the policy tool choices chosen to address the accountability issues in TARP and ARRA?" The answer differs between the two cases but the answers are largely the same in that accountability models do explain policy tool choice.

For TARP, the definition of the policy problem has a significant impact on the connection between policy tools choice and accountability models. In this case, the decision not to focus on economic regulation appears to have fallen victim to the definition of the policy problem as needing to solve the immediate causes of the crisis rather than the reasons the crisis happened in the first place. Specifically, the policy 
problem for TARP was defined as needing to solve the results of the crisis rather than the cause of it in the first place.

Doubtless part of the policy problem definition was due to the speed with which the policy was adopted, with the policy being enacted about two and a half weeks after its original inception. This speed meant that accountability was not as well-defined as many would have liked and arguably that it was not therefore as likely to be as well thought out a policy as many would have liked. As John Taylor said in February 2009, "the government's intervention plan had not been fully thought through (Taylor, 2009).” This speed and lack of full policy development that Taylor and others noted meant that policy tool choices were not necessarily those that were originally said to be part of the bill, most notably in the areas noted in chapter three.

Nonetheless, and as noted in chapter three and this chapter, accountability models do explain some of the tool choices and help us understand how they were both set up operationally and how the accountability of these tools would be determined. If one did not consider the accountability models in relation to the direct loan tool, for example, the evidence suggest that it would not be possible to understand the role professional standards played in determining which companies got loans, at what rates and how they were tracked.

In relation to ARRA, the link between policy tools and accountability models is more apparent. This is due primarily to three factors. First, ARRA was a more conventional bill than TARP and so was working with more established approaches; and the accountability models that are tied to the policy tools used in those approaches are fairly well established. Second, GAO and others in the accountability community 130 
insisted that policy tools be tied to clear accountability standards, at least when it came to areas other than tax expenditures (Mihm \& al, 2013). The accountability community asserted that it was critical that this be done because the large sums of money being expended under ARRA in a very public manner demanded clear standards tied to policy tool approaches (Mihm \& al, 2013). Third, OMB's own regulations concerning ARRA break down the bill's approaches into individual policy tools and the standards on which they will be evaluated relative to each are clear (Office of Management and Budget, 2009c). This was unusual as there does not appear to be another case in which OMB so clearly states the policy tool choices and ties them to accountability models.

Policy tool choice, at least in relation to TARP and ARRA, is explained in a variety of significant ways by accountability models. The extent to which it is may differ and its impact but this is nonetheless a clear and unique approach to connecting policy tools and accountability models.

\section{EVALUTING TARP AND ARRA: LESSONS THAT CAN BE LEARNED}

The following section will provide some lessons that can be learned from TARP and ARRA. It will evaluate how the policies were undertaken, how the circumstances in which they were created impacted them and what this tells us about policy design, accountability and policy tools.

Lessons that can be Learned from TARP:

When faced with a decision on how to resolve a problem as daunting as the great recession, TARP was a unique policy that responded to the major problems posed by this crisis. The following section will discuss and analyze this study's three main findings related to TARP alone. They are: (1) the decision to attack the results of the problems 
cause by the economic crisis of 2008 rather than the source itself; (2) the speed of response impacted tool choice; and (3) the fact that accountability was not initially as present as had been publicly asserted prior to the bill's passage. This is not an exhaustive list of findings but they are the three most important.

Attacking the Results of the Problem Rather than the Cause: Lack of Regulation

As discussed in chapter three, the economic crisis of 2008 came about in no small part due to decades of deregulation. The system had been left vulnerable to abuse as deregulation allowed riskier and riskier investments to take place with little to no government oversight. The system was indeed abused. It was apparent to many that part of the solution to this crisis needed to be re-regulation of some sort so as to control and prevent such events from occurring again (Krugman P. , 2009; Stiglitz, 2012, pp. 22-25). While this would later happen in part with the Dodd-Frank Wall Street Reform Consumer Protection Act of 2010, it did not in TARP (US Congress, 2010; Krugman P. R., 2012, pp. 86-89).

Congress did not address regulation at all in TARP except in the very limited sense that executive bonuses were supposedly to be limited for those receiving government funds (although this didn't turn out to be the case) (Green, 2013). Instead, TARP made a conscious choice to attack only the results of the problem and not the underlying problem itself (Green, 2013; Mihm \& al, 2013). For example, it provided loans to AIG and the big three auto manufacturers but did not reform the underlying regulations governing these industries (Mihm \& al, 2013).

This is not an invalid policy choice by any means but it did not get at the root of the problem. It was also unlike the response to the savings and loan crisis since the focus 
there was both on saving the system and on re-regulating it (Krugman P. R., 2012; Stiglitz, 2012).

TARP's decision to focus on the results of the crisis did not address the fundamental problems of the system, as Dr. Cooper points out (Cooper P. J., 2009). This left the system open for future abuse. TARP may have helped put out the fire started by the economic crisis of 2008 but it did little to make the financial system fire-proof for the future.

\section{Speed of Response Impacted Tool Choice:}

There was no question that members of Congress felt that they had to respond quickly. The markets agreed, with the precipitous drop after Congress failed to pass the first version of TARP being clear evidence of this. Add to that looming presidential and congressional elections and this was a situation in which members of Congress believed that they had to find a way to pass a bill that provided quick and politically sellable benefits (Baum, 2013; Wilkerson, 2013). Treasury sensed this too, which is why its initial proposal was only three pages; this initial proposal was designed specifically to force Congress to act quickly and to give Treasury broad authority to respond quickly (Paulson, 2008). Although this initial proposal was not reasonable or feasible, since few in Congress were prepared to turn over that much unchecked power, it was yet one more thing putting pressure on Congress to act quickly and not get bogged down in the details.

This decision to act quickly impacted the choice of tools that were in TARP in three primary ways. First, in multiple cases, as demonstrated in chapter three, some of the tools that were originally intended for the bill, or that one would expect to find in the bill, were not actually in the bill. Most notably, proponents of TARP said it was going to 
use public information and government as a corporation but TARP did not do so (Baum, 2013; Wilkerson, 2013). This was probably due, at least in part, to the speed with which the bill was put together.

Second, tools were often put in place without clear implementing guidelines. In several cases, according to those at GAO and COP, programs were announced without any implementing guidance just so that Congress and the President could demonstrate that they had taken action (Baum, 2013; Mihm \& al, 2013; Wilkerson, 2013). While this certainly happens in normal cases as well, those at GAO and COP believed that it happened far more often with TARP (Baum, 2013; Mihm \& al, 2013; Wilkerson, 2013). The agencies and the administration would then let the administration write the rules. Thus, it was clear that the speed with which the legislation was implemented impacted the tool choice.

In addition, the tools TARP did utilize were different than what might have been expected. As discussed in chapter three, for example, there was almost no usage of economic regulation as a policy tool. Instead, the focus was on fixing the results of the failure rather than the causes of the failure itself.

While there were many legitimate reasons for Congress to move with speed, there is no doubt that speed had an impact on the design of the bill. The next section will discuss how this focus on speed of response impacted accountability.

\section{Accountability Missing?}

Lack of accountability was one major reason why Secretary Paulson's initial three-page bill was rejected. Most in Congress simply did not trust him with that kind of power (Green, 2013). As it emerged from Congress, TARP was inlaid with 
accountability mechanisms but they were not as strong as many thought at the time (Baum, 2013; Mihm \& al, 2013; Wilkerson, 2013). Some of this was likely due to the lack of further time for reflection.

Under section 125 of the Emergency Economic Stabilization Act of 2008 or EESA, the act which contained TARP, Congress authorized creation of the COP (Emergency Economic Stabilization Act of 2008, 2008, p. Sec. 125). COP was vested with a broad mandate to "review the current state of the financial markets and the regulatory system. (Emergency Economic Stabilization Act of 2008, 2008, p. 125)” COP, however, was not vested with real authority, as its purpose was simply to report on both the markets in general, and the impacts/implementation of TARP more generally (Baum, 2013; Wilkerson, 2013). None of its recommendations were required to be implemented by anyone and, in fact, due to the one-per-month speed at which COP produced reports, there was little time for feedback or study before the next one came along (Baum, 2013; Wilkerson, 2013). Ultimately COP could do little more than sound the alarm about potential or real problems. It could not enforce additional accountability as problems arose.

Further complicating COP's work was the fact that many of TARP's programs were described only in the most basic terms in the legislation, with the details to be filled in later (Baum, 2013; Green, 2013; Wilkerson, 2013). As noted, this happens in many cases, but it happened far more often here than in general (Baum, 2013; Green, 2013; Wilkerson, 2013). A classic example of this, cited by multiple COP staffers as well as a Senate staffer in interviews, was the attempt to use TARP funds to do something about the home mortgage crisis (Baum, 2013; Green, 2013; Wilkerson, 2013). The Obama 
administration pushed ahead and announced that it was going to undertake a plan to solve the foreclosure problem but did not have any implementing standards in place (Baum, 2013; Green, 2013; Wilkerson, 2013). This put COP in the difficult position of trying to evaluate a program which, although ostensibly a key part of the policy, did not have any standards by which to measure it (Baum, 2013; Wilkerson, 2013). The result was that while COP did the best it could, COP was not as able as one might have wished to ensure accountability in this area. COP was only able to report generally on this and several other key programs.

Similarly, section 121 of the EESA authorized the creation of SIGTARP (Emergency Economic Stabilization Act of 2008, 2008, p. Sec. 121). SIGTARP was granted broad authority to ensure that the actions of the Secretary of the Treasury or any agencies or private entities receiving TARP funds followed federal law (Emergency Economic Stabilization Act of 2008, 2008, p. Sec. 121). SIGTARP was granted the same authority to subpoena information as any other inspector general, and its recommendations and reports, in theory, carried potential consequences (Emergency Economic Stabilization Act of 2008, 2008, p. Sec. 121). In fact, as of early April 2013, SIGTARP claimed to have successfully prosecuted 91 persons and recovered more than $\$ 3.8$ billion in court ordered restitution (SIGTARP, 2013b).

Nonetheless, SIGTARP got off to a slow start. In all five of the quarterly reports produced during the period primarily covered by this study, SIGTARP wrote that Treasury was either unwilling or unable to comply with its most basic recommendation that recipients of TARP funds fully report on their usage (SIGTARP, 2009, pp. 97-99; SIGTARP, 2009i, pp. 135-137; SIGTARP, 2009c, pp. 186-189; SIGTARP, 2009g, pp. 
165-167; SIGTARP, 2010, pp. 137-140). The reasons behind this refusal were supposedly because such information was either not readily available or because the recipients did not want to provide it (SIGTARP, 2010, p. 139). After much trying, SIGTARP declared a victory of sorts when it got Treasury to report very basic usage of funds information (SIGTARP, 2010, pp. 137-140). In fact, all SIGTARP ended up getting was a basic report on whether or not recipients could have undertaken business as they did without usage of TARP funds, which although arguably important is not perhaps what SIGTARP was looking for (SIGTARP, 2010, pp. 139-140).

In short, even where TARP created accountability structures, they did not have as much power or authority as the public or Congress may have wanted to believe (Baum, 2013; Green, 2013; Wilkerson, 2013). The policy's quick design, leading to an undeveloped approach and a lack of full tool development, left some aspects of accountability lacking. This is not entirely surprising since, as Cooper has routinely observed, emergency situations often result in lowered accountability because the perceived risk to the public of waiting to respond is seen as greater than the risk that funds would not be properly tracked or spent (Cooper P. J., 2003). In a true emergency, the argument goes, what other choice do you really have?

ARRA: A More Typical Stimulus Bill, Attacked the Right Problem and Multiple Models $\underline{\text { Used }}$

As described in chapter four in particular, ARRA was a broad and complex response to one of the worst economic crises in US history. When faced with a decision on how to resolve a problem as daunting as the great recession, ARRA had to be both complex and broad. The following section will discuss and analyze our five main 
findings related to ARRA alone. They are: (1) ARRA was a relatively typical stimulus bill; (2) ARRA attacked something closer to the problem it was originally intended to resolve; (3) accountability was clear and well defined within policy tools; and (4) yet did not address the long-term unemployment issues. This is not an exhaustive list of possible findings but they are the four most important in this case.

\section{A More Typical Stimulus Bill:}

When governments respond to economic crises, they often utilize countercyclical policies. These policies, perhaps most notably favored by Keynesian economics, argue that when the economy is weak, the government should spend more money in order to fill the gap created by a lack of private sector spending (Keynes, 1933). Keynesian economics suggests that this spending should be as broad and as deep as practicable in order to counteract the effects of the downturn (Keynes, 1933).

Although some, such as Krugman, have asserted that ARRA was too small, this is basically what ARRA did. It took a large amount of money ( $\$ 787$ billion), injected into the economy and spread it around broadly. While TARP may have been an atypical approach to the problem that it faced, ARRA was not. ARRA was more of a typical stimulus bill and thus fits more neatly into the categories and methods of analysis applied to such bills.

\section{Attacked Something Closer to the Root of the Problem:}

Similarly, and while TARP can be criticized for attacking the outcomes of the failure to regulate and therefore not attacking the root cause of the crisis, ARRA more closely attacked the problem it was originally meant to resolve. It did so in a number of ways. The following section will address how it did so in relation to each of its three major 
components: tax policy, backfilling state budget holes and direct/indirect spending on new projects.

The tax expenditures in ARRA were designed to provide economic support through broad-based tax benefits to most Americans. Although accountability was lacking, the policy nonetheless was broad, deep and fast, as one would have hoped.

In relation to the backfilling of state budgets, ARRA again addressed the root problem. Although ARRA did not come close to filling all of the gaps created by the economic downturn, it nonetheless addressed a specific portion of the gaps and stopped more significant job loss. Once again, the policy attacked the problem it was originally intended to resolve in this area and did so promptly.

The new direct and indirect federal spending, was designed to create quick jobs, and fund needed infrastructure improvements. One can quibble over how and where this money was spent and whether it was spent well but it did help provide new jobs and quickly inject money into the economy. It certainly was designed, therefore to address the problem of addressing the jobs crisis that was the administration's main concern in relation to ARRA.

In sum, the data show that ARRA did in fact address the right problem, and the problem that it was set out to address. One can rightly quibble with ARRA's design and its size but it is hard to argue that ARRA was not framed to address the right problem. ARRA is therefore different than TARP in this way.

This fact is further emphasized by the fact that the policy tools used were the result of work with the accountability agencies. OMB took great care to make clear how it was doing ARRA work, what tools it was using and how. The tool choice, although quick, 
was clearly intentional, based on known variables and represented a far more organized response than TARP.

\section{$\underline{\text { Accountability Generally Clear and Broad: }}$}

There is no question that accountability is hard to achieve in an emergency. As GAO's Chris Mihm said “The only way to ensure no waste, fraud or abuse in a program is not to spend any money on it. (Mihm \& al, 2013)" Still, unlike TARP, ARRA had clear accountability systems, and there are three primary reasons why.

First was the factor of time; TARP was put together in about two weeks, while ARRA was designed over a period of a few months. While many of the details of ARRA were up in the air until the last minute, it was no secret that President-elect Obama and Congressional Democrats wanted to pass the bill and, as noted in chapter four, had begun negotiating before Obama even took office (Obama, 2009). There was a much more deliberative process for ARRA than for TARP.

Second, the accountability community very forcefully insisted on greater tracking. GAO and others went to the administration before ARRA was passed and insisted on provisions in the law in order to ensure accountability (Mihm \& al, 2013). This led, for example, to the ARRA implementation guidelines being grouped by policy tools, something that made it easier for the accountability agencies to track spending (Office of Management and Budget, 2009; Office of Management and Budget, 2009b). Additionally, GAO was given far more funding to track ARRA than TARP, allowing it to set up field offices to track expenses on the ground and to do a more complete job (Mihm $\&$ al, 2013). This is so even though tax expenditures, fully one third of the bill, had very little accountability. 
Third, the public nature of the spending played a key role in ensuring accountability. While TARP raised constant concerns about how much government should intrude into private enterprise, there was no such concern with ARRA. Nearly all of the spending was undertaken directly by or on behalf of public agencies (Mihm \& al, 2013). These agencies, which provided multiple filters to ensure accountability, were also used to tracking standard spending and thus could do so publicly and effectively (Mihm \& al, 2013). While it is arguable that spending through contractors was harder to track, this spending was still done and tracked via established procedures related to contractors. And unlike TARP, all spending was public.

This is not to say that accountability was always clear for ARRA. Nonetheless, accountability was far more clear and present with ARRA than with TARP.

\section{Failure to Address Long-Term Job Challenges:}

For all that ARRA attacked the current problems of unemployment by trying to increase demand through government spending, it did nothing to address the long-term challenges revealed by the crisis. Very little actually went to solve the jobs problem, either in the short-term or long-term (Krugman P. R., 2012, pp. 120-123). For example, there was no 1930s style WPA program to create broad public works and directly hire the unemployed. In fact, such an approach was never seriously discussed by policymakers and never came close to being included in the final bill (Krugman P. R., 2012, pp. 120123; Stiglitz, 2012, pp. 232-234).

To be fair, it is not entirely clear what could have been done since, as Stiglitz observes, solving the long-term unemployment problem requires a "structural transformation (Stiglitz, 2012, p. 233)." That is to say that globalization has 
fundamentally changed what Americans should be doing in the workforce and therefore the changes in training and time needed to shift many in the American workforce to new types of work was beyond anything a policy of this size could have accomplished. After

all, these problems had been brewing for at least the past few decades and so the idea that ARRA could fix these long-term problems is highly questionable at best. Still, it is worth noting that this policy was not designed to solve these challenges.

\section{CONTRIBUTIONS TO THE LITERATURE AND IMPLICATION FOR FUTURE}

\section{RESEARCH: THEORETICAL AND PRACTICAL CONSIDERATIONS}

The primary research question led to two hypotheses: no single accountability model would fully explain most policy tool choices and utilizing multiple accountability models would result in a more complete picture. This was particularly apt in this case as accountability was a chief concern with regard to both TARP and ARRA. This concern makes drawing connections between accountability models and policy tools clearer. As noted earlier in this chapter, except for one tool choice each in TARP and ARRA, there is clear evidence that a single model does not fully explain policy tool choices and there is equally clear evidence that a multiple models approach is superior.

This study offers several lessons for both accountability and policy tools literature. Consider first the accountability literature. As noted in the literature review in chapter two, there is a tendency by many, especially those who back performance accountability, to assert that their model is the best and only correct model for ensuring accountability. This sort of thinking has led to policies such as the Government Performance and Results Act (GPRA), which is a "one-size-fits-all, government-wide approach to management reform that...does not fit easily into the third hole, the reality of 
policy design and politics (Radin, 2000, p. 127)." Indeed, policies such as the GPRA oversimplify the problem of accountability by assuming that a single model provides the best and only way to understand and ensure it.

This kind of assertion is not limited to performance accountability. Some authors in the political accountability literature, make similar claims for their model. For example, Adsera, Boix, \& Payne argue that "How well government functions hinges on how good citizens are at making their politicians accountable for their actions (Adsera, Boix, \& Payne, 2003, p. 445)." While political accountability and responsiveness are certainly-factors in accountability as a whole, they provide only a part of the overall picture.

The same is true for professional and legal accountability, although there are few who claim that these forms of accountability are sufficient by themselves. As this study has shown, no one model of accountability insufficient to explain complex policy designs such as TARP and ARRA.

Accountability literature therefore needs to consider multiple forms of accountability when deciding how to create and evaluate accountable policies. Although some authors such as Mulgan rightly argue that "accountability is a complex and chameleon-like term (Mulgan, 2000, p. 555)" that encompasses multiple different forms of accountability, including performance, professional and political, he and others do not go far enough (Mulgan, 2000, pp. 555-558). Instead, they claim that external control is still a necessary part of accountability, which it may be in many cases, but it may not be for example in professional accountability since the standards inherit within are internal to the profession (Mulgan, 2000, pp. 555-557). If, instead, we were to understand policies 
with a sensitivity for multiple accountability models this study suggests that we would have a more accurate and complete picture of the policy, the tools it uses, and the ways in which it addresses accountability. This point is particularly relevant in these cases because of the stated focus on accountability in their formulation. A focus on a multiple accountability model approach is therefore essential for the advancement of the literature and practice.

One other important contribution that this study suggests is that too often the accountability literature has focused on implementation or failures rather than paying attention to accountability in designing policies to be accountable in the first place (Romzek \& Dubnik, 1987, pp. 228-230). The accountability literature in public administration, like Romzek and Dubnick's famous piece on the Challenger crisis does a great job describing the organizational breakdowns that lead to that disaster but does not describe how to make organizations accountable in the first place. Accountability is too often reactive, rather than proactive. This study asserts that knowing how to work with the accountability models at the front end in the policy design phase might help design accountable policies in the first place rather than just being reactive.

From a practical perspective, GAO employees told me in interviews that placing the accountability more on the front end of the policy design in ARRA had a significant impact on accountability (Mihm \& al, 2013). By having it be more clearly part of the policy and focusing on real-time, rather than reactive accountability, GAO employees felt it resulted in a different perspective that they feel might be valuable (Mihm \& al, 2013). So therefore, this proactive approach might produce different, and perhaps better, results for accountability in practice as well as in theory. 
This proactive approach is arguably especially important in cases where accountability is a key component of the policy, such as TARP and ARRA, but it is not exclusive to these types of cases. Yet more generally, accountability in policy formulation would seem to be something the literature, and practice, should discuss but does not. This is perhaps one of the more significant contributions of this study. Policy Tools Literature and Practice:

One of the questions this study attempted to answer is how policy tools and accountability models were connected in terms of how the choice of one informed the other. Policy tools literature in general seeks to "highlight the political consequences of particular tools, as well as their underlying assumptions about problems, people and behavior (Sidney, 2006, p. 82)." This study provides evidence that accountability models played a significant part in the choice of a number of particular policy tools chosen for the designs of these two policies. There was certainly consideration of these factors in policy tool selection for both TARP and ARRA. For example, TARP's choice of loans and loan guarantees was a direct response to the assumption that money was needed to be provided in the form of a loan to troubled financial and other institutions. In the case of ARRA, the choice of tax expenditures was a political one grounded in the belief that such an approach was needed in order to get the public to accept the bill. This is not something that is clearly addressed in the existing policy tools literature.

Second, the study suggests something about the relationship between policy tool choice and formulating policy in an extremely stressed policy making in the context of a need for accountability. That is, policy tool choice appears to be impacted by the need to create a policy to solve an immediate problem. More generally, policy tool choice was 
impacted by how the policy problem was framed. Put another way, the way in which the problem definition behind a policy is defined matters. In this case, as Federal Reserve Chairman Ben Bernanke said in late 2008, "You want to put the fire out first and then worry about the fire code. (Simons, 2010, p. 46)" This clearly colored policy tool choice in this case.

More generally, this point that policies created in emergency situations have different tool choices may be new to the literature of policy tools (as Cooper has highlighted for example with contracting) and is it is relatively new to the literature of accountability as well. There is only limited research in this area in either field. Indeed, there exists for example, ample evidence that contract accountability changes in crisis situations. For example, in the case of the Hurricane Katrina response, accountability was a secondary concern to getting supplies and aid out to affected persons as quickly as possible (Koliba, Mills, \& Zia, 2011, pp. 215-217). In this case, the decision not to focus on economic regulation appears to have fallen victim to the definition of the policy problem as needing to solve the immediate causes of the crisis rather than the reasons the crisis happened in the first place.

This point that policies created in emergency situations result in different tool choices is one that the policy tools literature has not explored but should. While it is the case that in only maybe 5\% of cases policy makers operate in an emergency framework, knowing how and why they operate in that framework as they do is important. Learning how and why these decisions differ in these situations is important. Do only the process and outcomes differ or do those making the decisions differ as well? This is arguably particularly important as Congress seems perpetually lurching from crisis to crisis in 
major policy making, whether it is the "fiscal cliff", the debt limit, sequestration or something else. As a result of this, if the literature could examine how and why policymakers utilize policy tools differently in crisis situations is perhaps even more important than previously thought. Regardless, if the goal of policy tools literature is to get at the underlying assumptions behind policy tools, knowing how this and other factors impact how and when these tools are utilized would be important for literature, and invariably practice as well.

In addition, this study argues that incremental policymaking is not without its problems. While Lindbolm and others argue that incremental policy making will slowly but surely solve problems, it does not necessarily do so (Lindblom, 1959, pp. 80-82). In this case, incremental policy making in the area of regulation arguably led to the crisis itself. Perhaps the emergency mindset, rather than the incremental one, would therefore be better to solving big policy problems since you can always pick around the edges once a major policy is in place, but if you only do things incrementally it can be hard to make major changes.

In the case of ARRA, a different dynamic for policy tool choice occurred because GAO and others in the accountability community insisted on being involved in the design of ARRA's implementing regulations (Mihm \& al, 2013). This contrasted with OMB's typical role in such cases, which is to pass down regulations to GAO and others in the accountability community largely without consulting them (Mihm \& al, 2013). This focus on accountability at the front end did have at least some impact on the regulations, most notably in the decision to organize the implementing regulations by policy tool. While it remains unclear as to what impact this decision actually had on the 
accountability design or implementation of ARRA and whether it resulted in better or worse outcomes, it is nonetheless a unique approach for OMB to take and is certainly worth noting here.

\section{Questions for Future Research:}

This study began with the recognition that it presented a number of limitations. In light of the findings of this study, these limitations lead to possible questions for future research, in particular due to concerns about case choice and policy implementation. In addition, this study's findings have also presented additional questions for future research that could certainly prove fruitful.

First, due to the unique nature of both the events that led to the creation of TARP and ARRA as well as TARP and ARRA themselves, it might well be that some of the policy tool choices were atypical. It would therefore be useful in future research to address the question whether policy tool choices differ in cases in which the policy is enacted in times of stress or crisis rather than the normal course of business. For example, how does policy tool choice for the Dodd Frank financial reform bill differ from TARP and ARRA since Dodd Frank underwent a year-long process of committee hearings, policy development and deliberation and what explains the differences between the two types of policies? This is certainly a fertile area of research for policy tools literature and can answer the limitation presented by case choice.

This limitation also brings up two additional interesting questions. Namely, how, if at all, do policy makers consider the relationship between tool choice and accountability models? If so, which policy contexts are more likely to link accountability models and tool choice? The answer to these questions might help us understand why 
and how accountability plays a role in tool choice and policy design in some areas and not others and if it can, or should be, expanded to the areas where it is not currently as linked.

Another potential imitation was the choice to focus on only four of the eight accountability models discussed in this literature review even though that review shows that they are the most widely used models. Further research might therefore look to understand the role that contract, ethical, market and managerial/organizational accountability explain policy tool choices differently than the four models chosen for this study.

A related and fourth a potential limitation of this study was that does not evaluate the effectiveness of the policy tools choice or the resulting policy. This is because the focus of this research was on policy formulation rather than design. Even so, it might be useful to look at policies over time to see how important the relationship between accountability and tool choice in practice during the implementation of the policy. This is not a question that this study can answer, or to be frank anyone can for a few more years at least, but is at the heart of this study to begin with. After all, TARP and ARRA were created to solve the huge problems necessitated by the 2008 economic crisis and it would be helpful to learn how this linkage between policy tools and accountability models changed or did not change during implementation.

One could also ask whether these findings can be extended beyond the American context. For example, could they be applied in a system such as Canada or the UK's that utilizes a parliamentary government and does not put as much trust in federalism? Does legal accountability, in particular, rely on a common law legal system or could these 
findings do just as well in a civil law system? These questions are certainly worth exploring, especially as it comes to evaluating the policy design of the economic recovery packages proposed and implemented by other countries. This is particularly challenging in non-western societies due to the different framework under which they operate. How, for example, did Vietnam or Singapore or Egypt, construct policies in a similar way in emergencies? They are all non-western governments and they are all significantly different from each other both in the formulation of their economies and governments. Regardless, knowing whether these findings hold up in relation to those policies is certainly an area worth pursuing.

CONCLUSION:

In sum, while there are important questions for future research, this study adds to the accountability and policy tools literatures. It shows that a single model approach is insufficient to explain policy tool choice, that a multiple model approach is superior and that there is a connection, at least in these two cases, between policy tools and accountability models. It highlighted the importance of making accountability more proactive than reactive, how the policy problem is framed in tool choice, as well as the important considerations related to emergency policy. It presented many lessons that can be learned from TARP and ARRA, their histories and presented several questions for future research. This study is but one step in the growing fields of accountability and policy tools literature and will hopefully serve as a platform from which much can be learned and future research can be done. After all, something like the events of 2008 will likely occur again sometime in the future. As Mark Twain famously said "History 
doesn't repeat itself, but it does rhyme (Twain, 1903, p. 64)" and we had best be able to respond well when it does. 


\section{References}

Adsera, A., Boix, C., \& Payne, M. (2003). Are You Being Served? Political Accountability and Quality of Government. The Journal of Law, Economics and Organization, 19(2), 445-490.

AFP. (2008, October 3). Economic rescue swiftly signed into law. Retrieved September 5, 2010, from AFP:

http://afp.google.com/article/ALeqM5h40yrrEcqeJEeVRgcrDXB7egDo2A

Ahrens, F. (2008, September 23). Senate Banking Committee Goes After Regulators Past and Present. Retrieved May 15, 2013, from Washington Post: http://voices.washingtonpost.com/livecoverage/2008/09/senate_spanks_regulators _past.html

Alford, R. (2003, January 1). What are the Origins of Fannie Mae and Fredie Mac. Retrieved May 15, 2013, from History News Network: http://hnn.us/articles/1849.html

Aristotle. (350 BCE). Politics. Retrieved March 1, 2009, from MIT Classics Archive: http://classics.mit.edu/Aristotle/politics.html

Aristotle. (350 BCE, January 1). The Nicomachean Ethics. Retrieved February 10, 2011, from Internet Classics Archive: http://classics.mit.edu/Aristotle/nicomachaen.html

ARRA. (2009, Febuary 17). American Recovery and Reinvestment Act of 2009. PL 11102. 
Associated Press. (2008, November 15). Bush Names Bailout Overseer. LA Times.

Associated Press. (2009, Feburary 10). Obama: Stimulus Needed to Avoid Catastrophe. Associated Press.

Baker, P. (2009, January 23). Washington Confident It Can Forge Recovery Plan . Retrieved September 5, 2010, from NY Times: http://www.nytimes.com/2009/01/24/washington/24econcnd.html

Barth, J. (1991). The Great Savings and Loan Debacle. Washington, DC: AEI Press.

Baum, N. (2013, February 11). Accountability in relation to TARP. (D. Jarvis, Interviewer)

BBC. (2002, November 20). Enron: Timeline. Retrieved May 15, 2013, from BBC: http://news.bbc.co.uk/hi/english/static/in_depth/business/2002/enron/timeline/1.st $\mathrm{m}$

Bean, D. R., \& Conlan, T. J. (2002). Grants. In L. Salamon, The Tools of Government: A Guide to the New Governance (pp. 340-380). New York: Oxford Univeristy Press.

Behn, R. D. (2001). Rethinking Democratic Accountability. Washington, DC: Brookings Institution Press.

Behn, R. D. (2002, September). The Pyschological Barriers to PerformanceManagement: Or Why Isn't Everyone Jumping on the Performance-Management Bandwagon? Public Performance and Management Review, 26(1), 5-25. 
Bernanke, B. (2008, September 23). Statement of Ben Bernake Before the Committee on Banking, Housing and Urban Affairs.

Board of Governors of the Federal Reserve System. (2008, September 16). Press Release. Retrieved May 15, 2013, from Board of Governors of the Federal Reserve System: http://www.federalreserve.gov/newsevents/press/other/20080916a.htm

Board of Governors of the Federal Reserve System. (2008b, September 16). Press Release. Retrieved May 15, 2013, from Federal Reserve Board: http://www.federalreserve.gov/newsevents/press/other/20080916a.htm

Boone, C., Dube, A., \& Kaplan, E. (2014, January 29). The Political Economy of Discretionary Spending: Evidence from the American Recovery and Reinvestment Act. Retrieved from University of Maryland: http://econweb.umd.edu/ kaplan/PEStimulus.pdf

Boyd, J. H., Gomis, P., Kwak, S., \& Smith, B. D. (2000). A Users Guide to Banking Crises. Washington, DC : World Bank.

Breyer, S. (2005). Active Liberty: Interpreting Our Democratic Constitution. New York: Knopf.

Bureau of Ecnomic Analysis. (2013). GDP Growth by Year. Washington, DC : Bureau of Economic Analysis.

Bureau of Labor Statistics. (2009, June 21). Industries at a Glance. Retrieved May 15, 2013, from Bureau of Labor Statistics: http://www.bls.gov/iag/ 
Bureau of Labor Statistics. (2013, August 3). Graph: Unemployment Rate (Seasonally Adjusted). Retrieved August 3, 2013, from Bureau of Labor Statistics: http://data.bls.gov/timeseries/LNS14000000

Bureau of Labor Statistics. (2013b). Productivity and Average Family Income. Washington, DC: Bureau of Labor Statistics.

Burns, H. M. (1974). The Ameircan Banking Community and New Deal Banking Reforms. Westport, CT: Greenwood Press.

Carlson, M. (2007). A Brief History of the 1987 Stock Market Crash with a Discussion of the Federal Response. Washington, DC: Federal Reserve Board.

Cato Institute. (2009, February 9). Cato Institute. Retrieved May 15, 2013, from Cato Institute: http://www.cato.org/sites/cato.org/files/documents/cato_stimulus.pdf

Cato Institute. (2009, January 28). Cato Institute Stimulus Ad. Retrieved from Cato Institute: http://www.cato.org/sites/cato.org/files/documents/cato_stimulus.pdf

Center for American Progress Action Fund. (2009, January 27). Center for American Progress. Retrieved May 15, 2013, from Center for American Progress: http://www.americanprogressaction.org/issues/economy/news/2009/01/27/5490/le tter-to-congress-economists-across-the-spectrum-endorse-stimulus-package/

Chevron U.S.A., Inc. v. Natural Resources Defense Council, Inc., 467 U.S. 837 (Supreme Court of the United States February 29, 1984). 
Christensen, R. K. (2009, June). Running the Constitution: Framing Public Administration. Public Performance and Management Review, 32(4), 599-604.

Chubb, J. E., \& Moe, T. M. (1988, December). Poltiics, Markets and the Organization of Schools. American Political Science Review, 82(4), 1065-1087.

Clerk of the US House. (1999, November 4). Final Results for Roll Call 570. Retrieved from Clerk of the US House: http://clerk.house.gov/evs/1999/roll570.xml

Clerk of the US House. (2008, September 29). Final Vote Results from Roll Call 674. Retrieved May 15, 2013, from Clerk of the US House: http://clerk.house.gov/evs/2008/roll674.xml

Clerk of the US House. (2008b, October 3). Final Vote Results for Roll Call 681. Retrieved May 15, 2013, from Clerk of the US House: http://clerk.house.gov/evs/2008/roll681.xml

Clerk of the US House. (2009, January 28). Final Vote Results for Roll Call 46. Retrieved May 15, 2013, from Clerk of the US House: http://clerk.house.gov/evs/2009/roll046.xml

Clerk of the US House. (2009b, February 13). Final Vote Results for Roll Call 70. Retrieved May 15, 2013, from Clerk of the US House: http://clerk.house.gov/evs/2009/roll070.xml 
Clinton, W. J. (1999, November 12). Statement on Signing the Graham-Leach-Bliley Act. Retrieved from The American Presidency Project: http://www.presidency.ucsb.edu/ws/?pid=56922

Clinton, W. J. (1999b, November 12). Clinton remarks at Financial Modernization Act signing.

Cochrane, J. (2010). Lessons from the Financial Crisis. Regulation, 34-37.

Cody, B. (2013, February 12). The Congressional Research Service's Role in ARRA Accountability. (D. S. Jarvis, Interviewer)

Cole, R. A., McKenzie, J. A., \& White, L. J. (1995). The Causes and Costs of Depository Institution Failures. New York: Springer Publishing.

Condon, C. (2008, September 16). Reserve Primary Money Fund Falls Below $\$ 1$ a Share . Retrieved May 15, 2013, from Bloomberg News: http://www.bloomberg.com/apps/news?pid=newsarchive\&sid=a5O2y1go1GRU

Conference Commtitee on HR 1 (2009). (2009). House Report 111-016. Washington, DC: Conference Commmittee on HR 1 (2009).

Congressional Budget Office. (2009). Cost Estimate of HR 1. Washington: Congressional Budget Office.

Congressional Oversight Panel. (2009, January 9). Accountability for TARP. Retrieved September 20, 2009, from http://cop.senate.gov/reports/library/report-010909cop.cfm 
Congressional Oversight Panel. (2009b). Guarantees and Contingent Payments in TARP Related Programs. Congressional Oversight Panel.

Congressional Oversight Panel. (2009c). An Assessment of Foreclosure Mitigation Efforts After Six Months. Congressional Oversight Panel.

Congressional Oversight Panel. (2009d). Reviving Lending to Small Business and Families and the Impact of TALF. Congressional Oversight Panel.

Congressional Oversight Panel. (2009e). Foreclosure Crisis: Working Towards a Soltuion. Washington: Congressional Oversight Panel.

Congressional Oversight Panel. (2009f). TARP Repayments, Including the Repuchase of Stocke Warrants. Congressional Oversight Panel.

Congressional Oversight Panel. (2009g, December 1). Congressional Oversight Panel. Retrieved December 1, 2009, from http://cop.senate.gov/

Congressional Record. (2009, January 28). AMERICAN RECOVERY AND REINVESTMENT ACT OF 2009 -- (House of Representatives - January 28, 2009). Congressional Record, 111th Congress (2009-2010). Washington, DC.

Congressional Record. (2009b, February 13). AMERICAN RECOVERY AND REINVESTMENT ACT OF 2009--CONFERENCE REPORT -- (Senate February 13, 2009). Congressional Record. Washington, DC.

Congressional Research Service. (2009). Summary of HR 1 (2009) as Public Law. Washington, DC: Congressional Research Service. 
Congressional Research Service. (2009b). HR 1, Conference Report Filed in House. Washington: Congressional Research Service.

Congressional Research Service. (2009c). Summary of HR 1 (2009) passed as amended by the US House. Washington, DC: Congressional Research Service.

Cooper, P. J. (2003). Governing by Contract: Challenges and Opportunities for Public Managers. Washington, DC: CQ Press.

Cooper, P. J. (2007). Public Law and Public Administration (4th ed.). Belmont, CA: Thomson Wadsworth.

Cooper, P. J. (2009). The War Against Regulation: From Jimmy Carter to George W Bush. Lawrence, KS: University of Kansas Press.

Cooper, T. L. (2006). The Responsible Administrator: An Approach to Ethics for the Administrative Role (Fifth ed.). San Francisco: Jossey-Bass.

Cox, C. (2008, September 23). Testimony of Christopher Cox to the Committee on Banking, Housing and Urban Affairs. Washington, DC.

Crawford, P., \& Bryce, P. (2001). "Project Monitoring and Evaluation: A Tool for Enhancing the Efficiency and Effectiveness of Aid Project Implementation. International Journal of Project Management, 21, 363-373.

Crippen, D. (2001, May 23). Statement of Dan L Cippen Director. Retrieved May 15, 2013, from Congressional Budget Office: 
http://www.cbo.gov/sites/default/files/cbofiles/ftpdocs/28xx/doc2839/gsetestimony.pdf

DeLeon, L. (1998, Autumn). Accountability in a Reinvented Government. Public Administration, 76(3), 539-558.

Doardo, G. (2009, January 14). A Framework for Crafting and Assessing Proposals to Modernize the Outdated US Financial Regulatory System. Testimony to Congress GAO Testimony 09-314T. Washington, DC.

Doardo, G. L. (2009b, March 5). Statement of Gene L Doardo Before the Commitee on Homeland Security and Government Affairs, US Senate. Washington, DC.

Downs, A. (1965, March). A Theory of Bureaucracy. The American Economic Review, 55(1-2), 439-446.

Downs, A. (1967). Inside Bureaucracy. Boston: Little, Brown and Company.

Economist. (2000, Aguust 3). Europe's Dot Bombs. Economist.

Emergency Economic Stabilization Act of 2008. (2008, October 3). Emergency

Economic Stabilization Act of 2008. Retrieved May 15, 2013, from US

Government Printing Office: http://www.gpo.gov/fdsys/pkg/BILLS-

110hr1424enr/pdf/BILLS-110hr1424enr.pdf

ExpectMore.gov. (2009, March 1). About Us. Retrieved March 1, 2009, from

ExpectMore.gov: http://www.whitehouse.gov/omb/expectmore/about.html 
Federal Housing Authority. (2009). Making Home Affordable Program. Federal Housing Authortiy.

Federal Reserve Board. (2013, August 2). Open Market Operations Archive. Retrieved August 2, 2013, from Federal Reserve Board: http://www.federalreserve.gov/monetarypolicy/openmarket_archive.htm

Fenno, R. (1978). Home Style: House Members in Their Districts. Boston: Little Brown.

Financial Crisis Inquiry Commission. (2011). Financial Crisis Inquiry Commission Report. Washington, DC: Financial Crisis Inquiry Commision.

Finer, H. (1941). Administrative Responsibility in Democratic Government. Public Administration Review, 1(4), 335-350.

Fletcher, J. (1965). Situation Ethics: The New Morality. Philadelphia: The Westminster Press.

Flyvbjerg, B. (2006, April). Five Misunderstandings about Case Study Research. Qualitative Inquiry, 12(2), 219-245.

Fong, P. K. (2009, March 5). Statement of the Honorable Phyllis K Fong, Inspector General Before the Committee on Homeland Seucrity and Government Affairs, United States Senate. Washington, DC.

Freidman, M., \& Schwartz, A. J. (1993). A Monetary History of the United States: 18671960 (Ninth ed.). Princeton, NJ: Princeton University Press. 
Friedrich, C. J., Beyer, W. C., Spero, S. D., Miller, J. F., \& Graham, G. A. (1935). Problems of the American Public Service. New York, NY: McGraw-Hill Book Company, Inc.

Gilliam, S., \& Martin, J. D. (2007, December). Corporate Governance Post-Enron: Effective Reforms, or Closing the Stable Door? Journal of Corporate Finance, 13(5), 929-958.

Gilmour, R. S., \& Jensen, L. S. (1998, May/June). Reinventing Govenrment Accountability: Public Functions, Privatization and the Meaning of State Action. Public Administration Review, 58(3), 247-258.

Glater, J. D. (1995, February 28). Rubin urges changes in U.S. banking laws; Treasury chief would end curbs on competition. Washington Post, p. C1.

Goldfarb, Z. A., Cho, D., \& Appelbaum, B. (2007, September 7). Treasury to Rescue Fannie and Freddie: Regulators Seek to Keep Firms' Troubles From Setting Off Wave of Bank Failures. Washington Post, p. A1.

Gore, A. (1995). Common Sense Government. Works Better and Costs Less: Third Report of the Natioanl Performance Review. Washington: National Performance Review.

Government Accountability Office. (2009, September 20). Follow the Money: GAO's Oversight of the Recovery Act. Retrieved September 20, 2009, from http://www.gao.gov/recovery/ 
Government Accountability Office. (2009b). Status of Government Financial Asisstance Provided to AIG. Government Accountability Office.

Government Accountability Office. (2009c). Troubled Asset Relief Program: The US Government as Shareholder. Government Accountability Office.

Government Accountability Office. (2009d). Recovery Act: Contract Oversight Activities of the Recovery Accountability and Transparency Board and Observations on Contract Spending in Selected States. Washington, DC: Government Accountability Office.

Government Accountability Office. (2009e). Summary of Government Efforts and Automakers' Restructuring to Date. Washington: Government Accountability Office.

Government Accountability Office. (2009f). States and Localities' Current and Planned Use of Funds While Facing Fiscal Stresses. Washington, DC: Government Accountability Office.

Government Accountability Office. (2009g). GAO's Efforts to Work with the Accountabiility Community to Help Ensure Effective and Efficient Oversight. Washington, DC: Government Accountability Office.

Government Accountability Office. (2009h). GAO's Role in Helping to Ensure Accountability and Transparency. Washington, DC: Government Accountability Office. 
Government Accountability Office. (2009i). Recipient Reported Job Data Provide Some Insight Into Use of Recovery Act Funding but Data Quality and Reporting Issues Need Attention. Washington, DC: Government Accountability Office.

Government Accountability Office. (2009k). As Initial Implementation Unfolds in States and Localities, Continued Attention to Accountability Issues in Essential. Washington, DC: Government Accountabiilty Office.

Government Accountability Office. (20091). Grants Management: Grants.gov has Systematic Weaknesses that Require Attention. Washington, DC: Government Accountability Office.

Government Accountability Office. (2010). IRS Quickly Implemented Tax Provisions but Reporting and Enforcement Improvemens are Needed. Washington, DC: Government Accountability Office.

Government Accountability Office. (2010b). One Year Later, States and Localities' Use of Funds to Strengthen Accountability. Washington, DC: Government Accountability Office.

Government Accountability Office. (2010c). Project Selection Starts are Influenced by Certain Federal Requirements and Other Factors. Washington, DC: Government Accountability Office. 
Government Accountability Office. (2013). Troubled Asset Relief Program: Status of GAO Recommendations to Treasury. Washington, DC: Government Accountability Office.

Green, A. (2013, February 11). US Senate's Role in TARP Accountability. (D. Jarvis, Interviewer)

Greenberger, M. (2010, June 30). Testimony of Michael Greenberger Before the Financial Crisis Inquiry Commission. Retrieved from MichaelGreenberger.com: http://www.michaelgreenberger.com/files/FCICMichael_Greenberger_Testimony.pdf

Grossman, R. (1992, September). Deposit Insurance, Regulation, and Moral Hazard in the Thrift Industry: Evidence from the 1930's. The American Economic Review, $82(4), 800-821$.

Gulick, L., \& Urwick, L. (1937). Papers on the Science of Administration. Washington, DC: Insitute of Public Administration.

Gullapalli, D., \& Annand, S. (2008, September 20). Bailout of Money Funds Seems to Stanch Outflow. Retrieved May 15, 2013, from Wall Street Journal: http://online.wsj.com/article/SB122186683086958875.html

Hamilton, A., Jay, J., \& Madison, J. (1787-1788, Various 1). The Federalist Papers. Retrieved July 28, 2008, from The Federalist Papers: http://www.foundingfathers.info/federalistpapers/ 
Heer, J. (2009, March 19). Testimony of Jerome Heer, Director of Audits for Milwaukee County, WI Before the House Commitee on Oversight and Government Reform. Washington, DC.

Hellman, T. F., Murdock, K. C., \& Stiglitz, J. E. (2000, March). Liberalization, Moral Hazard in Banking, and Prudential Regulation: Are Capital Requirements Enough? The American Economic Review, 90(1), 147-165.

Hendrickson, J. M. (2001). The Long and Bumpy Road to Glass-Steagall Reform: A Historical and Evoluntionary Analysis of Banking Legislation. American Journal of Economics and Sociology, 60(4), 849-879.

Hirschfeld Davis, J. (2008, September 29). Bailout bill slapped aside; record stock plunge. Retrieved May 15, 2013, from Yahoo News: http://web.archive.org/web/20081003021448/http://news.yahoo.com/s/ap/200809 29/ap_on_bi_ge/financial_meltdown

Holland, W. G. (2009, March 19). Testimony of William G. Holland, Illinois Auditor General Before the Commitee on Oversight and Government Reform. Washington, DC.

Hoover, K. (2010, June 14). Political contributors get bigger stimulus deals. Retrieved from The Business Journals: http://www.bizjournals.com/bizjournals/washingtonbureau/2010/06/14/bureau6.ht $\mathrm{ml}$ 
Howard, C. (2002). Tax Expenditures. In L. M. Salamon, The Tools of Government: A Guide to the New Governance (pp. 410-444). New York: Oxford University Press.

HR 1. (2009, January 26). HR 1. Retrieved from http://thomas.loc.gov/cgibin/query/D?c111:2:./temp/ c111bQIhBO::

Hughes Aircraft Company v. United States, 520 U.S. 939 (United States Supreme Court June 16, 1997).

Hulse, C. (2008, October 1). Pressure Builds on House After Senate Backs Bailout. New York Times, p. A1.

Insurance Journal. (2004, November 24). AIG Forks Up \$126 Million to SEC on PNC Deals. Retrieved May 15, 2013, from Insurance Journal: http://www.insurancejournal.com/news/national/2004/11/24/47993.htm

Investment Company Institute. (2008, September 18). Money Market Fund Assets.

Retrieved May 15, 2013, from Investment Company Institute: http://www.ici.org/research/stats/mmf

Isidore, C. (2008, September 29). Bailout plan rejected - supporters scramble. Retrieved May 15, 2013, from CNN : http://money.cnn.com/2008/09/29/news/economy/bailout/

Jackson, M. (2009). Responsibility versus Accountability in the Friedrich-Finer Debate. Journal of Management History, 15(1), 66-77. 
Janis, I. L. (1972). Victims of Groupthink: A Psychological Study of Foreign-Policy Decisions and Fiascoes. Boston: Houghton Mifflin Company.

Jickling, M. (2010). Causes of the Financial Crisis. Washington, DC: Congressional Research Service.

Kassel, D. S. (2008, March/April). Performance, Accountability and the Debate over Rules. Public Administration Review, 68(2), 241-252.

Kelman, S. J. (2002). Contracting. In L. M. Salamon, The Tools of Government: A Guide to the New Governance (pp. 282-318). New York: Oxford University Press.

Kennedy, S. E. (1973). The Banking Crisis of 1933. Lexington, KY: University Press of Kentucky.

Keyes, W. N. (2000). Government Contracts in a Nutshell (Fourth Ed. ed.). St. Paul, MN: Thomson West.

Keynes, J. (1933, December 31). Open Letter to President Roosevelt. New York Times.

Kimmel, P. D., Kieso, D. E., \& Weygandt, J. J. (2009). Financial Accounting (Sixth ed.). Hoboken, NJ: Wiley.

Koliba, C. J., Mills, R. M., \& Zia, A. (2011). Accountability in Governance Networks: An Assessment of Public, Private, and Nonprofit Emergency Management Practices Following Hurricane Katrina. Public Administration Review, 71(2), 210220. 
Koppell, J. G. (2001, July/August). Hybrid Organizations and the Alignment of Interests: The Case of Fannie Mae and Freddie Mac. Public Administration Review, 61(4), 468-482.

Krugman, P. (2009, January 9). The Obama Gap. New York Times, p. A27.

Krugman, P. R. (2012). End This Depression Now. WW Norton and Company: New York.

Laing, J. L. (2005, June 20). The Bubble's New Home. Retrieved October 1, 2010, from Barron's Online: http://www.4sarasotahomes.com/images/6-20-05BarronsBubble.pdf

Lenan, C. K. (2002). Direct Government. In L. Salamon, The Tools of Government: A Guide to the New Governance (pp. 48-79). New York: Oxford University Press.

Levitan, D. M. (1946, December). The Responsibility of Administrative Officials in a Democratic Society. Poltiical Science Quarterly, 61(4), 562-598.

Lindblom, C. E. (1959, Spring). The Science of Muddling Through. Public Administration Review, 19(2), 79-88.

Locke, J. (1689, January 1). The First Treatise of Government. Retrieved February 25, 2010, from The Online Library of Liberty: http://oll.libertyfund.org/Texts/Locke0154/TwoTreatises/0057_Bk.html\#hd_lf057 .head.016-141 
Lockhart, J. B. (2008, September 7). Statement of James B. Lockhart. Retrieved May 15, 2013, from Federal Housing Finance Agency: http://www.fhfa.gov/PageError.htm?aspxerrorpath=/newsroom.aspx

Long, N. E. (1952). Bureaucracy and Constitutionalism. The American Political Science Review, 46(3), 808-818.

Long, N. E. (1954, Winter). Public Policy and Administration: The Goals of Rationality and Responsibility. Public Administration Review, 14(1), 22-31.

Lowenstein, R. (2003). Origins of the Crash: The Great Bubble and Its Undoing. New York: Penguin Books.

Makinen, G. (2002). The Economic Effects of 9/11: A Retrospective Assessment. Washington, DC: Congressional Research Service.

Markham, J. W. (2010). The Subprime Crisis-A Test Match For The Bankers: GlassSteagall vs. Gramm-Leach-Bliley. University of Pennsylvania Journal of Business Law, 12(4), 1092-1134.

Mason, D. (2010, February 1). Savings and Loan Industry. Retrieved May 15, 2013, from Economic History Association: http://eh.net/encyclopedia/article/mason.savings.loan.industry.us

Massachusetts v. Environmental Protection Agency, 549 U.S. 497 (Supreme Court of the United States April 2, 2007). 
Mayhew, D. (2004). Congress: The Electoral Connection. New Haven: Yale University Press.

McKnees, S. K. (1992). The 1990-91 Recession in Historical Persepctive. Washington, DC: Federal Reserve Board.

Mihm, C., \& al, E. (2013, February 13). GAO's Role in Accountability for TARP and ARRA. (D. Jarvis, Interviewer)

Mintzberg, H. (1983). Structure in Fives: Designing Effective Organizations. Upper Saddle River, NJ: Prentice-Hall, Inc.

Mirron, J. (2008, October 14). Why This Bailout is as Bad as the Last One. Retrieved from CNN News: http://www.cnn.com/2008/POLITICS/10/14/miron.banks/

Moe, R. C. (1987, November-December). Exploring the Limits of Privatization. Public Administration Review, 47(6), 453-460.

Moe, R. C., \& Gilmour, R. S. (1995, March-April). Rediscovering Principles of Public Administration: The Neglected Foundation of Public Law. Public Administration Reivew, 55(2), 135-146.

Moe, T. M. (2002). Poltiics, Control and the Future of School Accountability. Taking Account of Accountability (pp. 1-28). Boston: Kennedy School of Government, Harvard University.

Morgenson, G. (2008, September 27). Behind Insurer's Crisis, Blind Eye to a Web of Risk. New York Times, p. A1. 
Mulgan, R. (2000, Autumn). Accountability: An Ever-Expanding Concept? Public Administration, 78(3), 555-573.

Mullins, L. (2008, September 23). Chris Dodd: Economy and Constitution at Risk. Retrieved May 15, 2013, from US News and World Report: http://money.usnews.com/money/blogs/the-home-front/2008/09/23/chris-doddeconomy-and-constitution-at-risk

Neuman, S. (2008, December 19). Bush Sets \$17.4 Billion in Loans to Automakers. Retrieved September 20, 2013, from NPR News: http://www.npr.org/templates/story/story.php?storyId=98498125

New York Times. (2009, September 2009). Tracking the $\$ 700$ Billion Bailout. Retrieved September 20, 2009, from http://projects.nytimes.com/creditcrisis/recipients/table

Obama, B. H. (2009, January 8). Obama's Speech on the Econmy. New York Times, p. A1.

Obama, B. H. (2009b, January 20). Text of Obama's Inaugural Speech. Retrieved March 1, 2009, from MSNBC: http://www.msnbc.msn.com/id/28751183/

Obama, B. H. (2009c, February 25). Full Text of Obama's Speech to Congress. Retrieved March 1, 2009, from The Guardian Unlimited: http://www.guardian.co.uk/world/2009/feb/25/full-text-barack-obama-congressaddress

OECD. (1997). Regulatory Reform: A Synthesis. Paris, France: OECD. 
Office of Financial Stability. (2014, January 15). Office of Financial Stability-TARP Programs. Retrieved from Treasury.gov: http://www.treasury.gov/initiatives/financial-stability/TARPPrograms/Pages/default.aspx

Office of Management and Budget. (2009). Initial Reporting Act Guidance. Washington, DC: Office of Management and Budget.

Office of Management and Budget. (2009b). Updated Implementing Guidance for the American Recovery and Reinvestment Act of 2009. Washington, DC: Office of Management and Budget.

Office of Management and Budget. (2009c). Implementing Guidance for the Reports of Use of Funds Pursuant to the American Recovery and Reinvestment Act of 2009. Washington, DC: Office of Management and Budget.

Office of Management and Budget. (2009d, September 11). Improving Recovery Act Recipient Reporting. Retrieved September 30, 2009, from http://www.whitehouse.gov/omb/assets/agencyinformation_memoranda_2009_pd f/m09-30.pdf

Office of Management and Budget. (2011, November 2). News from OFPP. Retrieved August 3, 2013, from Office of Management and Budget: http://www.whitehouse.gov/blog/2011/11/02/news-ofpp 
Office of the Comptroller of the Currency. (2013, June 12). Derivatives . Retrieved from Office of the Comptroller of the Currency: http://www.occ.gov/topics/capitalmarkets/financial-markets/trading/derivatives/index-derivatives.html

Office of the Inspector General for the USDA. (2009). Oversight of Agency Impemention of the American Recovery and Reinvestment Act of 2009. Washington, DC : USADA IG.

Oregon's Senator Jeff Merkley. (2014, January 29). Education. Retrieved from Oregon's Senator Jeff Merkley: http://www.merkley.senate.gov/issues/issue/?id=bec2549820b8-446a-9191-c779157a8238

Ostrom, V. (2008). The Intellectual Crisis in American Public Administration (Third ed.). Tuscaloosa, AL: The University of Alabama Press.

Paulson, H. M. (2008, September 7). Statement by Secretary Henry M. Paulson, Jr. on Treasury and Federal Housing Finance Agency Action to Protect Financial Markets and Taxpayers. Retrieved May 15, 2013, from US Department of the Treasury: http://www.treasury.gov/press-center/press-releases/Pages/hp1128.aspx

Paulson, H. M. (2008b, September 23). Testimony by Henry Pauslon Before the Senate Banking Committee. Washington, DC.

Pear, R. (2008, October 1). Crisis Puts Tax Moves in Play. Retrieved September 5, 2010, from NY Times: http://www.nytimes.com/2008/10/02/business/02tax.html?_r=1 
Perrow, C. (1986). Complex Organizations: A Critical Essay (Third ed.). New York: Random House Publishing.

Pickert, K. (2008, July 14). A Brief History of Fannie Mae and Freddie Mac. Time Magazine.

Pope, C. (2011, July 14). Reps. Greg Walden, Peter DeFazio wade into treacherous waters to save county timber payments. Oregonian, p. A1.

Price, T. L. (2006). Understanding Ethical Failures in Leadership. New York: Cambridge University Press.

Radin, B. A. (2000). The Government Performance and Results Act and the Tradition of Management Reform: Square Pegs in Round Holes? Journal of Policy Research and Theory, 10, 111-135.

Radin, B. A. (2006). Challenging the Performance Movement: Accountability, Complexity and Democratic Values. Washington, DC: Georgetown University Press.

Recovery.gov. (2009, September 20). Accountability. Retrieved September 20, 2009, from http://www.recovery.gov/Accountability/Pages/Accountability.aspx

Recovery.gov. (2009b, September 20). The Recovery Accountability and Transparency Board. Retrieved September 20, 2009, from http://www.recovery.gov/About/board/Pages/TheBoard.aspx 
Recovery.gov. (2009c, November 25). Recovery.gov. Retrieved November 25, 2009, from Recovery.gov: http://www.recovery.gov/Pages/home.aspx

Recovery.gov. (2010, February 10). Accountability. Retrieved May 15, 2013, from Recovery.gov:

http://www.recovery.gov/Accountability/Pages/Accountability.aspx

Recovery.gov. (2010b, March 13). Overview of Funding. Retrieved May 15, 2013, from Recovery.gov: http://www.recovery.gov/pages/textview.aspx?List=\%7BEB595CCA-D93F48F4-AF9611E2D41DE73D\%7D\&xsl=FundingOverview/FundingOverviewChartTextView. xsl

Recovery.gov. (2010c, October 26). The Recovery Act. Retrieved November 3, 2010, from Recovery.gov: http://www.recovery.gov/About/Pages/The_Act.aspx

Reinhart, C. M., \& Rogoff, K. S. (2009). The Aftermath of Financial Crises. American Economic Review, 99(2), 466-472.

Reiss, D. J. (2008, July). The Federal Government's Implied Guarantee of Fannie Mae and Freddie Mac's Obligations: Uncle Sam Will Pick Up the Tab. Georgia Law Review, 42, 1022-1081.

Rogoff, K. (2008, September 18). America will need a \$1,000bn bail-out. Financial Times. 
Rohr, J. A. (1986). To Run a Constitution: The Legitimacy of the Administrative State. Lawrence, KS: University Press of Kansas.

Rohr, J. A. (1989). Ethics for Bureaucrats: An Essay on Law and Values (Second ed.). New York: Marcel Dekker.

Romer, C., \& Bernstein, J. (2009). The Job Impact of the American Recovery and Reinvestment Plan. Washington, DC: Office of President-Elect Barack Obama.

Romzek, B. S., \& Dubnick, M. J. (1987, May/June). Accountability in the Public Sector: Lessons from the Challenger Tragedy. Public Admnistration Review, 227-238.

Romzek, B. S., \& Ingraham, P. W. (2000). Cross Pressures of Accountability: Initative, Command and Failure in the Ron Brown Plane Crash. Public Administratoin Review, 60(3), 240-253.

Rose, A. K., \& Spiegel, M. M. (2009). Cross-Country Causes and Consequences of the 2008 Crisis: Early Warning. San Francisco: Federal Reserve Bank of San Francisco.

Rosenbloom, D. H., \& Piotrowski, S. J. (2005, June). Outsourcing the Constitution and Administrative Law Norms. American Review of Public Administration, 35(2), $103-121$.

S 1. (2009, January 6). S. 1 as Introduced. Retrieved May 15, 2013, from THOMAS: http://thomas.loc.gov/cgi-bin/query/z?c111:S.1.PCS: 
Salamon, L. M. (2001). The New Governance and the Tools of Public Action: An Introduction. Fordham Urban Law Journal, 1611-1675.

Salamon, L. M. (2002). The Tools of Government: A Guide to the New Governance. New York: Oxford University Press.

Samuelson, R. J. (2010, July 12). The Great Recession's stranglehold. Retrieved September 1, 2010, from The Washington Post: http://www.washingtonpost.com/wpdyn/content/article/2010/07/11/AR2010071103038.html

Savas, E. (2000). Privatization and Public-Private Partnerships. New York: CQ Press.

Schneider, A., \& Ingram, H. (1990, May). Behavioral Assumptions of Policy Tools. The Journal of Politics, 52(2), 510-529.

Seidman, L. W. (2000). Full Faith and Credit: The Great $S \&$ L Debacle and Other Washington Sagas. Frederick, MD: Beard Books.

Seidman, W. L. (1996, September 18). Lessons of the Eighties: What Does the Evidence Show. Retrieved September 5, 2010, from Federal Deposit Insurance Corporation: http://www.fdic.gov/bank/historical/history/vol2/panel3.pdf

Shoven, J., Smart, S. B., \& Waldfogel, J. (1991). Real Interest Rates and the Savings and Loan Crisis: The Moral Hazard Premium. Cambridge, MA: National Bureau of Economic Research. 
Sidney, M. S. (2006). Policy Formulation: Design and Tools. In F. Fischer, \& G. J. Miller, Handbook of Public Policy Analysis: Theory, Politics, and Methods (pp. 78-87). Boca Raton, FL: CRC Press.

SIGTARP. (2009, February 6). Initial Report to the Congress. Retrieved September 20, 2009 , from http://www.sigtarp.gov/reports/congress/2009/SIGTARP_Initial_Report_to_the_ Congress.pdf

SIGTARP. (2009b). Emergency Capital Injections Provided to Support the Viability of Bank of America, Other Banks and the US Financial System. SIGTARP.

SIGTARP. (2009c). Quarterly Report to Congress-July. Washington, DC : SIGTARP.

SIGTARP. (2009d). Treasury's Monitoring of Compliance with TARP Requirements for Companies Recieving Exceptional Assistance. SIGTARP.

SIGTARP. (2009e, December 1). Office of the Special Inspector General for the Troubled Asset Relief Program. Retrieved December 1, 2009, from http://www.sigtarp.gov/index.shtml

SIGTARP. (2009f). Opportunities to Strengthen Control to Avoid Undue External Influence Over Capital Purchase Program Deicsion-Making. SIGTARP.

SIGTARP. (2009g). Quarterly Report to Congress-October. Washington, DC: SIGTARP. 
SIGTARP. (2009h). Survey Demonstrates that Banks Can Provide Meaningful Information on their Use of TARP Funds. SIGTARP.

SIGTARP. (2009i). Quarterly Report to Congress-April. Washington, DC: SIGTARP.

SIGTARP. (2010). Assessing Treasury's Proces to Sell Warrants Recieved from TARP Recipients. SIGTARP.

SIGTARP. (2010b, October 26). Quarterly Report to Congress-Ocotber 26, 2010. Retrieved November 3, 2010, from SIGTARP: http://www.sigtarp.gov/reports/congress/2010/October2010_Quarterly_Report_to _Congress.pdf

SIGTARP. (2012, October 22). BANK OF AMERICA SUED FOR OVER \$1 BILLION FOR MULTI-YEAR MORTGAGE FRAUD AGAINST FANNIE MAE AND FREDDIE MAC. Retrieved from SIGTARP: http://www.sigtarp.gov/press\%20releases/bac_complaint_press_release.pdf

SIGTARP. (2013, April 24). Reports and Audits. Retrieved May 15, 2013, from Office of the Special Inspector General for the Troubled Asset Relief Program: http://www.sigtarp.gov/pages/reportsaudits.aspx

SIGTARP. (2013b, April 30). SIGTARP Investigative Outcomes. Retrieved June 20, 2013, from SIGTARP: http://www.sigtarp.gov/Pages/home.aspx 
SIGTARP. (2013c, May 15). About Us. Retrieved May 15, 2013, from Office of the Special Inspector General for the Troubled Asset Relief Program: http://www.sigtarp.gov/pages/aboutus.aspx

SIGTARP. (2013d, December 6). TARP RECIPIENT FIFTH THIRD BANK AND FORMER BANK CFO CHARGED FOR IMPROPER ACCOUNTING OF LOAN LOSSES DURING FINANCIAL CRISIS. Retrieved from SIGTARP: http://www.sigtarp.gov/Press\%20Releases/Fifth_Third_Settlement_Press_Release .pdf

Simkovic, M., \& Kaminetzky, B. S. (2011). Leveraged Buyout Bankruptcies, the Problem of Hindsight Bias, and the Credit Default Swap Solution. Columbia Business Law Review, 2011(1), 118-178.

Simons, K. (2010). The Policy Debate Over the Bailout Plan. Pepperdine Policy Review, 3(1), 39-53.

Sitglitz, J. E. (2012). The Price of Inequality. New York: WW Norton and Company.

Stanton, T. H. (2002b). Loans and Loan Guarantees. In L. Salamon, The Tools of Govenrment: A Guide to the New Governance (pp. 381-409). New York: Oxford Univeristy Press.

Stanton, T. H., \& Moe, R. C. (2002). Government Corporations and GovernmentSponsored Enterprises. In L. Salamon, The Tools of Government: A Guide to the New Governance (pp. 80-116). New York: Oxford University Press. 
Stiglitz, J. E. (2012). The Price of Inequality. New York: WW Norton and Company.

Storing, H. J. (1964, March). The Crucial Link: Public Administration, Responsibility and the Public Interest. Public Administration Review, 24(1), 39-46.

Strayhorn, C. K. (2006, October 25). Report on the Integrated Eligibility and Enrollment Contract between the Health and Human Services Commission (HHSC) and Accenture LLP. Retrieved July 1, 2008, from Texas Comptroller of Public Accounts: http://www.window.state.tx.us/comptrol/letters/accenture/accenture_letter.pdf

Swanborn, P. (2010). Case Study Research: What, Why and How? Thousand Oaks, CA: Sage.

Taylor, J. B. (1993). Discretion Versus Policy Rules in Practice. Carnegie-Rochester Confernce Series on Public Policy (pp. 195-214). San Francisco, CA: Elseiver Sciene Publishers.

Taylor, J. B. (2008). The Financial Crsis and Policy Responses: An Empirical Analysis of What Went Wrong. A Festschrift in Honor of David Dodge (pp. 1-18). Bank of Canada.

Taylor, J. B. (2009, February 9). How the Government Created the Financial Crisis. Wall Street Journal, p. A19. 
Texas Comptroller of Public Accounts. (2010, September 27). Requirements for ARRA Section 1512 Reporting. Retrieved October 1, 2010, from Texas Comptroller of Public Accounts: https://fmx.cpa.state.tx.us/fmx/recovery/sect1512/index.php

The Economist. (2012, April 27). Clear and present danger; Centrally cleared derivatives. The Economist, p. 83.

Twain, M. (1903). The Jumping Frog: In English, Then in French, and Then Clawed Back into a Civilized Language Once More by Patient, Unremunerated Toil. New York: Harper and Brothers .

United States Constitution. (1787-1788). United States Constitution. United States Government.

United States Department of the Treasury. (2008). Tranche Report to Congress \#1. United States Department of the Treasury.

United States Savings and Loan League. (1966). Savings and Loan Handbook. Chicago: United States Savings and Loan League.

United States Savings and Loan League. (1980). Savings and Loan Handbook. Chicago: United States Savings and Loan League.

Urwick, L. (1937). Organizaton as a Technical Problem. In L. Gulick, \& L. Urwick, Papers on the Science of Administration (pp. 47-88). New York: Columbia University.

US Code. (2007). Administrative Procedure Act. Title 5, Part 1, Chapter 5. 
US Code. (2008). Inspector General Reform Act of 2008. PL 110-409.

US Code. (2011, January 7). Inspector General Act of 1978. Retrieved January 10, 2012, from Cornell Legal Information Institute: http://www.law.cornell.edu/uscode/html/uscode05a/usc_sup_05_5_10_sq2.html

US Congress. (2010, July 10). Dodd-Frank Wall Street Reform and Consumer Protection Act of 2010 PL 111-203. Retrieved August 3, 2013, from Government Printing Office: http://www.gpo.gov/fdsys/pkg/PLAW-111publ203/html/PLAW111publ203.htm

US Department of the Treasury. (2008, September 7). Statement by Secretary Henry M. Paulson, Jr. on Treasury and Federal Housing Finance Agency Action to Protect Financial Markets and Taxpayers. Retrieved September 5, 2010, from US Department of the Treasury: http://www.ustreas.gov/press/releases/hp1129.htm

US Department of the Treasury. (2008, September 17). Treasury Announces Supplementary Financing Program. Retrieved September 5, 2010, from US Department of the Treasury: http://www.ustreas.gov/press/releases/hp1144.htm

US Department of the Treasury. (2008b, September 20). FACT SHEET: Proposed Treasury Authority to Purchase Troubled Assets. Retrieved September 5, 2010, from US Department of the Treasury: http://www.ustreas.gov/press/releases/hp1150.htm 
US Department of the Treasury. (2008b, September 20). FACT SHEET: Proposed Treasury Authority to Purchase Troubled Assets. Retrieved May 15, 2013, from US Department of the Treasury: http://www.treasury.gov/press-center/pressreleases/Pages/hp1150.aspx

US Department of the Treasury. (2009, September 20). Financialstability.gov. Retrieved September 20, 2009, from http://financialstability.gov/

US GPO. (2009, Febuary 17). American Recovery and Reinvestment Act of 2009. PL $111-02$.

US House Financial Services Committee. (2008, September 24). Transcript of Hearing on the Future of Financial Services: Exploring Solutions to the Market Crisis. Retrieved from US House Financial Services Committee: http://www.gpo.gov/fdsys/pkg/CHRG-110hhrg45625/pdf/CHRG110hhrg45625.pdf

US Office of Financial Stability. (2012, July 4). About OFS. Retrieved May 15, 2013, from US Office of Financial Stability: http://www.treasury.gov/initiatives/financial-stability/Pages/about-ofs.aspx

US Office of Finanical Stability. (2010). Annual Report 2009. US Office of Finanical Stability.

US Securities and Exchange Commission. (2008, September 18). SEC Issues New Rules to Protect Investors Against Naked Short Selling Abuses. Retrieved May 15, 2013, 
from US Securities and Exchange Commission:

http://www.sec.gov/news/press/2008/2008-204.htm

US Senate. (1999, May 6). Roll Cal Vote \#105. Retrieved from US Senate: http://www.senate.gov/legislative/LIS/roll_call_lists/roll_call_vote_cfm.cfm?con gress $=106 \&$ session $=1 \&$ vote $=00105$

US Senate. (2008, October 1). On Passage of the Bill (H. R. 1424 As Amended). Retrieved May 13, 2013, from US Senate: http://www.senate.gov/legislative/LIS/roll_call_lists/roll_call_vote_cfm.cfm?con gress $=110 \&$ session $=2 \&$ vote $=00213$

US Senate. (2009, February 7). Roll Call Vote \#59. Retrieved May 15, 2013, from US Senate: http://www.senate.gov/legislative/LIS/roll_call_lists/roll_call_vote_cfm.cfm?con gress $=111 \&$ session $=1 \&$ vote $=00059$

US Senate. (2009b, February 9). Roll Call Vote \#60. Retrieved May 15, 2013, from US Senate: http://www.senate.gov/legislative/LIS/roll_call_lists/roll_call_vote_cfm.cfm?con gress $=111 \&$ session $=1 \&$ vote $=00059$

US Senate. (2009c, February 13). Roll Call Vote \#64. Retrieved May 15, 2013, from US Senate: http://www.senate.gov/legislative/LIS/roll_call_lists/roll_call_vote_cfm.cfm?con gress $=111 \&$ session $=1 \&$ vote $=00064$ 
Vekshin, A., \& Rowley, J. (2008, September 26). House Republicans Undercut Bush on Rescue, Slow Talks. Retrieved May 15, 2013, from Bloomberg News: http://www.bloomberg.com/apps/news?pid=newsarchive\&sid=azwqk86I6nbk\&re fer=home

Walker, H. (1937). Public Administration in the United States. New York: Farrar \& Rinehart, Inc.

Washington Post. (2008, September 28). Breakdown of Final Bailout Bill. Washington Post.

Weiss, J. A. (2002). Public Information. In L. Salamon, The Tools of Government: A Guide to the New Governance (pp. 217-254). New York: Oxford University Press.

White, L. J. (2010). The Gramm-Leach-Bliley Act of 1999: A Bridge Too Far? Or Not Far Enough? Suffolk University Law Review, 43(4), 938-946.

Wilkerson, T. (2013, February 11). The Congressional Oversight Panel and Its Role in TARP Accountability. (D. Jarvis, Interviewer)

Willoughby, J. (2000, March 20). Burning Up: Warning Internet Companies are Running Out of Cash...Fast. Barron's , pp. 1-5.

Wilson, K. (2008, September 27). Bailout push is fueled by market fears, pizza. Retrieved May 15, 2013, from Thomson Reuters: http://web.archive.org/web/20081001104901/http://www.reuters.com/article/vcCa 
ndidateFeed2/idUSTRE48Q3GG20080927?pageNumber=2\&virtualBrandChanne $1=10112$

Wilson, W. (1886, November 1). The Study of Administration. Retrieved January 27, 2011, from The Teaching of American History: http://teachingamericanhistory.org/library/index.asp?document=465

Woehr, M. (2010, October 26). Greenberg Found Liable for AIG Fraud. Retrieved May 15, 2013, from The Street.com: http://www.thestreet.com/story/10898446/greenberg-found-liable-for-aigfraud.html

Wolfers, J. (2008, September 23). Economists on the Bailout. Retrieved May 15, 2013, from Freakonomics: http://www.freakonomics.com/2008/09/23/economists-onthe-bailout/

Yin, R. K. (2008). Case Study Research: Design and Methods (Fourth ed.). Thousand Oaks, CA: Sage Publications.

Zuill, L. (2009, March 3). AIG Meltdown Has Roots in Greenberg Era. Retrieved May 15, 2013, from Reuters: http://www.reuters.com/article/2009/03/03/us-aiggreenberg-idUSTRE5222EV20090303 


\section{$\underline{\text { Appendix A: Coding of Documents }}$}

In order to evaluate which models and tools were at use in each case, this study coded 237 different documents based initially on 125 different codes. These codes consisted of one each for case one of Salamon's policy tools was applied without an apparent accountability model, one for each of the eight accountability models identified in this study where they were applied without regard to a specific policy tool and then eight each for each policy tool as it was applied in concert with the accountability models. After an initial review of the documents and analysis of the trends of which policy tools and accountability models were being utilized, the number of codes was reduced to 39 as the data showed that there were seven total policy tools in play, each of which got one code, and four accountability models in play, each of which got one code and four codes for each of the seven policy tools where accountability models were applied in concert with policy tools. These documents were then fully reviewed twice more to find all cases where these codes could be applied. Following these reviews, an analysis was conducted to determine where the intersections of policy tools and accountability models occurred. In cases where there were several instances where the two were coded together, it was determined that there was a link. It is believed that given the same set of documents although others might have relied upon different codes and a different approach, the results of this coding could be substantially reproduced by another researcher and thus are repeatable as recommended by standard methodological standards. 


\section{Appendix B: Interview List}

The following is a list of the persons interviewed as part of this study, their role and importance in relation to the policies and the location and dates of each interview.

Interviewee: Naomi Baum

Organization and Title (former): Congressional Oversight Panel, Executive Director Date/Location: February 11, 2013, Washington, DC

Role: Oversaw the Congressional Oversight Panel's work as it evaluated various aspects of TARP.

Interviewee: Betsy Cody

Organization and Title: Congressional Research Service Analyst

Date/Location: February 12, 2013, Washington, DC

Role: Helped evaluate projects in the natural resources area in relation to ARRA.

Interviewee: Andrew Green

Organization and Title: Senator Jeff Merkley (D-OR) Banking, Housing and Urban Affairs Committee Staffer

Date/Location: February 11, 2013, Washington, DC

Role: Helped Senator Merkley undertake accountability in relation to both TARP and ARRA. 
Interviewee: Chris Mihm, et. Al.

Organization and Title: Government Accountability Office, Managing Director for Strategic Issues.

Date/Location: February 13, 2013, Washington, DC

Role: GAO had a fundamental role in evaluating both TARP and ARRA; Mr. Mihm assembled a group of staffers who had worked on one or both policies in order to help me understand GAO's process and role in evaluating both policies.

Interviewee: Tewana Wilkerson

Organization and Title (former): Congressional Oversight Panel, Deputy Executive

Director

Date/Location: February 11, 2013, Washington, DC

Role: Helped oversee the Congressional Oversight Panel's work as it evaluated various aspects of TARP. 